\title{
(3) USAID \\ PREPARING DISTRIBUTION \\ UTILITIES FOR THE FUTURE - \\ EVOLVING CUSTOMER \\ CONSUMPTION IN \\ RENEWABLE RICH GRIDS: \\ A Novel Analytical Framework
}

GREENING THE GRID (GTG)

A Partnership Between USAID and Ministry of Power, Government of India

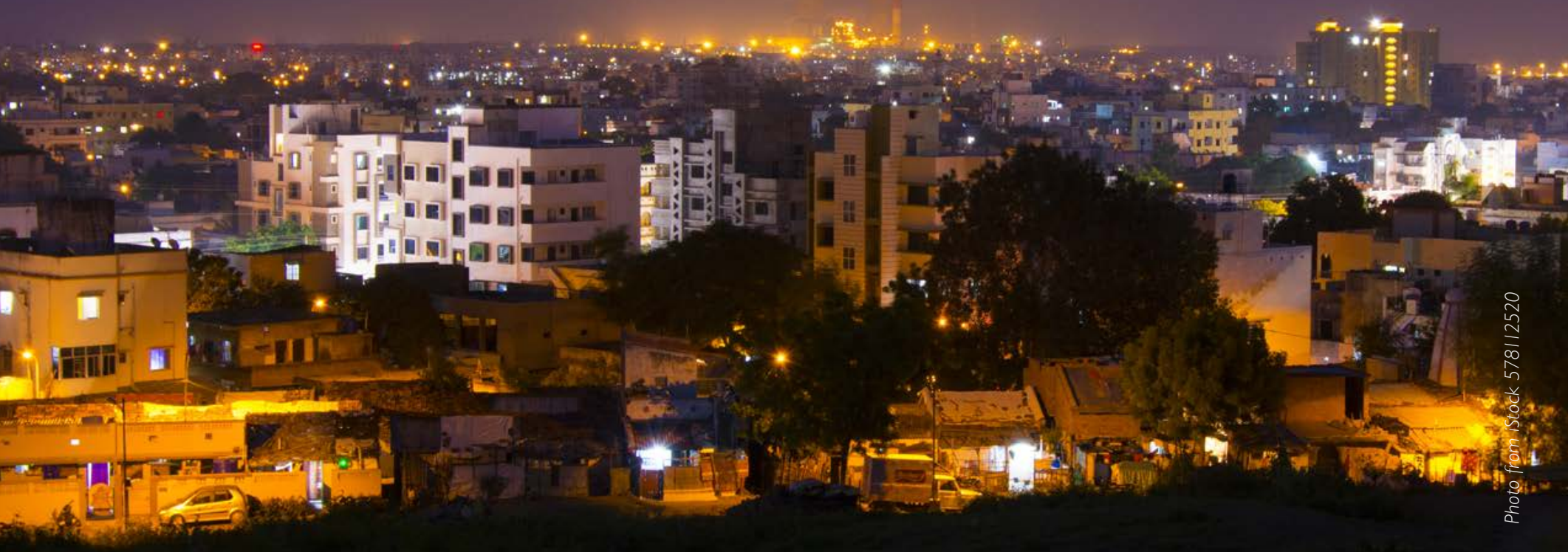

APRIL 2021

This report was produced by the National Renewable Energy Laboratory. 
Prepared by

\section{WNREL}

\section{Disclaimer}

This report is made possible by the support of the American People through the United States Agency for International Development (USAID). The contents of this report are the sole responsibility of National Renewable Energy Laboratory and do not necessarily reflect the views of USAID or the United States Government.

This work was supported by the U.S. Department of Energy under Contract No. DE-AC36-08GO28308 with Alliance for Sustainable Energy, LLC, the Manager and Operator of the National Renewable Energy Laboratory. 


\section{PREPARING DISTRIBUTION UTILITIES FOR THE FUTURE - EVOLVING CUSTOMER CONSUMPTION IN RENEWABLE RICH GRIDS: A Novel Analytical Framework}

\section{Authors}

Adarsh Nagarajan, Shibani Ghosh, Kapil Duwadi, Marty Schwarz, Richard Bryce, Ilya Chernyakovskiy, David Palchak, National Renewable Energy Laboratory (NREL)

Jitendra Nalwaya, Mukesh Dadhich, Prashant Agarwal and Manu Sharma, BSES Yamuna Power Ltd. 


\section{Acknowledgments}

This study was supported by the U.S. Agency for International Development (USAID), as part of the Greening the Grid Renewable Integration and Sustainable Energy (GTG-RISE) initiative, in collaboration with BSES Yamuna Power Ltd (BYPL). The authors thank the Hon. CEO of BYPL Mr. Prem R Kumar, and the team - including Jitendra Nalwaya, Mukesh Dadhich, Prashant Agarwal, and Manu Sharma — for their timely support and help regarding the data sets used in this report, as well as the GTG-RISE team for their feedback and coordination. 


\section{List of Acronyms}

BESS

BYPL

DER

ELCC

EV

EVOLVE

GTG

LOLE

LOLP

NREL

PRAS

PV

RISE

SAM

USAID

VRE battery energy storage system

BSES Yamuna Power Ltd

distributed energy resource

effective load carrying capability

electric vehicles

EVOlution of net-Load Variation from Emerging technologies

Greening the Grid

loss of load expectation

loss of load probability

National Renewable Energy Laboratory

Probabilistic Resource Adequacy Suite

photovoltaics

Renewable Integration and Sustainable Energy

System Advisor Model

U.S. Agency for International Development

variable renewable energy 


\section{Executive Summary \\ Context and Problem Description}

The Government of India has set a target of installing $175 \mathrm{GW}$ of renewable energy capacity by the year 2022, which includes $100 \mathrm{GW}$ from solar, $60 \mathrm{GW}$ from wind, $10 \mathrm{GW}$ from bio-power, and $5 \mathrm{GW}$ from small hydropower. Out of $100 \mathrm{GW}$ solar, $40 \mathrm{GW}$ is targeted from rooftop solar photovoltaics (PV). These renewable targets can lead to a new paradigm for power grid planning and operations.

Historically, power distribution utilities were designed to serve low voltage loads within their territories, and for decades their planning works were based on the premise that customers only consume power. During this time, distribution utilities learned customer consumption patterns, identified peak, off-peak, and shoulder hours and crafted proficient planning and operational strategies to match them.

Over the past decade, solar PV and wind energy adoption has increased at all scales (transmission and distribution), as illustrated in Figure ES-1. Also, recent and anticipated adoption of battery energy storage systems (BESS) and electric vehicles (EVs) are changing the landscape of supply and demand. Some of these emerging technologies are variable in nature and others are not fully understood, thus posing a need for distribution utilities to update the way that they plan and operate their systems.

Opportunities and challenges posed by these technologies (solar PV, BESS and EVs) on the power distribution grid are yet to be comprehended, holistically. Typically, wind farms are planned and built at large scale (100 MW to GW) and interconnected to transmission systems. Solar PV, on the other hand, can either be connected to transmission systems at the GW scale or at rooftops at the $\mathrm{kW}$ scale. Thus, challenges and opportunities vary significantly depending on the size and point of interconnection (transmission or distribution system).

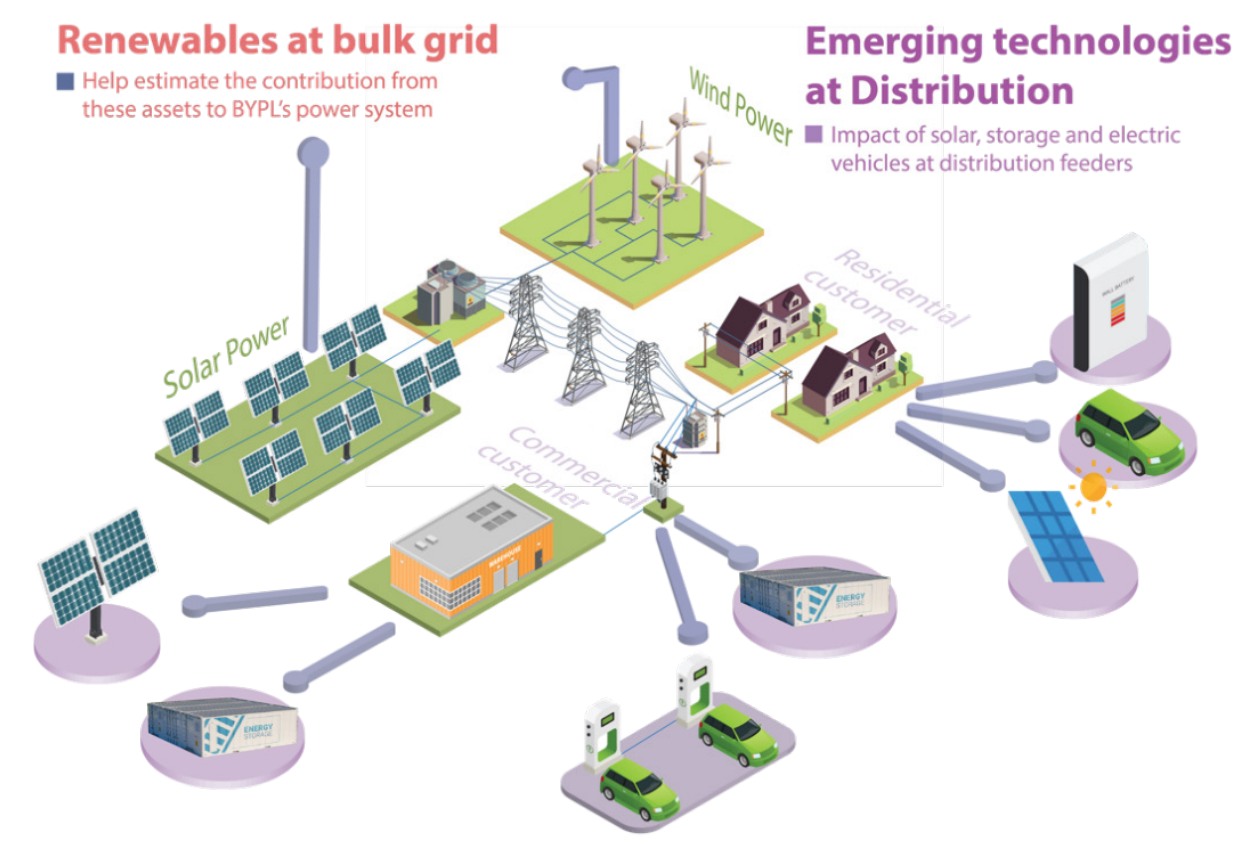

Figure ES-1. Variable renewable resources integrated on the power grid at transmission and distribution levels are posing challenges for distribution utilities

The research collaboration between the U.S. Agency for International Development (USAID), NREL and BSES Yamuna Power Ltd. (BYPL) focuses on the challenges caused by renewable integration into the 
power grid at large. Because the challenges and opportunities vary depending on the point of interconnection (distribution or transmission), we identified two tracks for research as listed below:

1. Power procurement: This research track examines the challenges and opportunities caused by GW-scale renewable integration at the transmission level. Specifically, this track investigates the contribution that utility-scale renewable energy procurement provides to distribution utilities, both from energy and capacity perspectives. In this track of research, utility customers are only considered as traditional (one-directional) consumers of energy.

2. Distributed energy resources (DERs): This research track focuses on the challenges and opportunities caused by many small-scale distributed renewable resource integrations at the distribution systems. At the power-distribution level, distribution utilities may face not only new solar energy technologies, but also battery energy storage and electric vehicles (EVs). Combined, these three technologies (solar PV, battery energy storage, and EVs) pose unique challenges to distribution utilities. This track focuses on assessing the net-load evolution that distribution utilities will observe as these emerging technologies make their way to the grid.

\section{Power Procurement Track}

As developers plan and build utility-scale solar PV and wind farms, distribution utilities sign up to purchase power in part or full via power purchase agreements. Renewable resources, however, are naturally variable and not completely predictable. Distribution utilities must still serve their customers' load at all hours, so as wind and solar PV plants start to make up a significant portion of the utility's portfolio, the non-dispatchable resources may pose reliability challenges.

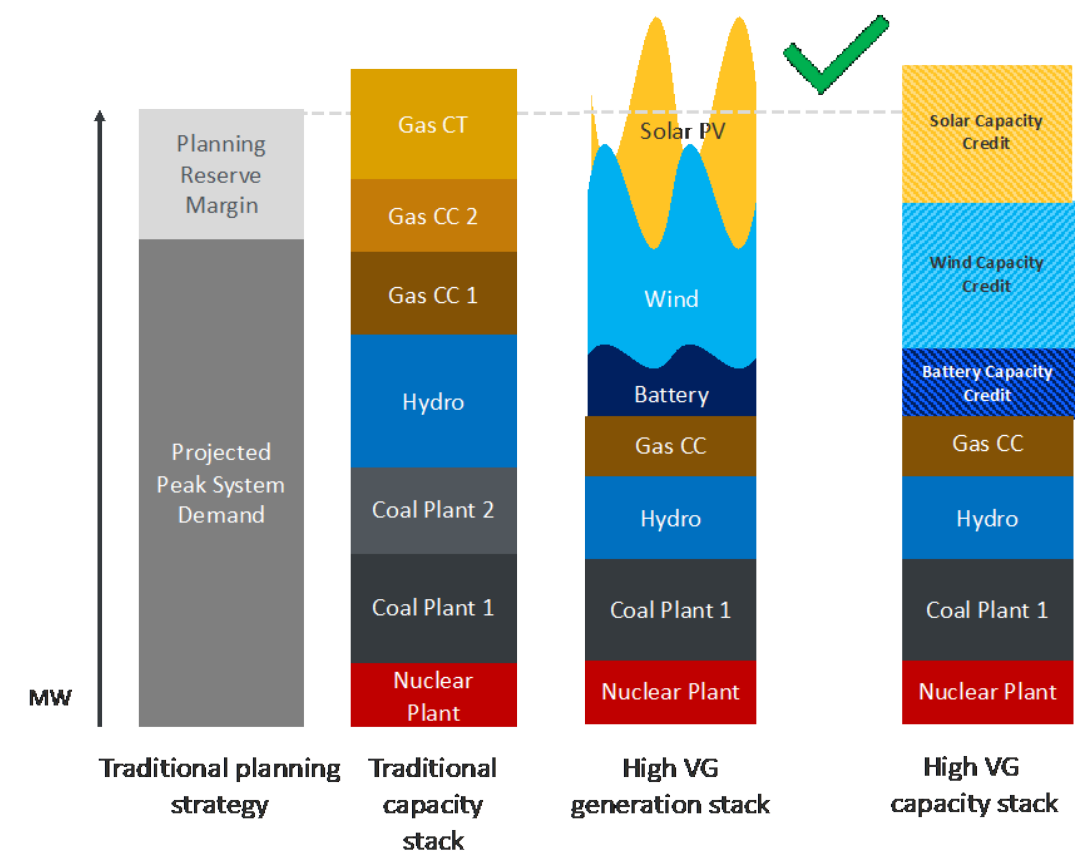

Figure ES-2. Capacity credit of resources in traditional vs. high VG power systems ${ }^{1}$

\footnotetext{
1 "Gas CC" refers to combined cycle natural gas plants. The height of the blocks is not to scale and is not meant to represent the capacity mix of any specific power system.
} 
This track considers renewable integration at bulk grids and assesses their value addition. In order for distribution utilities such as BYPL to make informed decisions when signing power purchase agreements (PPAs), it is crucial for them to understand how much energy and capacity their contracted renewable energy generators can provide. We address the situation faced by utilities by modeling variable renewable energy (VRE) plants from two perspectives: (1) energy production, and (2) capacity credit.

Capacity credit describes the percentage of a plant's nameplate capacity that can be reliably counted on to serve load. The capacity credit perspective is illustrated in Figure ES-2, which shows that effective planning includes the possible contributions of VRE. Use of capacity credit unlocks a unique path for understanding the planning reserves provided by solar PV and wind resources. To demonstrate the value from this research, NREL utilized existing knowledge of load, VRE contracts, and planning reserves. The framework we describe in this paper can be used by any distribution utility to assess the potential of contracted variable renewable resources to provide accurate planning reserves.

\section{Key Outcomes}

Renewable energy will play a pivotal role in the future of Indian distribution utilities like BYPL. BYPL has recently contracted around $250 \mathrm{MW}$ of wind and $300 \mathrm{MW}$ of solar PV plants across the country, some of which have recently been commissioned. However, due to the variable and uncontrollable nature of these weather-based generation, adding such resources to a utility's portfolio is more complicated than adding traditional fuel-based resources. To set up an efficient power purchase agreement with an RE generator, for instance, a utility needs to understand the potential of the plant to both produce energy and provide capacity when it is most needed.

The goal of this research track is to understand the full value of these specific generation resources to the energy and capacity needs of BYPL. As wind and solar PV plants start to make up a significant portion of BYPL's portfolio, understanding the full value of VREs becomes critical to avoiding overinvesting in generation capacity. NREL developed a reusable framework that can be deployed as new wind and solar plants are considered for future generation needs and has applied it to the recent $550 \mathrm{MW}$ of contracted VRE capacity.

The key outcomes from the study are listed below. Because BYPL has distinct winter and summer consumption patterns, the findings are broken up into these seasons.

1. Capacity factor for all additional utility-scale renewable energy is estimated to be $27 \%$ in summer (March to October) and 15\% in winter (November to January). In 2019, BYPL served 7,314 MWh of load. Had all the additional $250 \mathrm{MW}$ wind, and $300 \mathrm{MW}$ solar plants been commissioned in 2019, BYPL's system would have experienced $15.2 \%$ annual renewable penetration by generation, and $16.0 \%$ and $15.2 \%$ renewable penetration in summer and winter, respectively.

2. Wind energy, especially when imported from Coimbatore, Tamil Nadu, can contribute significantly to BYPL's planning reserve. Solar PV supplies minimal benefit to the planning reserve. The wind plants modeled in this study have a capacity credit of $53 \%$. This means that $53 \%$ of the planned installed wind capacity can be relied upon during periods of high system risk. The Coimbatore plant has a capacity credit of $64 \%$, and aggregate VRE has a capacity credit of $29 \%$. These values are quite high compared to other service regions. For instance, the Southwest Power Pool, which contains some of North America's strongest and most consistent wind resources, measured its wind capacity credit at $24.3 \%$. But previous studies show that the 
capacity credit of wind and solar PV often reduces dramatically as these resources make up a larger percentage of the generation mix (Haley 2019).

\section{Wind turbine model and hub height have a significant impact on estimated output and} capacity credit. Understanding the physical attributes of the contracted wind is critical for efficient system-wide planning. For example, modeling the wind turbines with a 110-meter rotor diameter mounted at a 110 -meter hub height resulted in an annual energy production $72 \%$ higher than that measured with turbines with an 80-meter rotor diameter mounted at 80 meters.

Furthermore, performing the capacity credit analysis with a 110-meter rotor diameter mounted at 110 meters resulted in a $68 \%$ capacity credit, whereas analyzing 80 -meter rotor diameter turbines mounted at 80 meters produced an approximate capacity credit of $45 \%$. This equates to a $57-\mathrm{MW}$ change in firm capacity needed to fill the gap in the capacity planning reserve margin for BYPL. As this difference is greater than the nameplate capacity of one of the wind plants, identifying these parameters is necessary for producing precise results in future analyses.

\section{As renewable energy penetration increases in BYPL's system, the capacity credit of VRE} plants may decline. While wind capacity credit in our study remains relatively stable at high penetrations, solar PV capacity credit drops to zero after 15\% VRE penetration. This finding, however, does not take into account the benefit of increased geographic diversity that will likely arise from increased penetration.

\section{DER Track}

Focusing on several smaller size installations (also referred to as distributed assets), this track looks at the impact of emerging technologies on customer load shape and their aggregated form (i.e., distribution feeder profile). Grid-connected DERs - such as solar PV, BESS, and EVs - are expected to increase substantially in distribution systems in the coming years. These emerging technologies pose challenges to distribution utilities, forcing overhauls in infrastructure planning and operational practices. They can also cause more frequent system operational violations (e.g., network voltage bounds and loading thresholds) if not properly integrated; however, if well understood and managed, DERs can also create opportunities for distribution utilities such as increased demand, flexible loads, and flatter load curves.

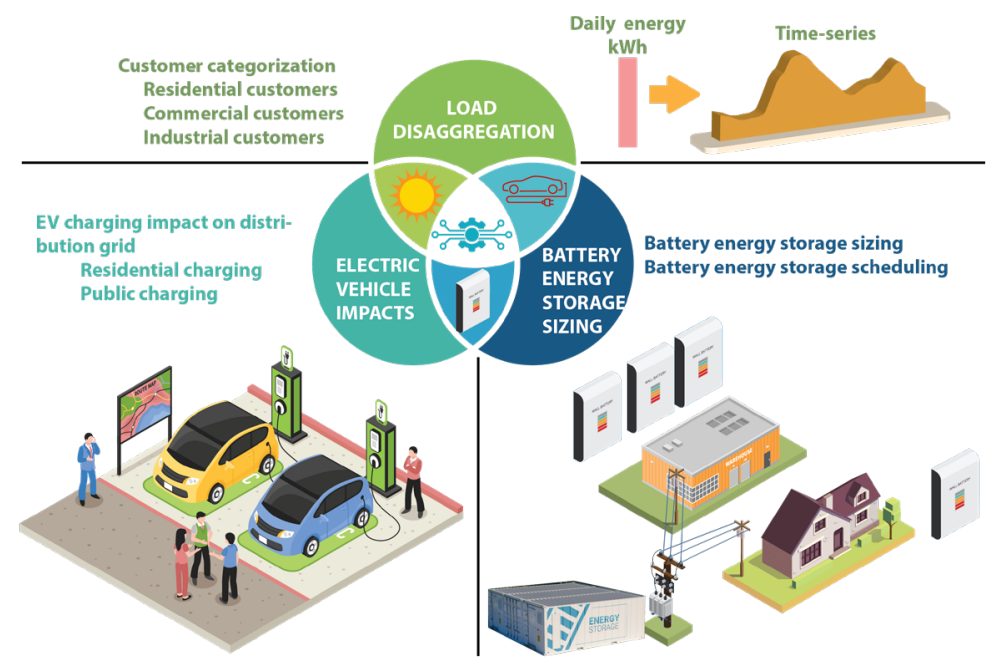

Figure ES-3. Illustration of modules in the EVOLVE interactive dashboard developed by NREL

The impacts on the localized power distribution grid from these emerging technologies manifest in possible increased infrastructure investments and erratic shifts in demand patterns. These impacts are not yet well understood, and analytical solutions are not readily available. To address these challenges, NREL 
developed a scalable framework in the form of an interactive dashboard, EVOLVE (EVOlution of netLoad Variation from Emerging technologies). EVOLVE represents a set of models/algorithms developed by NREL that can help a distribution utility understand the potential impacts of having more DERs and emerging technologies to a feeder. Using this interactive dashboard distribution utilities can assess relevant scenarios (e.g., increased penetration of rooftop PV on a feeder), observe the predicted shift in customer demand, and make decisions accordingly. EVOLVE has key modules that enable utilities to transform existing data to usable information. The modules are load disaggregation, EVs, and BESS integration. Tunable parameters include integration levels of solar PV, EV, and BESS, as illustrated in Figure ES-3.

\section{Key Outcomes}

The DERs research track was set up to help BYPL understand the evolution of customer demand with the growing adoption of emerging technologies. As illustrated in Figure ES-4, customer demand evolves incrementally as these DERs get integrated. Typical observations include: (1) solar PV integration creates a dip during the afternoons; (2) EVs add to the base load during night; and (3) energy storages reduce early morning peaks. All these incremental updates happening at scale in distribution utilities quickly escalate to a unique shift in consumption at distribution transformers. Aggregated demand shift at distribution transformers leads to a distinct change at the distribution feeder head.

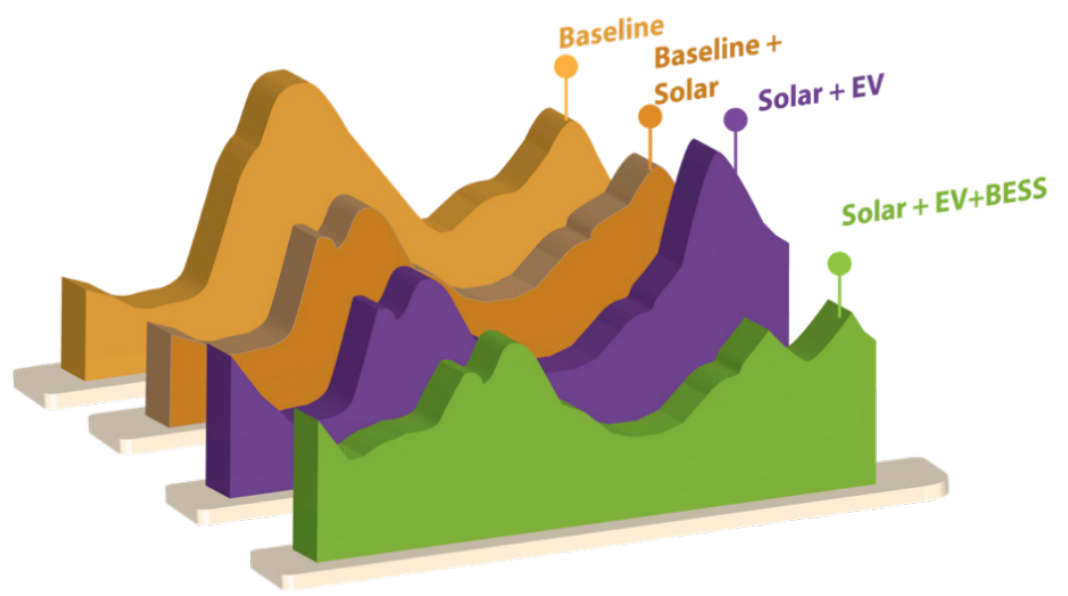

Figure ES-4. Illustration of evolving customer demand as emerging technologies are integrated with the distribution grid

The distributed technologies at customers' premises create small shifts in demand that, when aggregated, intensify the need for significant overhaul in utility operation and planning. For this purpose, NREL developed a set of comprehensive modeling tools and packaged those as a publicly available, interactive dashboard, which any distribution utility can use to learn the aggregate impacts of customer adoption of emerging distributed technologies. This dashboard-EVOLVE-helps distribution utilities to better understand feeder-level impacts of adding more of these emerging technologies, such as solar PV, EVs, and BESS. The dashboard allows for easy changes to inputs, such as penetration level of PV on a feeder, to allow for a quick understanding of how the network may be impacted and help decision-making regarding whether further technical studies may be required.

One of the key outcomes from DERs research is this easy-to-use open-source dashboard for learning evolution of net load with increasing emerging technologies. The view of the EVOLVE dashboard is shown in Figure ES-5. Figure ES-6 summarizes some analytics out of the dashboard, regarding a set of EV integration scenarios for a given fleet of vehicles in a feeder area. This plot showcases how distributed 
or residential charging creates overnight EV loading spikes, and more centralized approach such as EV charging stations can spread out the load temporally.

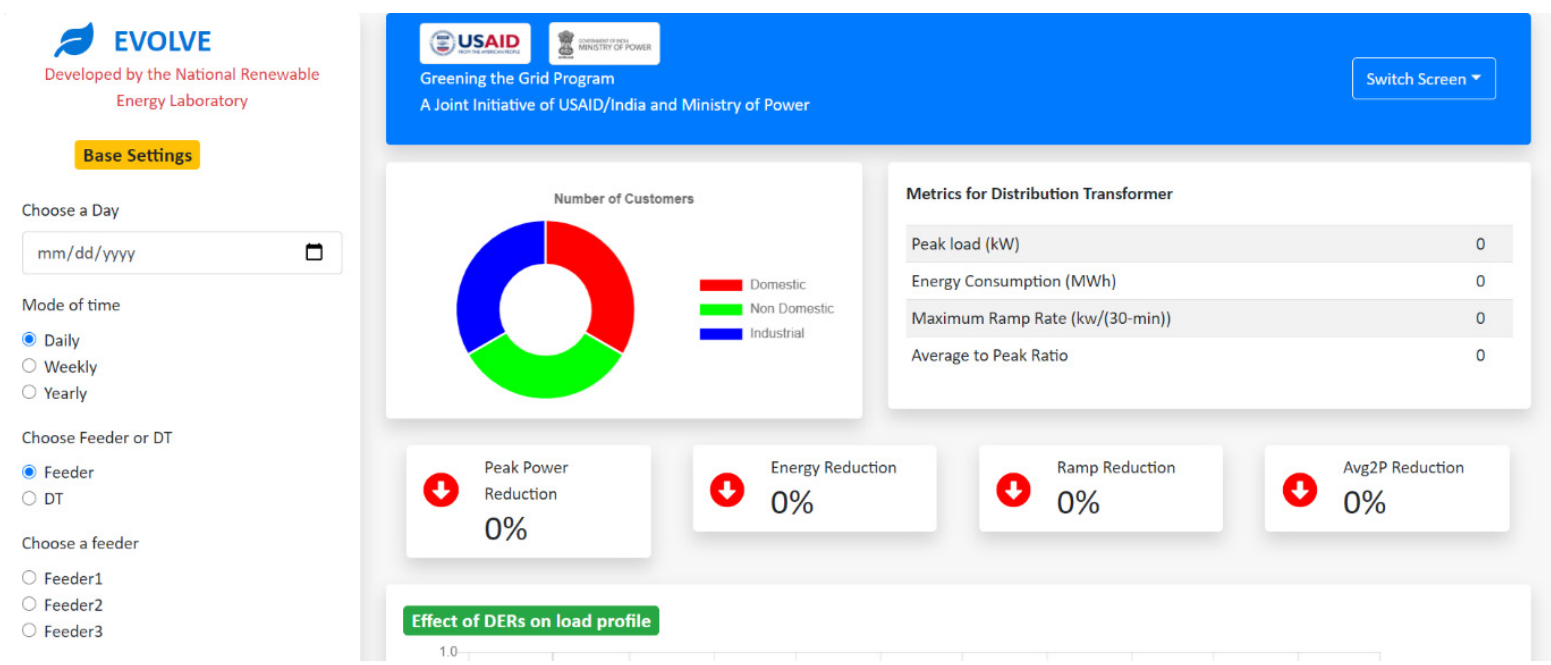

Figure ES-5. Partial view of dashboard for net load evolution study (EVOLVE)

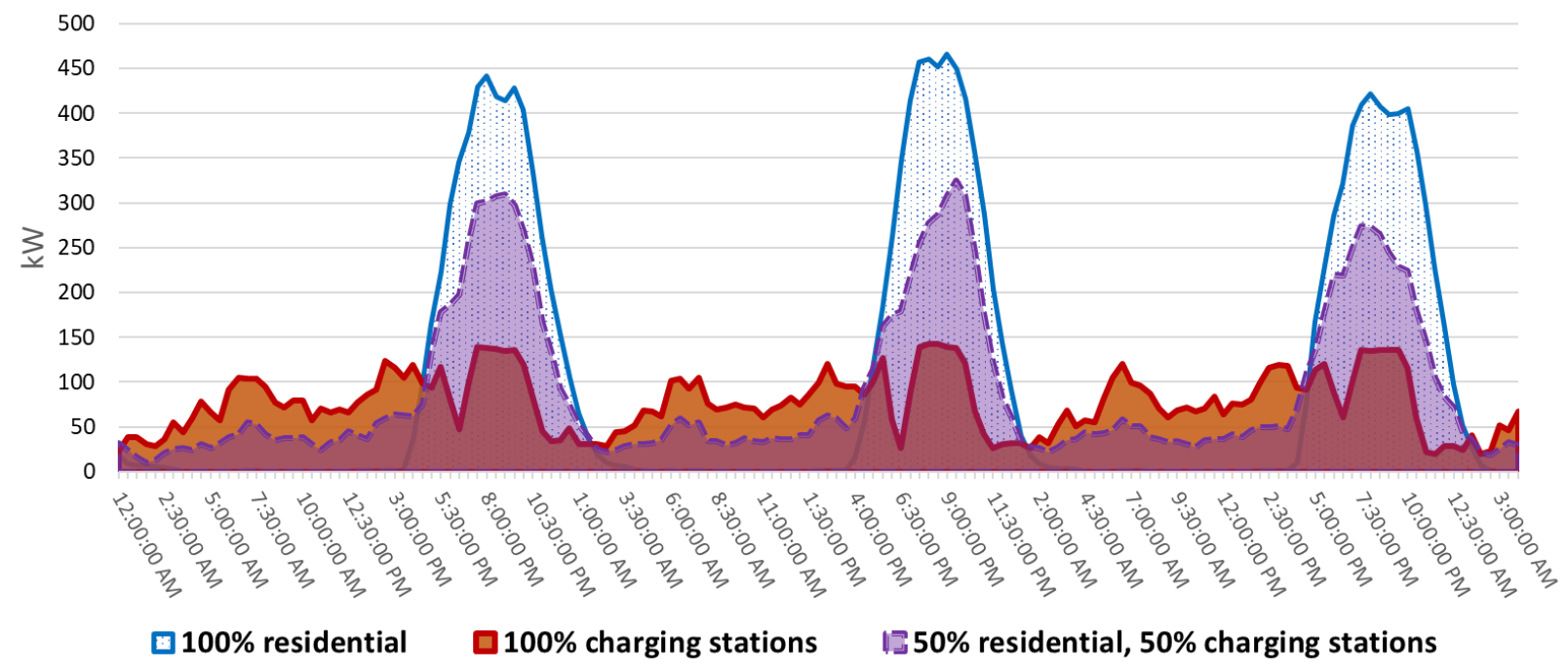

Figure ES-6. Net load profile for a charging station operation for a day 


\section{Table of Contents}

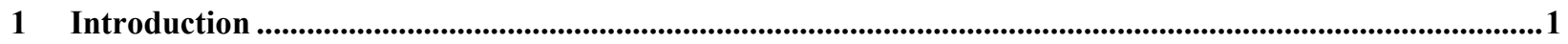

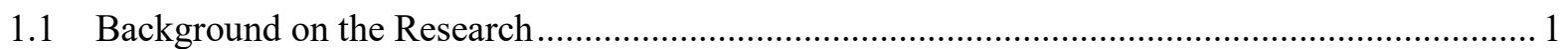

1.2 Power Procurement: Estimating Capacity Credit From Utility-Scale Wind and Solar................. 1

1.3 DERs: Evolution of Net Load With Growing Emerging Technologies .................................... 3

2 Power Procurement: Estimating Capacity Credit From Utility-Scale Wind and Solar .................................6

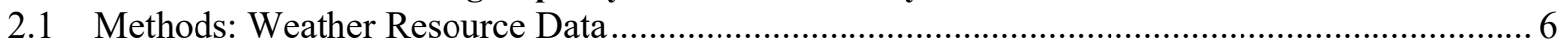

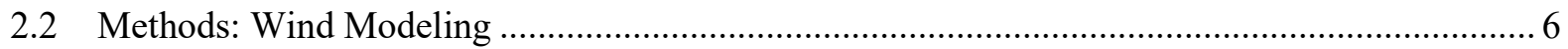

2.3 Methods: Solar PV Modeling....................................................................... 8

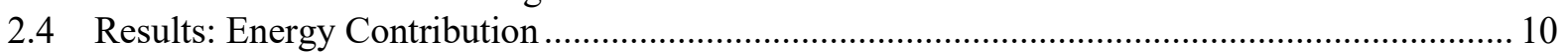

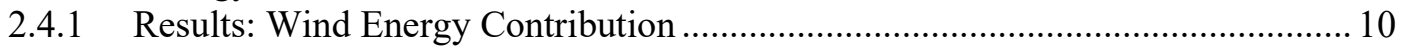

2.4.2 Results: Solar PV Energy Contribution .............................................................. 13

2.5 Capacity Contribution of Renewable Energy Plants: Capacity Credit..................................... 14

2.5.1 Capacity Credit Method 1: Capacity Factor Approximation .................................. 16

2.5.2 Capacity Credit Method 2: Reliability Modeling ................................................... 20

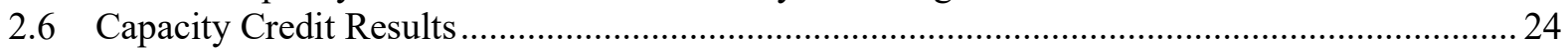

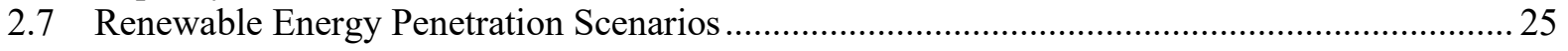

3 DERs: Evolution of Net Load With Increasing Emerging Technologies..............................................................29

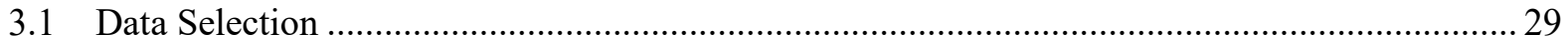

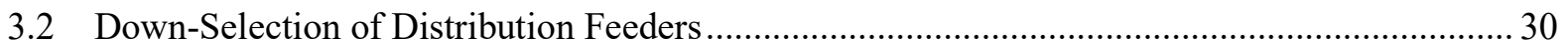

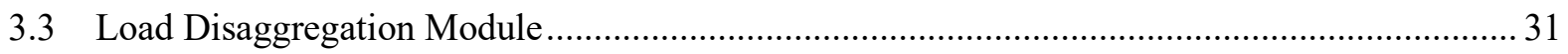

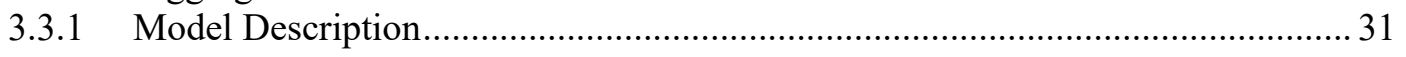

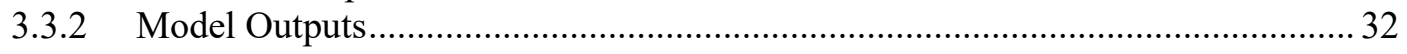

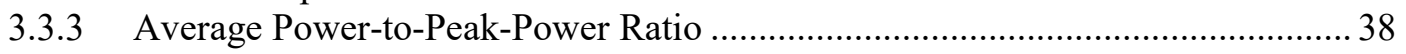

3.3.4 Percentage Peak Power Reduction .................................................................. 39

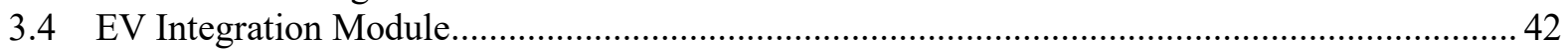

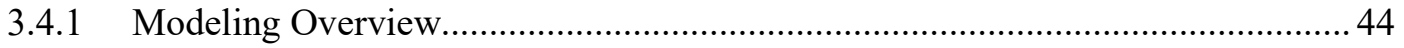

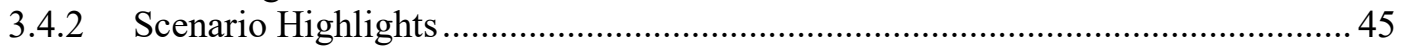

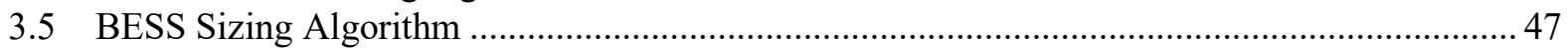

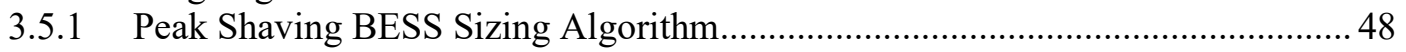

3.5.2 Behind-the-Meter Applications Sizing Algorithm ........................................ 51

3.5.3 Charging/Discharging Time and Threshold Selection Algorithm......................... 53

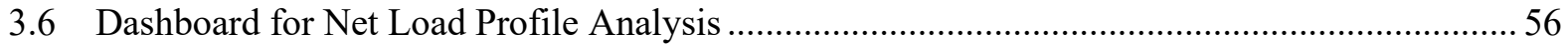

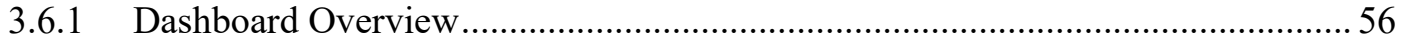

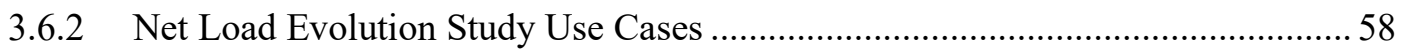

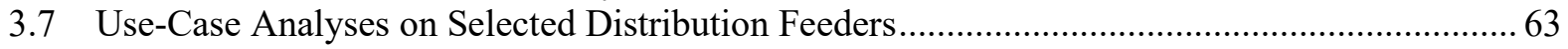

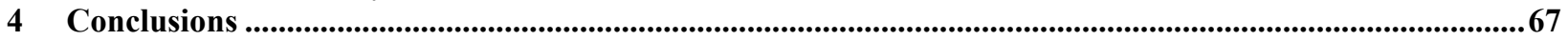




\section{List of Figures}

Figure ES-1. Variable renewable resources integrated on the power grid at transmission and distribution

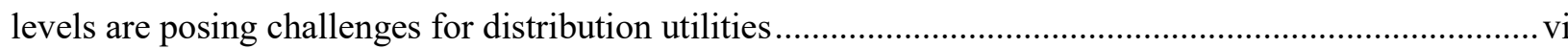
Figure ES-2. Capacity credit of resources in traditional vs. high VG power systems ...............................vii Figure ES-3. Illustration of modules in the EVOLVE interactive dashboard developed by NREL ............ix Figure ES-4. Illustration of evolving customer demand as emerging technologies are integrated with the

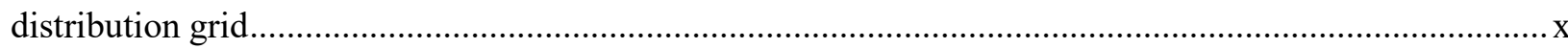

Figure ES-5. Partial view of dashboard for net load evolution study (EVOLVE)...................................xi Figure ES-6. Net load profile for a charging station operation for a day............................................... Figure 1. Average daily load profiles for 2014-2019, plotted for summer (left) and winter (right)........... 3 Figure 2. Illustration of evolving customer demand as emerging technologies get integrated with the

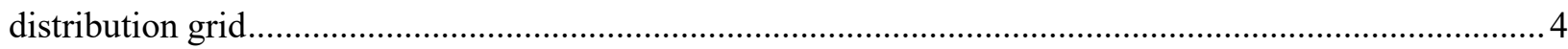

Figure 3. Process involved in developing EVOLVE for assessing evolution of net load with growing

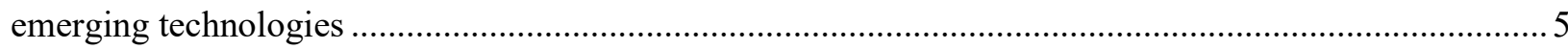
Figure 4. Power curves for a 2-MW turbine model with 80-meter rotor diameter (V80-2.0) mounted at an 80-meter hub height (left), and a 2-MW turbine model with 110-meter rotor diameter (V120-2.0) mounted at a 110 -meter hub height (right).

Figure 5. Wind power output for November through February. The wind resource is light and variable,

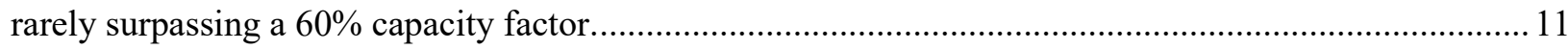
Figure 6. Heat map showing impact of wind turbine model and hub height on annual energy production of the three wind plants in BYPL's portfolio.

Figure 7. Comparison of summer power profiles for the two wind turbine models described in Figure 3.13 Figure 8. Illustrative firm capacity stacks for a traditional (all thermal and hydro) and a high renewable energy power system.

Figure 9. Representative capacity factor approximation results utilizing different percentages of load hours, compared with capacity credit calculated with a more robust method.

Figure 10. Time-of-day histogram of BYPL's top 10\% load hours (left axis), overlaid with the annual

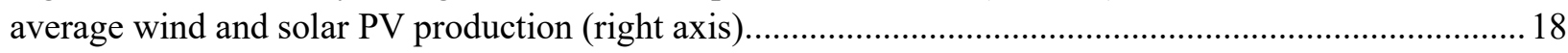

Figure 11. Example day, which represents the difference between demand and net load........................ 19 Figure 12. Time-of-day histogram of BYPL's top 10\% net load hours (left axis), overlaid with the annual average wind and solar PV production (right axis).

Figure 13. Time-of-day histogram of all hours in a year with a calculated LOLP $>1 \%$ (left axis), overlaid with the annual average wind and solar PV production (right axis) .................................................... 20

Figure 14. The workflow for NREL's in-house resource adequacy model, PRAS ................................2 21

Figure 15. Generic representation of ELCC calculation......................................................................... 23

Figure 16. Renewable energy penetration PRAS scenario results for ELCC .........................................2 27

Figure 17. Percentages of customers in domestic, nondomestic, and industrial sectors for three selected

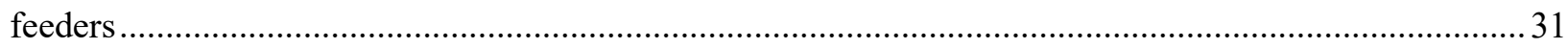

Figure 18. Disaggregated profiles of DT1 transformer with original profile for 2019 ............................ 33

Figure 19. Disaggregated profiles of DT1 transformer with original profile for summer week of 2019 ... 34

Figure 20. Disaggregated profiles of DT1 transformer with original profile for winter week of 2019 ...... 34

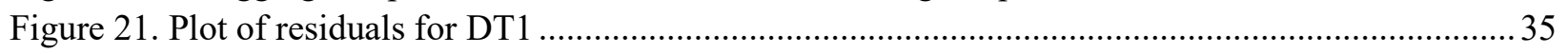

Figure 22. Disaggregated profiles of DT2 transformer with original profile for 2019 .......................... 36

Figure 23. Disaggregated profiles of DT2 transformer with original profile for summer week of 2019 ... 36

Figure 24. Disaggregated profiles of DT2 transformer with original profile for winter week of $2019 \ldots . . .37$ 
Figure 25. Plot of residuals for DT2

Figure 26. Monthly average power-to-peak-power ratio for three BYPL feeders from 2016 to 2020 for 0\%

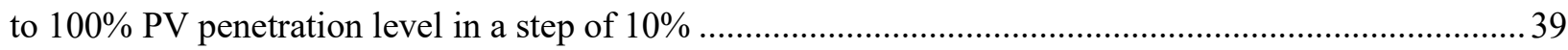

Figure 27. Monthly percentage peak power reduction for three BYPL feeders from 2016 to 2020 for $0 \%$

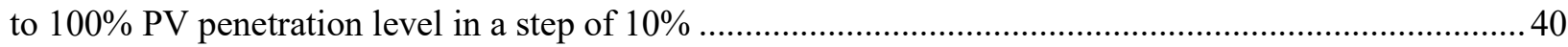

Figure 28. Monthly percentage of energy consumption reduction for three BYPL feeders from 2016 to 2020 for $0 \%$ to $100 \%$ PV penetration level in a step of $10 \%$

Figure 29. Monthly maximum change in the energy consumption in a 30-minute interval for three BYPL feeders from 2016 to 2020 for $0 \%$ to $100 \%$ PV penetration level in a step of $10 \%$.............................. 42

Figure 30. Charging events for different types of vehicles (sampled for one week) .............................. 43

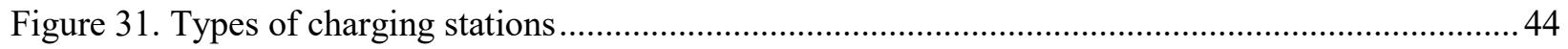

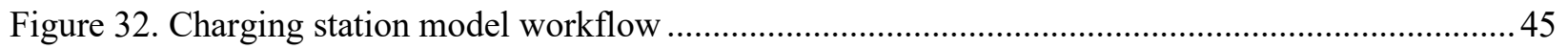

Figure 33. Resultant net EV load profile for all-residential charging scenario...................................... 45

Figure 34. Key parameters for charging station operation for one day.................................................. 46

Figure 35. Net load profile for charging station operation for one day ................................................ 46

Figure 36. Net EV charging load profile for charging station operation for one day .............................. 47

Figure 37. Various overloading conditions observed for a distribution transformer rated at $990 \mathrm{kVA} \ldots . . .48$

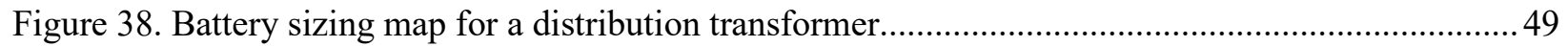

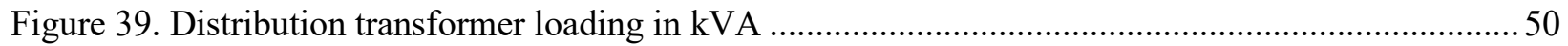

Figure 40. A scatter plot of the overloading instances observed in 2019 ................................................ 50

Figure 41. The BESS scheduled operation, the customer load, the PV generation, the basis load, and the

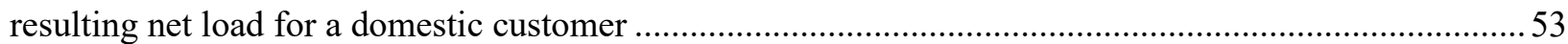

Figure 42. The optimal solution of the battery scheduling subproblem for the example customer............53

Figure 43. Original and new load profile with battery energy profile after applying algorithm to determine

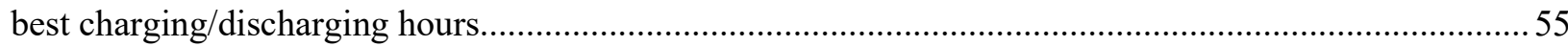

Figure 44. Original and new load profile with battery energy profile after applying algorithm to determine best charging/discharging thresholds (for power-based strategy)........................................................5 56

Figure 45. Partial view of dashboard for net load evolution study (EVOLVE).......................................... 56

Figure 46. Schematic software architecture for EVOLVE .............................................................. 57

Figure 47. Base or native load profile of summer week in a domestic distribution transformer for 2019.59

Figure 48. Base and new load profiles after addition of $100 \mathrm{~kW}$ of solar for one week in June 2019 .......59

Figure 49. Solar profile and metrics specific to solar energy generation for summer week of 2019 ......... 60

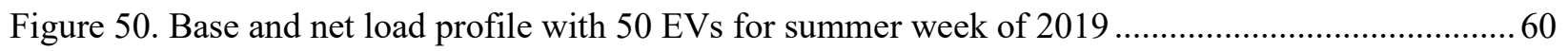

Figure 51. EV power profile and metrics of energy consumption for summer week of 2019.................60

Figure 52. Base and new load profile with energy storage for summer week of 2019 ........................ 61

Figure 53. Battery energy, charging/discharging power profile, and metrics for summer week of $2019 \ldots 61$

Figure 54. Base and new load profile with energy storage for automatic sizing and threshold selection for summer week of 2019 .

Figure 55. Battery energy, charging/discharging power profiles, and metrics for automatic sizing and threshold selection for summer week of 2019

Figure 56. Base and new load profile after adding solar, EV, and energy storage for summer week of 2019

Figure 57. Battery energy, charging/discharging power profile after adding solar and EVs for summer week of 2019 (automatic sizing and threshold selection turned on).....

Figure 58. Impact on load profile of Feeder1 due to DERs on summer day of 2019. Starting from the top, first figure shows new and base profile, second figure shows solar generation profile (1 MW solar 
capacity), third figure shows battery energy, charging and discharging profile (1,000 MWh, $500 \mathrm{~kW})$, and last figure shows aggregated consumption pattern of EVs (10 vehicles, $25 \%$ residential). 64

Figure 59. Impact on load profile of Feeder2 due to DERs on summer day of 2019. Starting from the top, first figure shows new and base profile, second figure shows solar generation profile (1 MW solar capacity), third figure shows battery energy, charging and discharging profile (1,000 MWh, $500 \mathrm{~kW})$, and last figure shows aggregated consumption pattern of EVs (10 vehicles, $25 \%$ residential). 65 Figure 60. Impact on load profile of Feeder3 due to DERs on summer day of 2019. Starting from the top, first figure shows new and base profile, second figure shows solar generation profile (1 MW solar capacity), third figure shows battery energy, charging and discharging profile (1,000 MWh, $500 \mathrm{~kW})$, and last figure shows aggregated consumption pattern of EVs (10 vehicles, $25 \%$ residential)..................... 66 Figure A-1. Correlogram for wind, solar PV, and load for every hour of the year.................................. 71

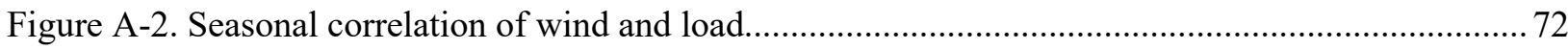

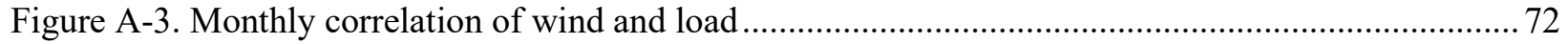

\section{List of Tables}

Table 1. Summary Energy Output of the Modeled Renewable Energy Plants in GWh .......................... 10

Table 2. Summary Capacity Factor of the Modeled Renewable Energy Plants ...................................... 10

Table 3. P50/P90 solar analysis for 2010-2014 ................................................................................. 14

Table 4. Capacity Credit Results for Each Calculation Method by Plant ...............................................25

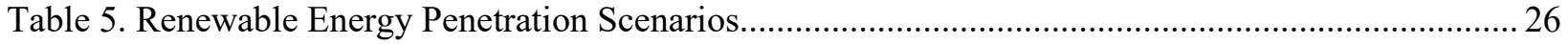

Table 6. Results From PRAS Renewable Energy Penetration Scenarios ................................................ 27

Table 7. List of Parameters Used to Down-Select Three Distribution Feeders From the Initial Ten .......... 30

Table 8. Number of Customers in Each Customer Category for Four Distribution Transformers

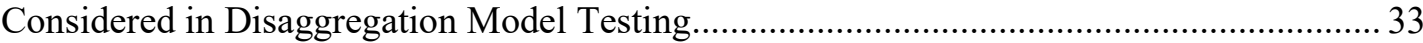

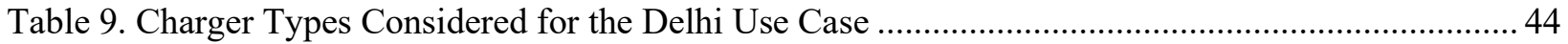

Table 10. Optimal BESS Size and Peak Load With and Without the BESS ............................................ 52 


\section{Introduction}

India plans to deploy high levels of renewable energy on its power grid, which can greatly reduce the carbon intensity of its economy and strengthen energy security. Compared to conventional power, India's renewable energy options are more variable, uncertain, and often further from demand centers. Experience in other systems around the world has shown that when renewable energy penetration reaches significant levels, grid operators need specialized tools to deal with the non-dispatchable and variable nature of renewables, helping them assess the power grid's capacity to manage challenges with electricity reliability and affordability. Reliability issues could ultimately affect electricity end users, but are foremost a concern for grid operators, utilities, and renewable energy investors.

BSES Yamuna Power Ltd (BYPL) is one of the five electrical utility companies operating in Delhi, India. Growth in electrical demand has recently been accompanied by a corresponding expansion in the penetration of solar photovoltaics (PV), both from behind the meter and as part of the wholesale generation mix. Thus, BYPL has a vested interest in understanding two coupled features of the evolution of its energy supply: the projected evolution of the net load profile and the potential value of procuring utility-scale wind and solar energy to serve its loads.

\subsection{Background on the Research}

Distribution utilities are faced with growth in renewable energy from multiple perspectives: (1) the growth in solar and wind at the bulk power system, affecting their power procurement strategies; and (2) at the distribution interconnection points, affecting the traditional role of balancing supply with demand as well as many potential technical challenges, such as maintaining system reliability and controlling distribution component loading. The research collaboration between the National Renewable Energy Laboratory (NREL) and BYPL takes a close look at both challenges caused by renewable integration. Because the challenges and opportunities vary depending on the point of interconnection (distribution or transmission), we identified two tracks for research:

1. Power procurement research: This research track examines the challenges and opportunities caused by GW-scale renewable integration at the transmission level. Specifically, the track investigates the contribution that utility-scale renewable energy procurement provides to distribution utilities, both from energy and capacity perspectives. Utility customers are only considered as traditional consumers of energy.

2. Distributed energy resources (DERs) research: This research track focuses on challenges and opportunities caused by the integration of a large number of small-scale DERs at the distribution systems. At the power distribution system, utilities not only manage integration of solar technology, but also battery energy storage and electric vehicles (EVs). Combined, these three technologies (solar PV, battery energy storage, and EVs) pose unique challenges to distribution utilities. This research focuses on assessing the net-load evolution that distribution utilities observe as these emerging technologies make their way to the grid.

\subsection{Power Procurement: Estimating Capacity Credit from Utility-Scale Wind and Solar}

BYPL has historically procured most of its power by contracting portions of thermal and hydropower generators in Delhi and farther afield. As of 2019, this amounted to 1,726 MW of contracted power. The utility does not plan to add much more thermal generation to its portfolio, and some of the thermal plants with which they have contracts are approaching retirement. Furthermore, utility-scale wind and solar PV have become cost-competitive with thermal generation resources, and these types of plants also help BYPL meet its state-mandated renewable purchase obligation. As a result, the utility has contracted 250 
MW of wind and $300 \mathrm{MW}$ of solar PV plants across the country, some of which have recently been commissioned.

As these new wind and solar PV plants start to make up a significant portion of BYPL's portfolio, they will challenge the utility to reliably meet its customers' electrical demands. The purpose of this component of the study is to estimate the ability of these plants to do so. We address this question by modeling each of the future variable renewable energy (VRE) plants from two perspectives: (1) energy production, and (2) capacity credit.

Measured as a percentage of a particular generator's nameplate capacity, capacity credit describes the amount of power a generator can reliably provide to the system and is a critical element of power system planning. Understanding how much capacity a renewable energy generator can reliably provide may help inform decision making regarding PPA contracts. For instance, when planning power procurement for future projected peak demand, assessing capacity credit may help a utility decide how much renewable capacity of which technologies (e.g., wind, solar PV, or hybrid wind + solar PV) will contribute to meeting its planning reserve. In addition, knowing the capacity credit of existing renewable plants will impact how much additional capacity the utility will require from new PPAs.

There has been significant research in the capacity credit space, and many methods for its calculation have emerged (Milligan and Porter 2005). These methods have a broad spectrum of trade-offs between complexity and robustness. We employ two methods in this study to highlight the insights that can be gained and the data requirements across this spectrum. First, the capacity factor approximation offers a simple method that is easy to compute using only a spreadsheet editing tool, but it has several shortcomings: it is deterministic, neglects thermal outages, does not accurately reflect the effects of increasing RE penetration, and it assumes that a unit's historical performance during high-risk hours will continue in future years. To represent the more complex end of the spectrum we calculate effective load carrying-capability (ELCC), which is a robust, probabilistic method used to assess system risk at every hour. To estimate grid integration challenges in BYPL's future, we analyze different VRE penetration scenarios using this probabilistic method.

BYPL considers the balancing of its load and generation portfolio on a seasonal basis based on significantly different load shapes. These are shown in Figure 1. Summer, marked by air-conditioning loads which cause an evening peak, lasts from March to October. Winter spans November to February, and has significantly less overall demand and two peaks, with the morning peak generally higher. Because BYPL uses these two seasons when making procurement decisions, we split our bulk power system results in the same fashion. 


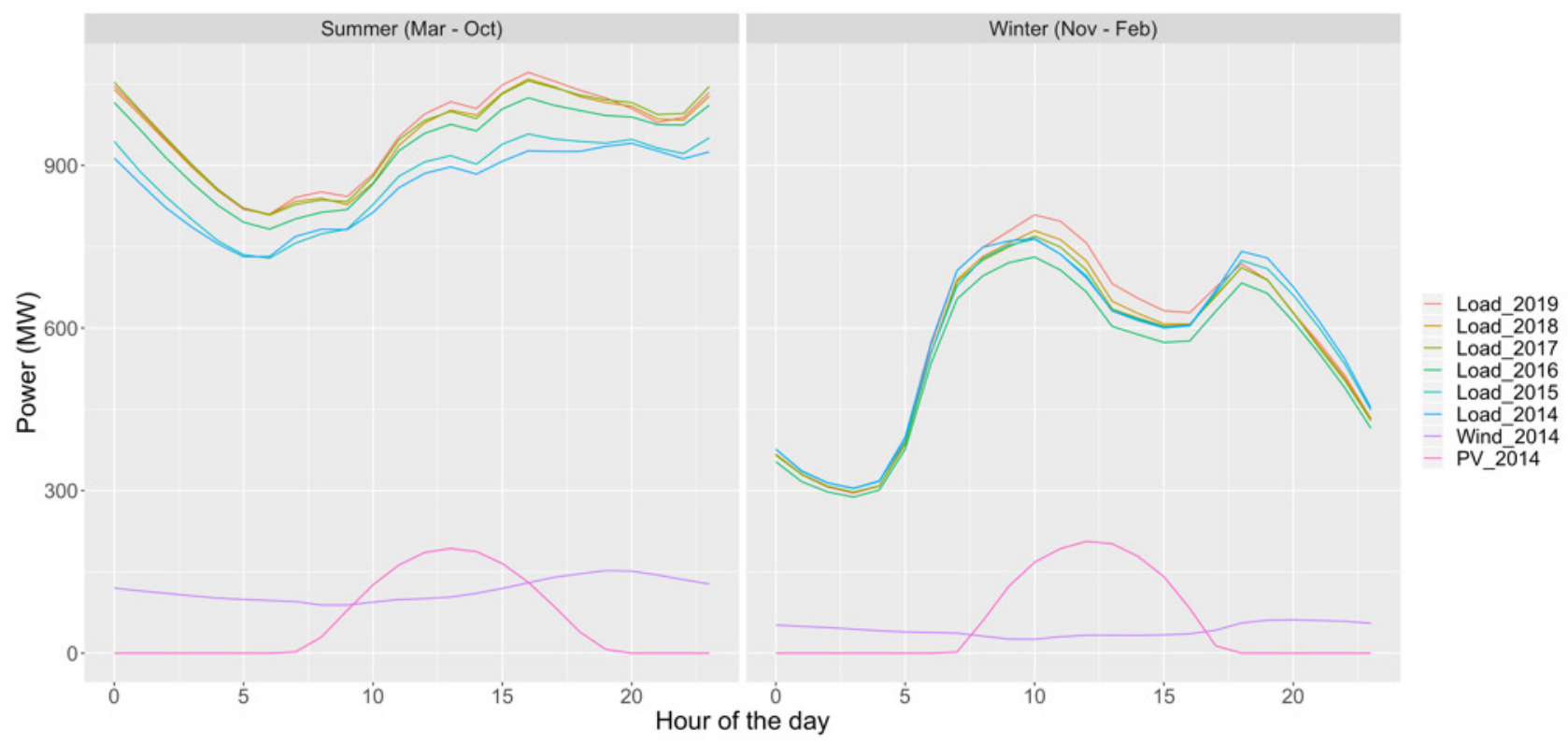

Figure 1. Average daily load profiles for 2014-2019, plotted for summer (left) and winter (right).

Note: Average wind and solar PV profiles are also plotted.

\subsection{DERs: Evolution of Net Load With Growing Emerging Technologies}

Distribution utilities had decades to master the customer consumption profiles prior to emerging technologies (solar PV, battery energy storage systems [BESS], and EV) made its way. Historically, power generation used to happen at specific locations, and the generated power used to flow to bulk grid and then to distribution network, to cater to customer energy needs. Over the past decade, increased integration of solar PV (rooftop and utility-scale) kicked off a shift in the power consumption pattern. An aggregate effect of these solar PVs generating during the day led to the assessment of the "duck curve" as an impact. As impact of solar PV generation on the distribution grid is being examined all around the world, BESS and EVs are getting integrated as well.

The DERs research track was set up to help BYPL understand the evolution of customer demand with the growing adoption of emerging technologies. As illustrated in Figure 2, customer demand evolves incrementally as these DERs are integrated. Typical observations include: (1) solar integration creates a dip during the afternoons; (2) EVs add the base load during night; and (3) energy storage adds load during early mornings with reducing peaks. All these incremental updates happening at scale in the BYPL service territory quickly escalates to a unique shift in consumption at distribution transformers. 
Aggregated demand shift at distribution transformers led to a distinct change at the distribution feeder head and goes on.

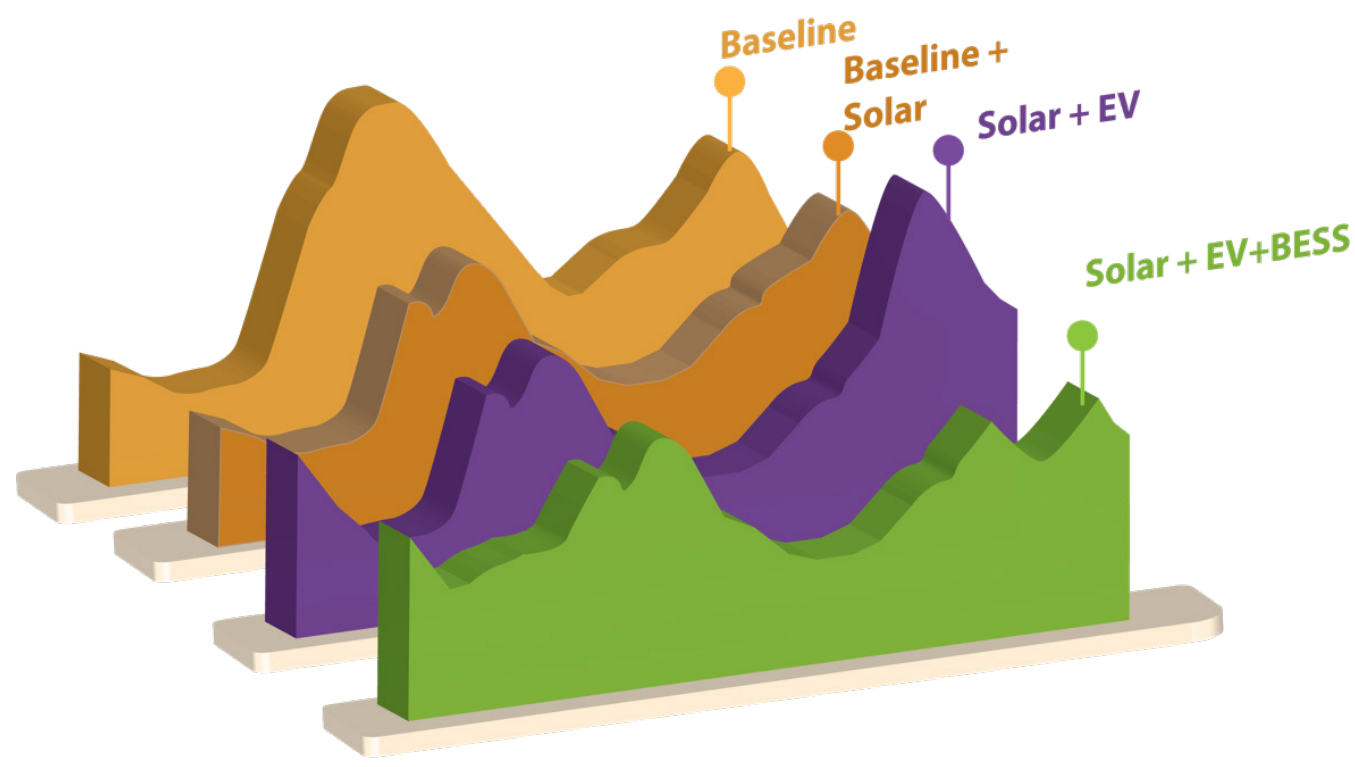

Figure 2. Illustration of evolving customer demand as emerging technologies get integrated with the distribution grid

These distributed emerging technologies create a small shift in demand/profile, and, when aggregated, quickly escalate into a need for significant overhaul in utility operation and planning. For this purpose, NREL developed an interactive dashboard - using which any distribution utility can learn the aggregate impacts of customer adoption of distribution emerging technologies. This dashboard EVOLVE (EVOlution of net-Load Variation from Emerging technologies), enables distribution utilities to enter relevant scenarios, observe the shift in customer demand, and help make decisions accordingly.

EVOLVE provides a way for compiling available data in distribution utilities to evaluate the future net load and its implications. Figure 3 illustrates the steps involved with the operation of the EVOLVE dashboard. The first step is for users to set the desired levels of emerging technologies-PV, BESS, and EV. The second step is to identify the duration of analysis ranging between a day to a decade. In the second step, the user can also choose the level of aggregation, distribution transformer or feeder head. The third step is where the user can compare the base load profile with the evolved profile and learn the shift of the key parameters. The interactive dashboard helps distribution utilities quantify the following parameters for desired penetration of emerging technologies in their territory:

- Customer demand along with shift in profile caused by PV and EVs

- Change in peak power at distribution transformers caused by BESS and EVs

- Variation in ramp rates caused by PV, BESS, and EVs. 
1 Drivers for Net Load Evolution
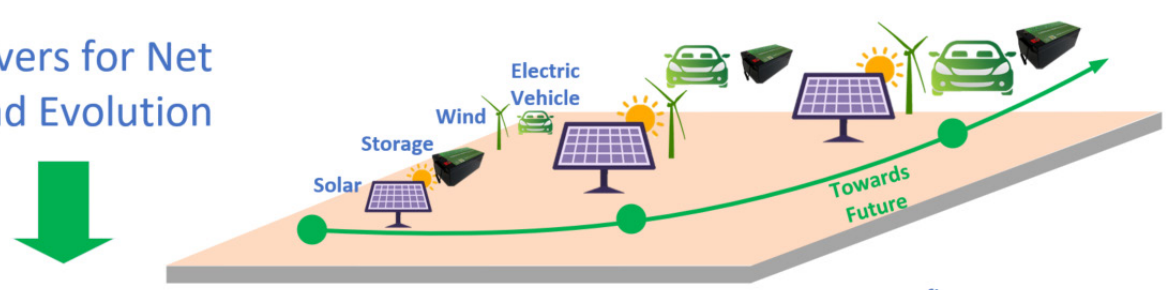
2 Net Load Shape and Space

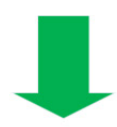

Parameters of Net
Load Shape Affected
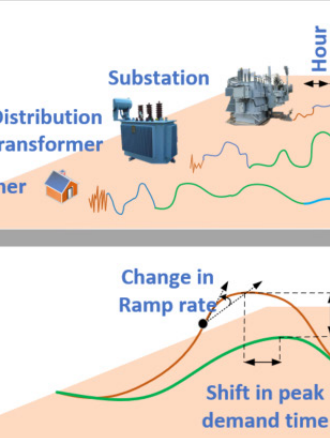

$\underset{4}{\stackrel{5}{y}}$
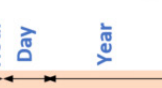

苋 Net load profile

Figure 3. Process involved in developing EVOLVE for assessing evolution of net load with growing emerging technologies 


\section{Power Procurement: Estimating Capacity Credit from Utility-Scale Wind and Solar}

This section describes the methodologies and modeling results used to estimate the contribution of seven new wind and solar PV plants in BYPL's portfolio. To produce representative power profiles for the RE plants, this study utilizes NREL's open-source techno-economic modeling software, the System Advisor Model (SAM) (Blair et al. 2014). SAM was designed to facilitate decision-making for project developers as well as grid operators and planners. It can model many types of renewable energy systems, including solar PV (small residential rooftop and large utility-scale systems), wind power (from individual turbines and large wind farms), hybrid PV + battery systems, concentrating solar power, battery storage, geothermal, and biomass. ${ }^{2}$

\subsection{Methods: Weather Resource Data}

Wind speed and direction, and air temperature and pressure at a variety of altitudes was obtained from data that was created for USAID's Greening the Grid RE integration study (Palchak et al. 2016). This data was created using the Weather Research and Forecasting model (v3.7) and is based on the 2014 weather year (Draxl et al. 2015). ${ }^{3}$ This data set has 5-minute time interval wind resource data for $3 \times 3 \mathrm{~km}$ grid cells for all of India, and it was directly applied to sites with exact latitude and longitude information. When the latitude and longitude of a VRE plant was not known, we used NREL's Renewable Energy Data Explorer to select a location with the highest-quality weather resource still within a reasonable distance from the appropriate city or village. The RE Data Explorer is a user-friendly geospatial analysis tool for analyzing renewable energy potential and informing decisions, specifically in developing countries (Cox and Leisch 2019). It compiles international wind resource data into an easily downloadable format. We used the following land-use restrictions: cropland/grassland mosaic, cropland/woodland mosaic, deciduous broadleaf forest, dryland cropland and pasture, evergreen broadleaf forest, evergreen needleleaf forest, herbaceous wetland, irrigated cropland and pasture, mixed forest, mixed shrubland/grassland, mixed tundra, savanna, shrubland, snow or ice, urban and build-up land, water bodies, wooded tundra, and wooded wetland.

To calculate detailed wind power predictions, SAM utilizes temperature, atmospheric pressure, wind speed and direction at four altitudes: $40 \mathrm{~m}, 80 \mathrm{~m}, 100 \mathrm{~m}$, and $120 \mathrm{~m}$.

Solar PV modeling in SAM requires three forms of solar irradiance data, measured in $\mathrm{W} / \mathrm{m}^{2}$ : clearsky direct horizontal irradiance, clearsky direct normal irradiance, and clearsky global horizontal irradiance. In addition, SAM incorporates local dew point and temperature pressure in its calculations. These data were obtained from NREL's National Solar Radiation Database, a serially complete collection of halfhourly time series of the above data, modeled using multichannel measurements from geostationary satellites (Sengupta et al. 2018).

\subsection{Methods: Wind Modeling}

BYPL procured a total of $250 \mathrm{MW}$ of utility scale wind to be commissioned by 2020 . One site (100 MW) will be located in the district of Coimbatore, Tamil Nadu, and two (50 MW each) will be portions of wind farms in the district of Kutch, Gujarat. BYPL provided plant location and size. When the exact location

\footnotetext{
${ }^{2}$ SAM also incorporates financial models for various types of renewable energy developments, but the financial implications of these VRE procurements are beyond the scope of this study.

${ }^{3}$ The Weather Research and Forecasting model is a product of the National Center for Atmospheric Research in Boulder, Colorado.
} 
was unknown, we consulted with BYPL to identify likely locations for the site based on the quality of the wind resource and various land use exclusions.

Few specific technical parameters were known about the wind turbines and turbine configuration to be used in BYPL's allocated plants. When details were uncertain, we employed the SAM defaults, which are industry-standard assumptions:

- Wake effects: simple wake model, turbine coefficient $=0.1$, constant loss $=11.02 \%$

- Gridded farm configuration

- Wake losses (internal wake + external wake + future wake) $=1.1 \%$

- Availability losses (turbine + balance of plant + grid $)=5.5 \%$

- Electrical losses (efficiency + parasitic consumption $)=2.0 \%$

- Turbine performance losses (suboptimal performance + generic power curve adjustment + site-specific power curve adjustment + high wind hysteresis $)=4.0 \%$

- $\quad$ Environmental losses (icing + environmental + degradation + exposure changes) $=2.2 \%$. SAM uses a default icing loss of $0.21 \%$. None of the wind locations experience belowfreezing temperatures, so we use $0 \%$.

- Curtailment and operational strategies losses (load curtailment + grid curtailment + environmental and permit curtailment + operational strategies) $=2.8 \%$

- $\quad$ Wind turbine shear coefficient $=0.14$.

Perhaps the most significant technical parameters used when modeling wind farm production are the size of wind turbine rotor and hub height. Wind speeds tend to be stronger and more consistent at higher altitudes, and larger diameter rotors capture more energy. 

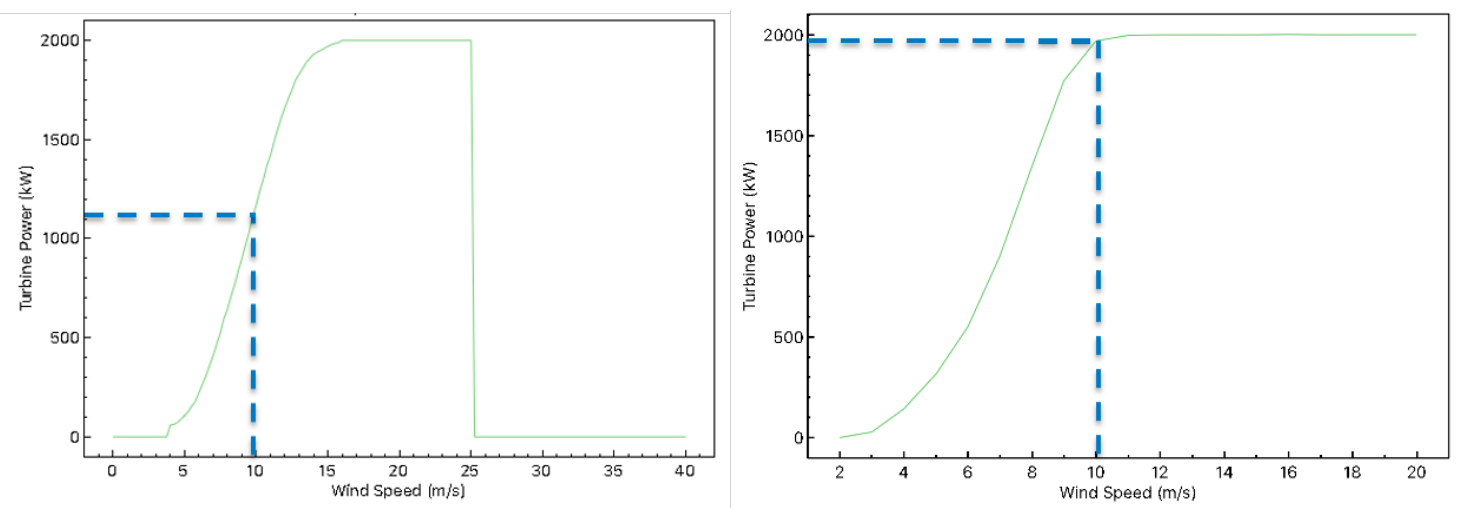

Figure 4. Power curves for a 2-MW turbine model with 80-meter rotor diameter (V80-2.0) mounted at an 80-meter hub height (left), and a 2-MW turbine model with 110-meter rotor diameter (V1202.0) mounted at a 110-meter hub height (right).

Note: The blue dotted line provides a reference to compare output at $10 \mathrm{~m} / \mathrm{s}$ wind speed with between the two models. The V110-2.0 model reaches its maximum output at slower wind speeds than the V80-2.0 turbine, and therefore captures more wind energy and has a higher yearly capacity factor. Adapted from NREL's System Advisor Model GUI. ${ }^{4}$

These differences are highlighted in Figure 4. Figure 4a plots the power curve (electrical output versus wind speed) for a 2.0 MW turbine with an 80-meter rotor diameter, mounted at an 80-meter hub height. The curve exhibits the four regions typical of all variable-speed pitch-controlled wind turbines in use today. At just under $4 \mathrm{~m} / \mathrm{s}$, the turbine reaches its cut-in speed and begins producing electricity (Region 1). Region 2 represents the gradual ramp in power output as speeds increase. For this model turbine, 10 $\mathrm{m} / \mathrm{s}$ lies in the middle of this region and corresponds to an output of about $1,100 \mathrm{~kW}, 55 \%$ of the maximum output. Starting at $15 \mathrm{~m} / \mathrm{s}$, the turbine produces at its nameplate capacity (Region 3), until the cut-out speed of $25 \mathrm{~m} / \mathrm{s}$ when the brake is applied to prevent damage (Region 4). Region 4 is not relevant for the wind plants studied here, as the wind resource data does not include any instances of wind speeds surpassing $25 \mathrm{~m} / \mathrm{s}$ in any of the three wind sites.

By contrast, Figure $4 \mathrm{~b}$ shows the power curve for a 2-MW turbine with a 110-meter rotor diameter, mounted at 110-meter hub height. While both turbines have a maximum output of $2 \mathrm{MW}$, the larger turbine reaches this maximum at $10 \mathrm{~m} / \mathrm{s}$, two-thirds the speed of the smaller wind turbine. Furthermore, the cut-in speed of the larger turbine is $2 \mathrm{~m} / \mathrm{s}$, so it will start producing electricity in lighter winds.

\subsection{Methods: Solar PV Modeling}

BYPL's new solar PV procurements consist of four separate locations, summing to $300 \mathrm{MW}$ : two 50MW allotments and two 100-MW allotments, grouped into two power purchase agreements. All sites are located in the dry and relatively cloud-free state of Rajasthan. The solar resource is quite consistent across the year in Rajasthan, though there is a dip during the cloudier monsoon season.

Using developer information, geography, and local news reports, we were able to positively identify the locations of three of these sites. To locate the final site, a $100 \mathrm{MW}$ solar PV allocation near Jodhpur, we used the RE Data Explorer heuristic method described in Section 2.1. Candidate locations for the fourth

\footnotetext{
${ }^{4}$ Vestas turbines were used for reference. The figure highlights the smallest (left) and largest (right) models available in SAM.
} 
site were abundant, but because the solar resource in Rajasthan is notably flat across a large geographic area, the exact location would have little effect on the modeled power output.

As with wind, we largely relied on SAM's default technical assumptions:

- $\quad$ Array type $=$ fixed open rack

- $\quad$ Ground coverage ration $=0.4$

- $\quad$ Azimuth $=180$ degrees

- $\quad$ Tilt angle $=$ latitude of the site, rounded to nearest degree

- $\quad$ Inverter efficiency $=96 \%$

- $\quad$ Module type $=$ standard silicon (thin film cadmium telluride modules for the Pokharan site)

- $\quad$ Total system losses $=11.42 \%$ :

$$
\begin{array}{ll}
\circ & \text { Soiling }=2 \% \\
\circ & \begin{array}{l}
\text { Shading }=0 \% \text { (changed from the SAM default of 3\%, due to Rajasthan's perennially } \\
\text { clear skies) }
\end{array} \\
\circ \quad \text { Snow }=0 \% \\
\circ \quad \text { Mismatch }=2 \% \\
\circ \text { Wiring }=2 \% \\
\circ \text { Connections }=0.5 \\
\circ \text { Light-induced degradation }=1.5 \% \\
\circ \text { Nameplate }=1 \% \\
\circ \text { Age }=25 \text { years } \\
\circ \text { Availability }=3 \% .
\end{array}
$$

No solar PV array will operate at its maximum nameplate capacity more than a handful of hours of the year, if at all. Therefore, solar PV inverters are usually sized below the nameplate capacity of the solar panel array to which they are connected. Energy is curtailed during times when the array produces more than the inverter can handle, but the revenue lost from not converting this energy will often be made up by the lower cost of the smaller inverter. Adjusting the ratio of solar panel nameplate capacity to inverter capacity - known as the "DC-to-AC ratio"-allows solar PV developers to fine-tune this trade-off. For instance, a 100-MW solar farm modeled with a DC-to-AC ratio of 1.1 will have a rated inverter size (and maximum AC power capacity) of $91 \mathrm{MW}$. We assume a standard DC-to-AC ratio of 1.1 based on typical PV array designs in the United States. The solar resource in Rajasthan is significantly more seasonally and diurnally consistent than the solar resource in North America and other locations, so this is likely a conservative estimate. 


\subsection{Results: Energy Contribution}

Table 1 summarizes the summary energy production, in GWh, for each of the VRE plants. The capacity factor, as a percentage, is reported in Table 2. Because the total available renewable resource varies greatly with the season, grid operators will have to employ novel flexibility strategies.

Table 1. Summary Energy Output of the Modeled Renewable Energy Plants, in GWh

\begin{tabular}{|c|c|c|c|c|c|c|c|c|c|c|}
\hline & $\begin{array}{l}\text { Coimbatore } \\
\text { Wind (100 } \\
\text { MW) }\end{array}$ & $\begin{array}{l}\text { Kutch } \\
\text { Wind } \\
1 \text { (100 } \\
\text { MW) }\end{array}$ & $\begin{array}{l}\text { Kutch } \\
\text { Wind } \\
2 \text { (50 } \\
\text { MW) }\end{array}$ & $\begin{array}{c}\text { All } \\
\text { Wind } \\
(250 \\
\text { MW) }\end{array}$ & $\begin{array}{c}\text { Jaisalmer } \\
\text { PV } 1 \text { (100 } \\
\text { MW) }\end{array}$ & $\begin{array}{c}\text { Jaisalmer } \\
\text { PV } 2 \text { (50 } \\
\text { MW) }\end{array}$ & $\begin{array}{c}\text { Jodhpur } \\
\text { PV 1 } \\
\text { (100 } \\
\text { MW) }\end{array}$ & $\begin{array}{c}\text { Jodhpur } \\
\text { PV } 2 \text { (50 } \\
\text { MW) }\end{array}$ & $\begin{array}{c}\text { All } \\
\text { Solar } \\
\text { PV } \\
\text { (300 } \\
\text { MW) }\end{array}$ & $\begin{array}{c}\text { All } \\
\text { RE } \\
(550 \\
\text { MW) }\end{array}$ \\
\hline $\begin{array}{l}\text { Summer } \\
\text { (Mar- } \\
\text { Oct) }\end{array}$ & 261 & 168 & 106 & 534 & 116 & 56 & 114 & 56 & 342 & 876 \\
\hline $\begin{array}{l}\text { Winter } \\
\text { (Nov- } \\
\text { Feb) }\end{array}$ & 24 & 32 & 19 & 74 & 56 & 27 & 55 & 27 & 164 & 239 \\
\hline All Year & 285 & 199 & 125 & 609 & 172 & 83 & 169 & 83 & 506 & 1,114 \\
\hline
\end{tabular}

Table 2. Summary Capacity Factor of the Modeled Renewable Energy Plants, in \%

\begin{tabular}{|c|c|c|c|c|c|c|c|c|c|c|}
\hline & $\begin{array}{c}\text { Coimbatore } \\
\text { Wind (100 } \\
\text { MW) }\end{array}$ & $\begin{array}{l}\text { Kutch } \\
\text { Wind } \\
1 \text { (100 } \\
\text { MW) }\end{array}$ & $\begin{array}{l}\text { Kutch } \\
\text { Wind } \\
2 \text { (50 } \\
\text { MW) }\end{array}$ & $\begin{array}{l}\text { All } \\
\text { Wind } \\
(250 \\
\text { MW) }\end{array}$ & $\begin{array}{c}\text { Jaisalmer } \\
\text { PV } 1 \text { (100 } \\
\text { MW) }\end{array}$ & $\begin{array}{c}\text { Jaisalmer } \\
\text { PV } 2 \text { (50 } \\
\text { MW } \\
\text { solar PV) }\end{array}$ & $\begin{array}{c}\text { Jodhpur } \\
\text { PV 1 } \\
\text { (100 } \\
\text { MW) }\end{array}$ & $\begin{array}{c}\text { Jodhpur } \\
\text { PV } 2 \text { (50 } \\
\text { MW } \\
\text { solar } \\
\text { PV) }\end{array}$ & $\begin{array}{c}\text { All } \\
\text { Solar } \\
\text { PV } \\
\text { (300 } \\
\text { MW) }\end{array}$ & $\begin{array}{c}\text { All } \\
\text { RE } \\
(\mathbf{5 5 0} \\
\text { MW) }\end{array}$ \\
\hline $\begin{array}{l}\text { Summer } \\
\text { (Mar- } \\
\text { Oct) }\end{array}$ & $44 \%$ & $28 \%$ & $36 \%$ & $36 \%$ & $20 \%$ & $19 \%$ & $19 \%$ & $19 \%$ & $19 \%$ & $27 \%$ \\
\hline $\begin{array}{l}\text { Winter } \\
\text { (Nov- } \\
\text { Feb) }\end{array}$ & $8 \%$ & $11 \%$ & $13 \%$ & $10 \%$ & $19 \%$ & $19 \%$ & $19 \%$ & $19 \%$ & $19 \%$ & $15 \%$ \\
\hline All Year & $32 \%$ & $23 \%$ & $28 \%$ & $28 \%$ & $20 \%$ & $19 \%$ & $19 \%$ & $19 \%$ & $19 \%$ & $23 \%$ \\
\hline
\end{tabular}

\subsubsection{Results: Wind Energy Contribution}

Wind energy in India exhibits large seasonal variability due to starkly different wind patterns during the center of the summer season, also referred to as the Indian Summer Monsoon. During this time, wind capacity factors increase dramatically across the region, and so it is responsible for most of the hours of maximum wind generation. This time also corresponds to the periods of highest load in Delhi. As such, wind energy, in general, provides a relatively dependable resource when it is most needed. This effect, formalized in a metric called capacity credit, is described in greater detail in Section 2.2. By contrast, wind energy during the winter months of November through February is substantially lower. As shown in Figure 5 , the wind farms rarely surpass $60 \%$ capacity factor in this season. 
The choice of wind turbine has a significant impact on modeled annual wind energy production, as shown in Figure 6. The difference in annual energy production between the smallest, shortest turbine (V80-2.0 at $80 \mathrm{~m}$, bottom left) and the largest, tallest turbine (V110-2.0 at $110 \mathrm{~m}$, upper right) is $72 \%$. To provide the most conservative estimates, the rest of our analysis assumes the V80-2.0 turbine mounted at an 80-meter hub height. Because of the significant difference in power due to different models and hub heights, future analyses should identify the specific turbines used in each wind farm.

These impacts are also evident when comparing results by season. The power outputs for each wind farm during the windier summer months are plotted in Figure 7. Flat sections of the profiles represent periods when the wind turbines are operating at their maximum output (Region 4 of the power curve).

Throughout July and August, total wind power modeled with larger, taller turbines regularly reaches this maximum of about $209 \mathrm{MW}$ (top panel), which represents a maximum capacity factor of $84 \%$. By contrast, the small turbines rarely reach their maximum throughout this period (bottom panel).

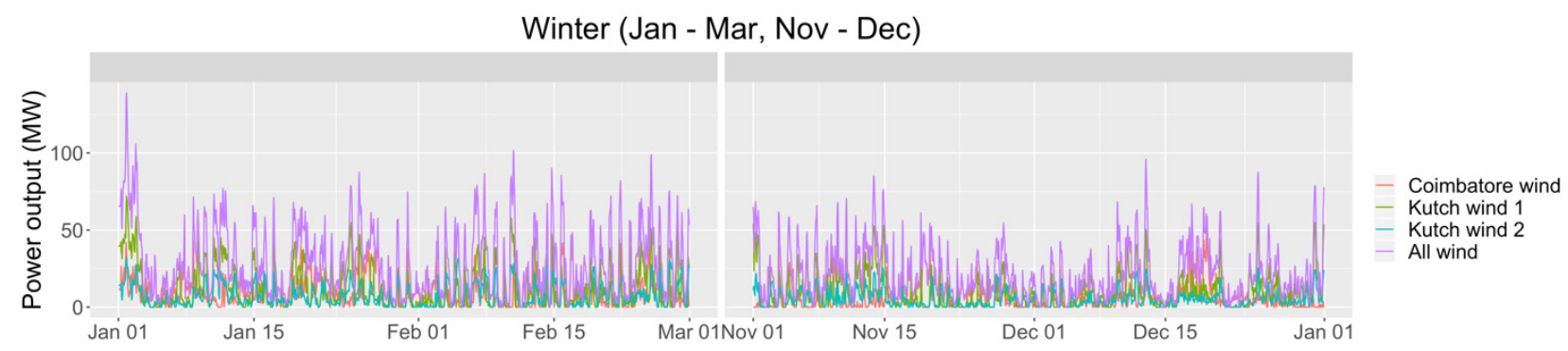

Figure 5. Wind power output for November through February. The wind resource is light and variable, rarely surpassing a $60 \%$ capacity factor. 


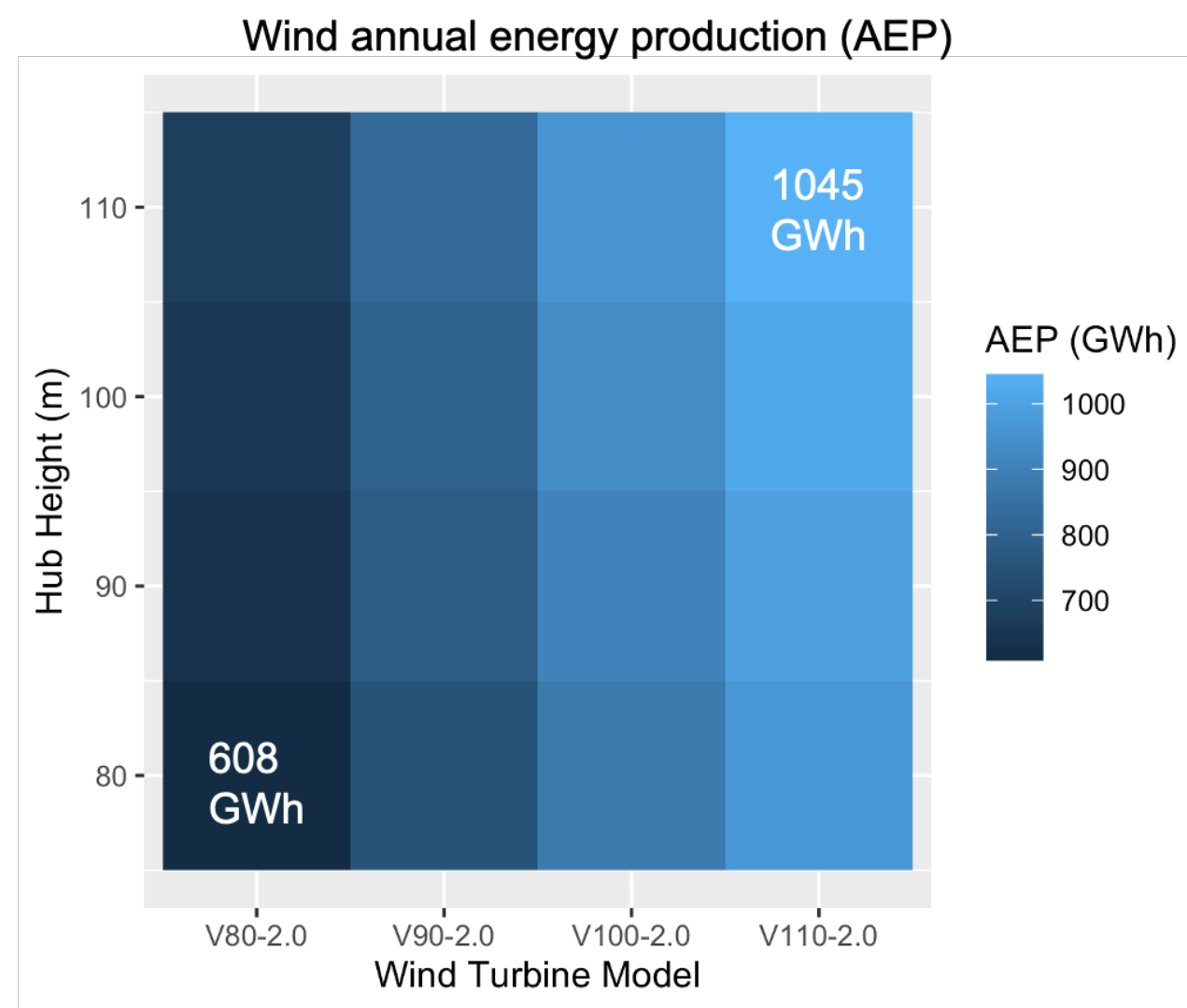

Figure 6. Heat map showing impact of wind turbine model and hub height on annual energy production of the three wind plants in BYPL's portfolio.

Note: The difference between the smallest, shortest turbine (bottom left) and largest, tallest turbine (upper right) is $72 \%$. 

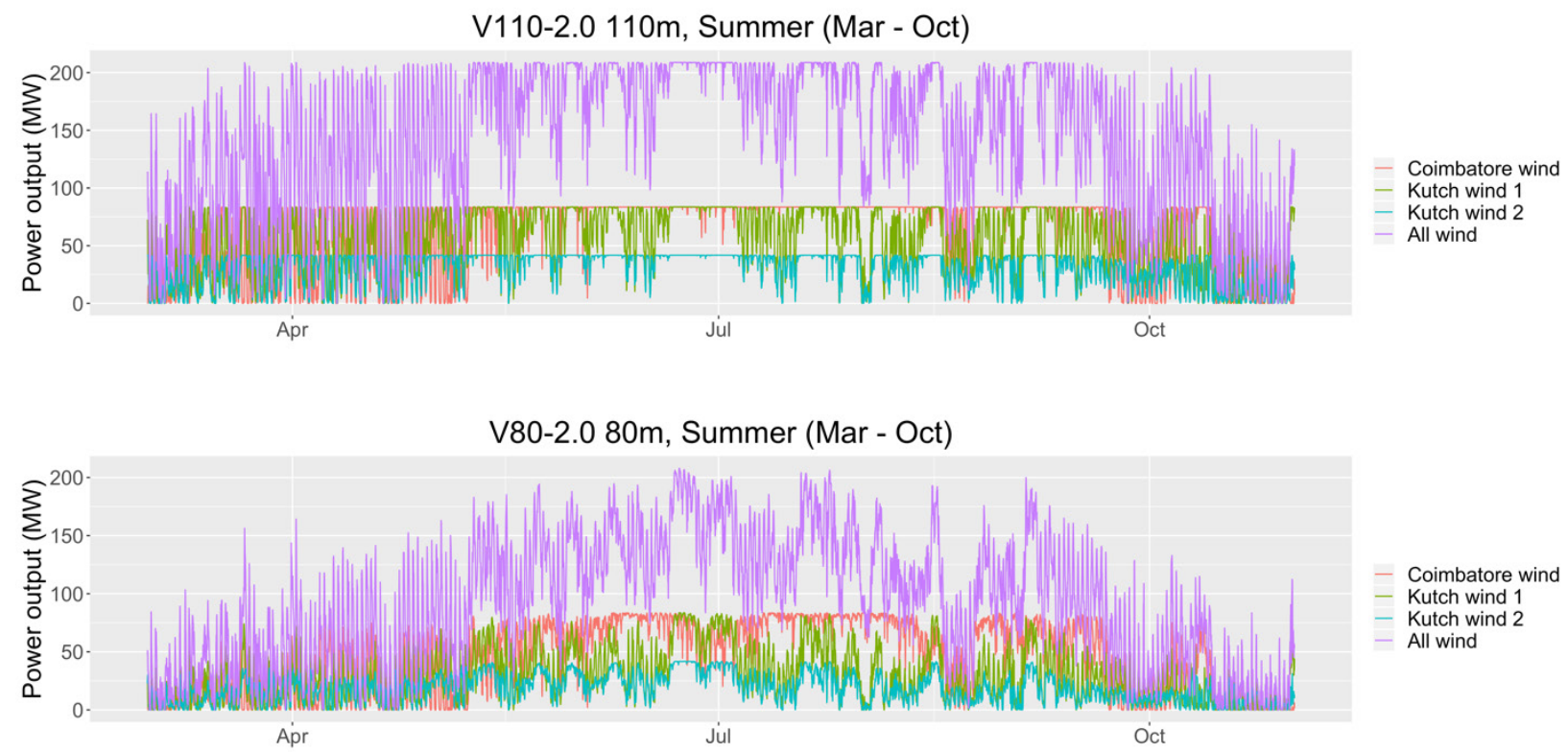

Figure 7. Comparison of summer power profiles for the two wind turbine models described in Figure 3.

Note: The larger turbines operate at their maximum for much of the summer, while the smaller turbines rarely reach their maximum.

\subsubsection{Results: Solar PV Energy Contribution}

As illustrated in Table 2, the modeled Rajasthani solar energy shows exceptionally little summer vs. winter variability based on the 2014 meteorological year. However, it is important to consider the impact of different weather years on the solar resource. ${ }^{5}$ To describe the interannual variability of the solar PV plants, we run a P50/90 analysis for 2000-2014. Also known as "exceedance values," P50/90 values are statistical summaries of a multiyear data set. In the context of annual energy production, a plant is expected to meet or exceed its P90 annual energy production value in $90 \%$ of years and meet or exceed its P50 annual energy production value in 50\% of years. As shown in Table 3, total solar energy production changes little from year to year; the solar plants can be expected to produce $7.6 \%$ of the total $2019 \mathrm{BYPL}$ demand in $50 \%$ of years, and $7.5 \%$ in $90 \%$ of years. This tight $\mathrm{P} 50 / 90$ range gives us confidence that using only a single year of solar data does not significantly affect the results. The remaining sections of analysis use 2014 solar irradiance data to match the only available year of data for the wind resource.

\footnotetext{
${ }^{5}$ While there may be larger fluctuations in solar PV capacity factor on a weekly or monthly basis, because BYPL characterizes its load in two seasons (summer and winter), we aggregated the plant performance to this level. Additional work could better characterize solar PV variability in Rajasthan on different timescales.
} 
Table 3. P50/P90 solar analysis for 2010-2014.

Note: Percentages refer to the fraction of the total BYPL demand in 2019 that would be met by these solar plants.

\begin{tabular}{|c|c|c|c|c|c|}
\hline & $\begin{array}{c}\text { Jaisalmer } \\
\text { PV } 1 \text { (100 } \\
\text { MW) }\end{array}$ & $\begin{array}{c}\text { Jaisalmer } \\
\text { PV } 2 \text { (50 } \\
\text { MW) }\end{array}$ & $\begin{array}{c}\text { Jodhpur } \\
\text { PV } 1 \text { (100 } \\
\text { MW) }\end{array}$ & $\begin{array}{c}\text { Jodhpur } \\
\text { PV } 2 \text { (50 } \\
\text { MW) }\end{array}$ & $\begin{array}{c}\text { Total } \\
\text { PV (300 } \\
\text { MW })\end{array}$ \\
\hline $\begin{array}{l}\text { Total energy } \\
\text { (P50) }\end{array}$ & $172 \mathrm{GWh}$ & $83 \mathrm{GWh}$ & $170 \mathrm{GWh}$ & $83 \mathrm{GWh}$ & $\begin{array}{c}508 \\
\text { GWh }\end{array}$ \\
\hline $\begin{array}{l}\text { Total energy } \\
\text { (P90) }\end{array}$ & $170 \mathrm{GWh}$ & $82 \mathrm{GWh}$ & $167 \mathrm{GWh}$ & $82 \mathrm{GWh}$ & $\begin{array}{c}501 \\
\text { GWh }\end{array}$ \\
\hline $\begin{array}{l}\text { Percentage of total } \\
2019 \text { demand } \\
\text { (P50) }\end{array}$ & $2.6 \%$ & $1.2 \%$ & $2.6 \%$ & $1.2 \%$ & $7.6 \%$ \\
\hline $\begin{array}{c}\text { Percentage of total } \\
2019 \text { annual } \\
\text { demand (P90) }\end{array}$ & $2.5 \%$ & $1.2 \%$ & $2.5 \%$ & $1.2 \%$ & $7.5 \%$ \\
\hline
\end{tabular}

\subsection{Capacity Contribution of Renewable Energy Plants: Capacity Credit}

BYPL ensures reliable electricity for its customers by procuring enough generation capacity to meet future peak load. In general, a fixed planning reserve margin is added to predicted peak load for a future year and electricity sources are procured to supply this total power. Figure 8 illustrates this strategy. Each generator in the portfolio provides a "firm capacity," which represents the amount of power the generator can reliably provide. Capacity credit expresses firm capacity as a percentage of the installed nameplate capacity. For example, a 100-MW coal-fired power plant with a capacity credit of $75 \%$ could be relied on 
to provide at least $75 \mathrm{MW}$ of power during times of greatest need. This plant would contribute $75 \mathrm{MW}$ of firm capacity to the system's planning reserve.

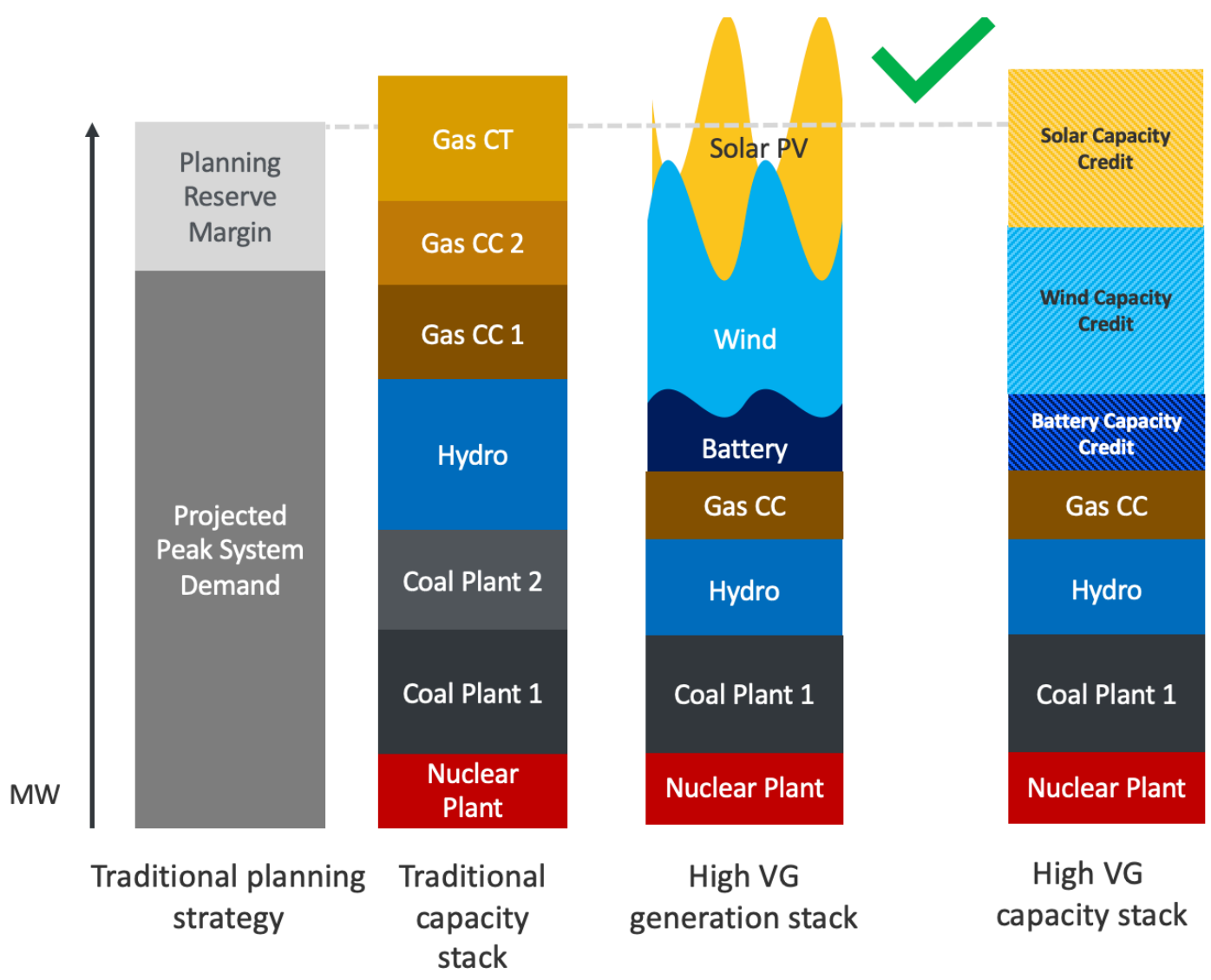

Figure 8. Illustrative firm capacity stacks for a traditional (all thermal and hydro) and a high renewable energy power system.

Note: The rightmost stack illustrates the process of translating the variable output of wind, solar PV, and battery storage into defined capacity credits.

Assessing the capacity credit of dispatchable thermal or hydro generators is relatively simple, as this often depends solely on their forced outage range. A study of the costs of renewable energy integration for the California renewable portfolio standard found that the capacity credit of a hypothetical conventional unit was indirectly proportional to its forced outage range. For instance, a combustion turbine power plant with 876 hours $(10 \%)$ of outages in a year would have a capacity credit of $90 \%=100 \%-10 \%$ (Milligan and Porter 2005).

However, the planning reserve stack becomes more complex once large amounts of weather-based, variable renewable generation are added to the system. As shown in the third stack in Figure 8, the contribution of wind and solar PV may at times bring the system over the required margin, but at other times (i.e., windless nights) it may not. Historically, utilities did not count VRE at all in their planning reserve margin and they filled the entire stack in Figure 8 with dispatchable thermal and hydro generators. While this practice ensures adequate supply in the event of realistic unplanned outages it may not be accounting for contributions that could be made from VRE and can result in overbuilt systems.

Furthermore, given many load-serving entities' commitment to high penetrations of renewable energy and thermal retirements, fully utilizing the potential contributions of VRE will be critical. Utilities are now 
beginning to consider fixed seasonal capacity credits for VRE when calculating their planning reserve margins (Carden et al. 2020).

BYPL does not plan to add significantly more thermal generators to their portfolio, so as their load continues to grow, variable generators must be included in the planning reserve stack to properly evaluate the contributions from all generators. To do this, we assign variable generators a capacity credit. Capacity credit summarizes a generator's ability to reliably serve load and is reported as a fraction of nameplate capacity.

Past studies have described several ways to address the calculation of capacity credit for renewables (Milligan and Parsons 1999). We utilize two methods to measure the capacity credit of BYPL's wind and solar PV plants. Both address the same fundamental question: how reliable is the renewable resource during the periods of highest system stress?

\subsubsection{Capacity Credit Method 1: Capacity Factor Approximation}

The most robust method to assess the capacity credit of a generator is to determine its impact on the reliability of the power system; however, reliability calculations are complex and rely on knowledge of the entire power system. Instead, utilities often approximate the capacity credit of a generator by describing its ability to reliably operate when it is most needed (Madaeni et al. 2012). The simplest metric for generator performance is capacity factor. Capacity factor describes the average power produced by the generator as a percentage of its nameplate capacity.

\subsubsection{Capacity Factor Approximation with Top Demand Hours}

In traditional power systems, periods when reliable power is "most needed" correspond to peak demand hours. ${ }^{6}$ Therefore, a basic approximation of capacity credit can be obtained by averaging the capacity factor of a generator during peak demand hours. The selection of how many peak demand hours to include, however, often varies.

A foundational NREL study investigated the impact of the selection of peak demand hours on the capacity factor approximation. The researchers compared the capacity factor approximation to capacity credit calculated with a robust reliability-based method known as effective load carrying capability (ELCC) (Milligan and Parsons, 1999). In short, ELCC describes the amount of additional load a generator could allow the system to serve while maintaining the same level of reliability. This metric, which will be explained in more depth in Section 2.5.2, is plotted using the blue line in Figure 9. The red line plots the capacity factor of the generator, calculated using different percentages of top demand hours. The

\footnotetext{
${ }^{6}$ Generator maintenance is often scheduled outside of these times, such as during the spring and fall shoulder seasons.
} 
researchers found wind energy capacity factor to be the best approximation of capacity credit when the top $\sim 10 \%$ of demand hours are considered.

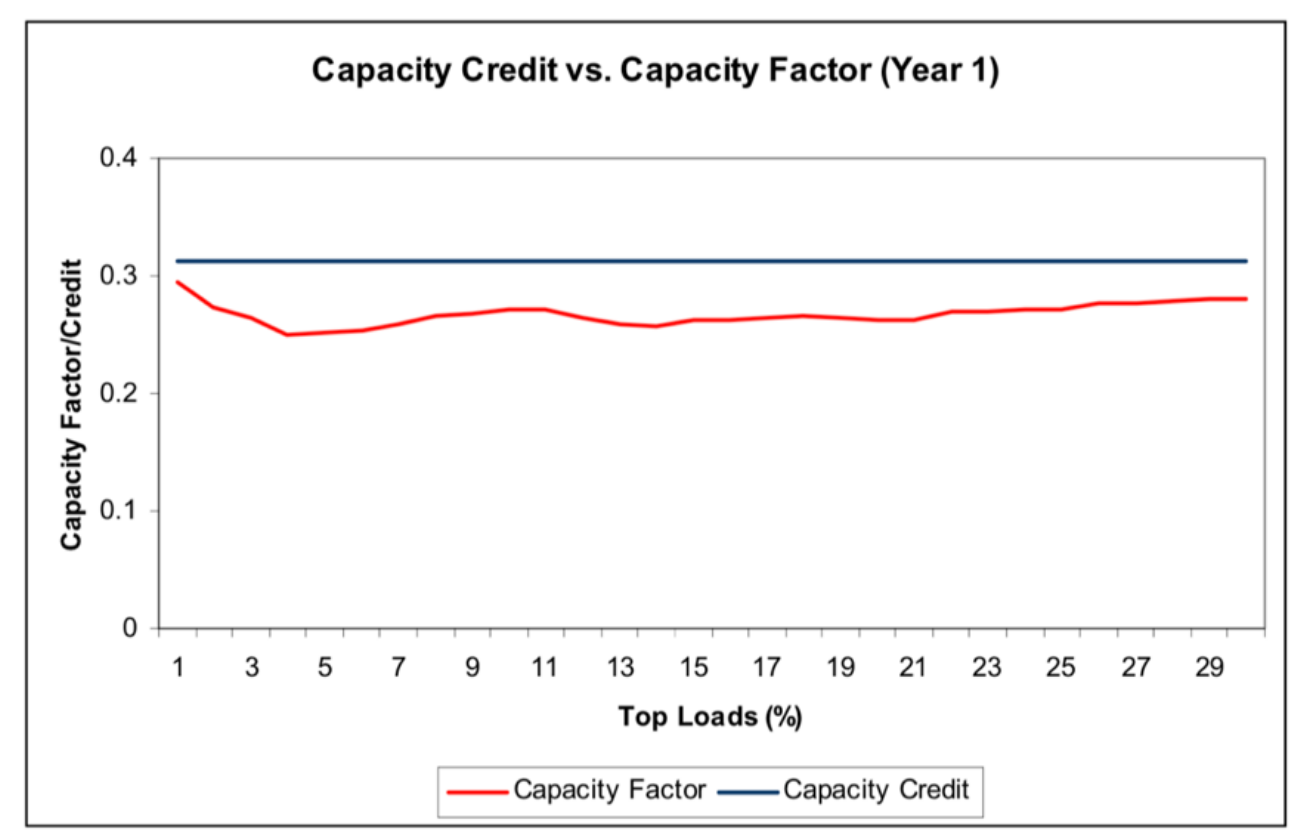

Figure 9. Representative capacity factor approximation results utilizing different percentages of load hours, compared with capacity credit calculated with a more robust method.

Source: Milligan and Parsons (1999)

In order to illustrate this method, Figure 10 plots a histogram of the time of day of BYPL's highest 10\% demand hours. The left axis shows the number of top demand hours that occurred during a particular hour. For instance, almost 75 of the 876 top 10\% demand hours occurred between 16:00 and 17:00. As can be seen by the height of the bars in the right half of the plot, these high-demand hours occur largely in the late afternoon and middle of the night.

The blue and red lines represent annual average wind and solar PV energy production, respectively, and are plotted on the right axis. The peak wind production hours roughly coincide with the largest number of top demand hours, suggesting that wind energy has a relatively higher capacity credit in this system. The opposite is true, however, for solar PV. Peak solar hours coincide with relatively few peak demand hours, so the capacity contribution of solar PV using this approximation is relatively low. The lack of correlation between load and solar PV production is also evident in Table 4. 


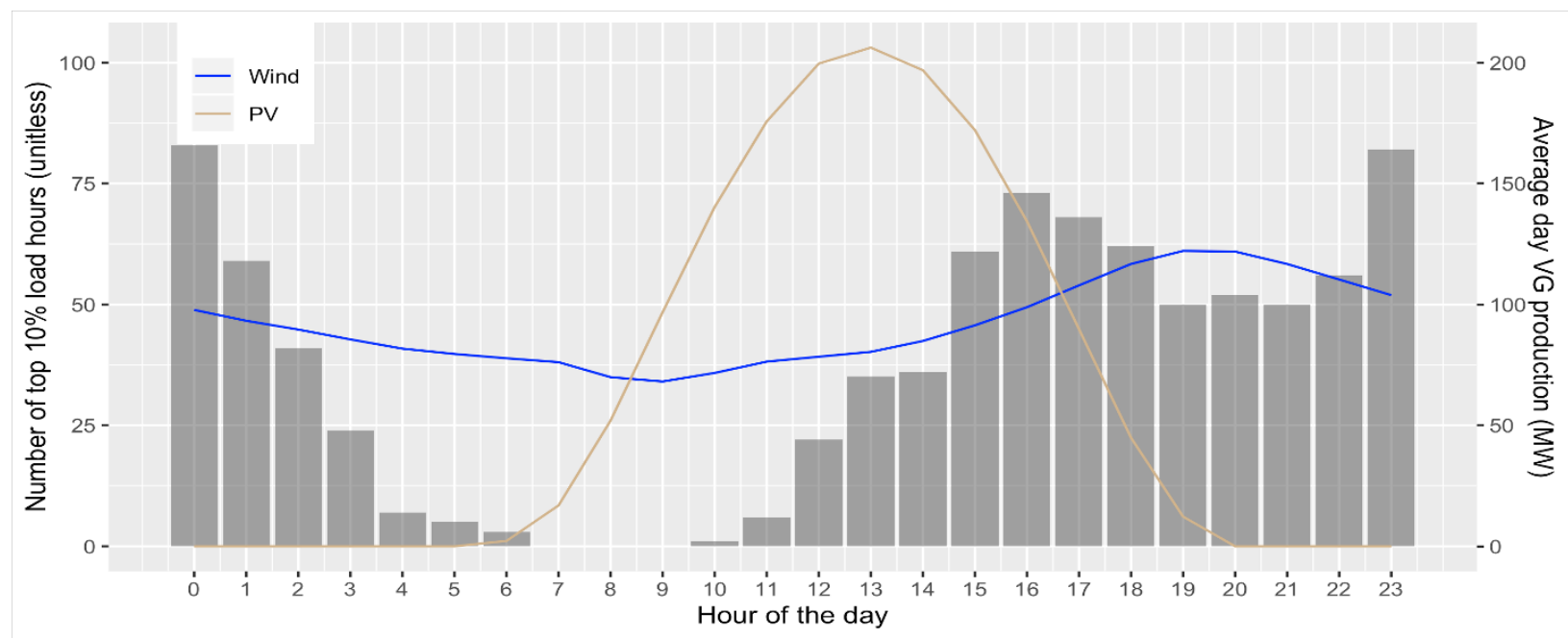

Figure 10. Time-of-day histogram of BYPL's top $10 \%$ load hours (left axis), overlaid with the annual average wind and solar PV production (right axis).

Note: Peak load hours occur largely in the evening and night, which lines up well with wind generation but not solar PV.

\subsubsection{Capacity Factor Approximation with Top Net Load Hours}

While simply considering peak demand hours in the capacity credit calculation is an accurate assumption for systems based mostly on dispatchable generation, large penetrations of renewable energy technologies has rendered this assumption less useful. Periods of system stress are now increasingly defined by the coincidence of high demand and low renewable energy resource. The metric net load, defined as total renewable energy generation subtracted from time synchronous demand, helps characterize these periods. ${ }^{7}$ Net load, at any given hour, represents the "remaining" demand that still must be served by dispatchable resources like thermal plants, hydro plants, or energy storage.

Figure 11 illustrates the difference between demand and net load. Throughout the daytime hours when the solar resource is strong, the power that needs to be met by dispatchable generation (net load) is small. As the sun fades, net load nearly converges with demand. This sharp increase in net load must be managed by quickly ramping dispatchable generation. In fact, the sharp evening ramp in net load has become so common in some systems that it has earned the nickname "duck curve" (Denholm et al. 2015).

\footnotetext{
${ }^{7}$ This net load calculation does not take into account behind-the-meter solar PV installations or battery storage, EVs,
} or other distribution-level net load drivers. Refer to Section 3 for additional details on BYPL's future net load. 


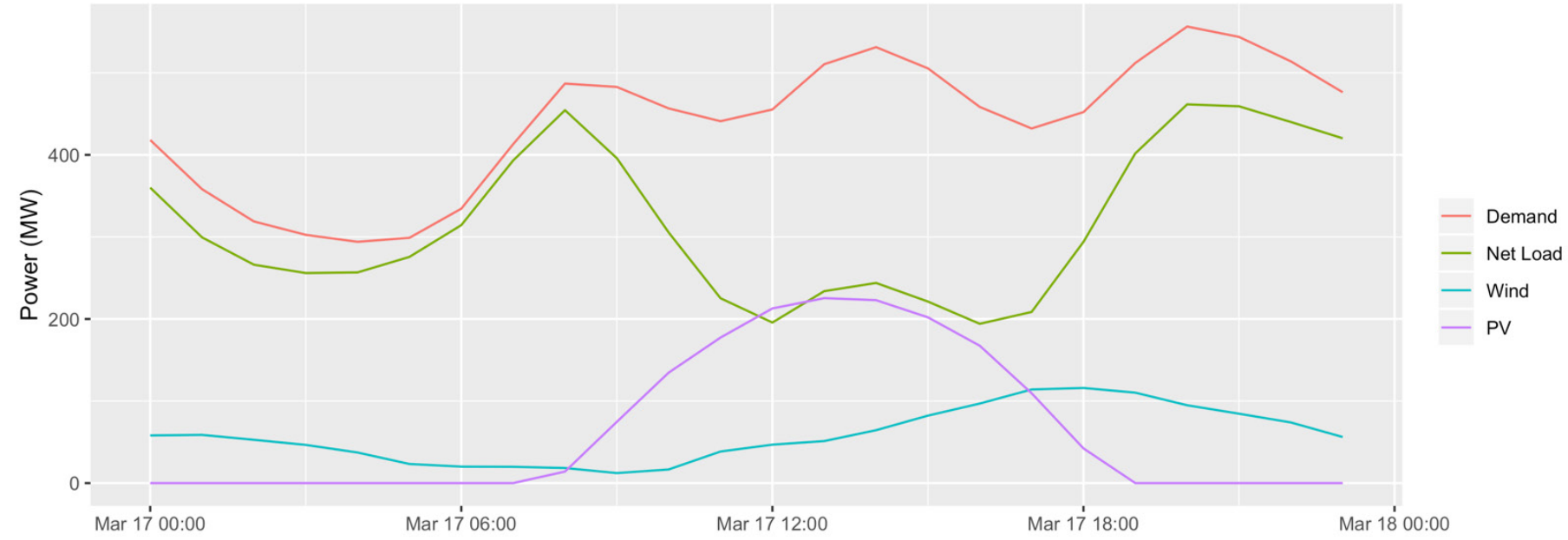

Figure 11. Example day, which represents the difference between demand and net load

Due to impacts like the duck curve, net load is a better proxy for system stress than peak demand. As such, net load can be a more accurate parameter to use in the capacity factor approximation of capacity credit. The time-of-day distribution of the highest 10\% net load hours in BYPL's system is plotted in Figure 12. Similar to Figure 10, the annual average wind and solar PV generation profiles are overlaid. Due to the subtraction of solar PV in the net load calculation, the highest net load hours occur almost exclusively outside of daylight hours. Therefore, solar PV capacity credit is even lower when approximated with the top net load hours. Wind capacity credit is still relatively high, as it peaks in the evening.

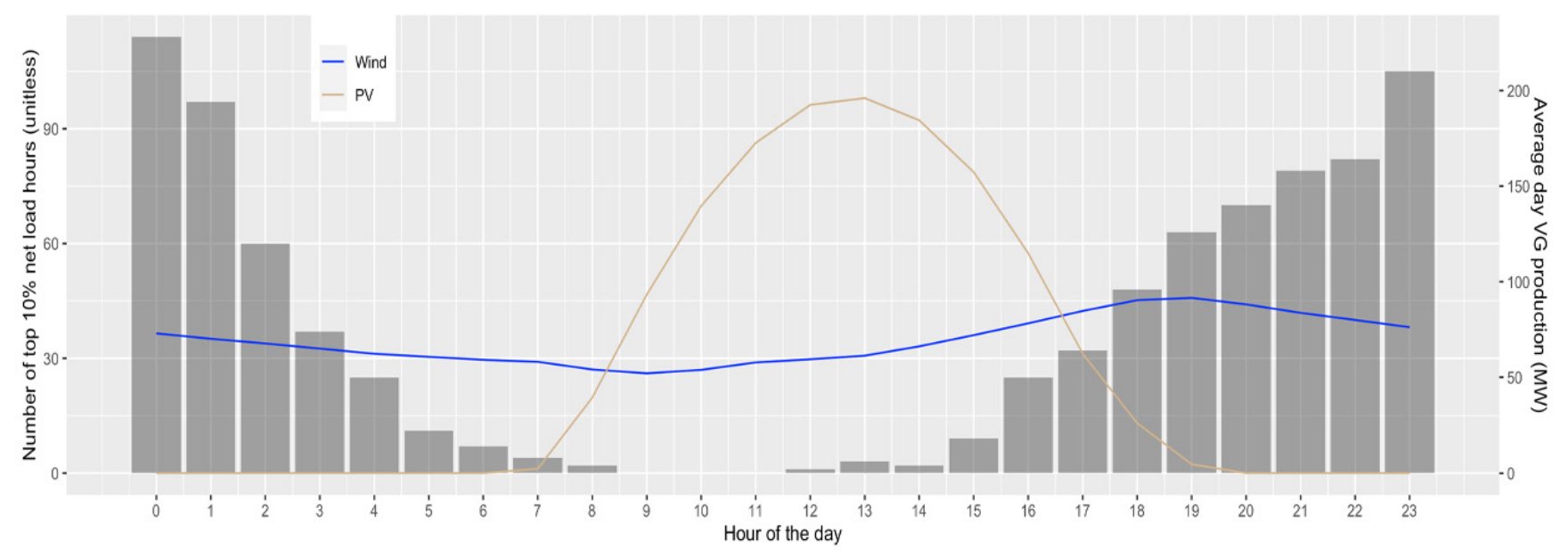

Figure 12. Time-of-day histogram of BYPL's top $10 \%$ net load hours (left axis), overlaid with the annual average wind and solar PV production (right axis)

The details of the capacity factor approximation method are still evolving. Rather the top $10 \%$, many researchers are moving now selecting much smaller subsets of hours to include in their capacity factor approximations. For instance, NREL's state-of-the-art capacity expansion models, the Regional Energy Deployment System (ReEDS) and Resource Planning Model (RPM), process the top 100 net load hours in their capacity credit calculations (Brown et al., 2019, Mai et al., 2013). Recent work has compared the use of the top 10, 50, 100, and 200 net load hours in RPM and found that while no alternative choice consistently outperformed the accepted 100-hour method in tracking robust reliability metrics like ELCC, 
the 10-hour method was frequently more accurate when valuing distributed or utility PV in the very high penetration PV scenarios (Stephen et al., 2020).

While the top 100 net load hour method is currently best practice for United States-based models, this practice is based on projections of US load evolution and US case-studies. The same method may not be ideal for the Indian power system. Section 2.6 includes results from the top 100 net load method - we see a slight decrease in BYPL's overall renewable energy capacity credit from $23 \%$ to $19 \%$-- but more research would be required to identify the ideal approximation for BYPL's unique demand curve. To ensure a reliable power system, the best practice may be to employ all capacity credit methods described in this section and plan based on the lowest estimates.

\subsubsection{Capacity Credit Method 2: Reliability Modeling}

While the capacity factor approximation can provide a rough idea of the capacity contribution of a renewable energy plant, the most accurate planning practice procures future capacity based on an acceptable level of system risk. Planners often purchase enough generation capacity of the appropriate types in the appropriate locations such that their system will experience no more than an agreed-upon amount of failure. System failure is measured by two common metrics:

1. Loss of load probability (LOLP). For a given time period (often 1 hour), LOLP measures the probability that some load will go unmet. Multiplying LOLP by the study time period (e.g., 8,760 hours), we calculate loss of load expectation (LOLE). A power system is often considered "adequately reliable" when it has an LOLE below 1 day per 10 years. Figure 13 plots the timeof-day distribution of high LOLP hours (LOLP > 1\%) in BYPL's system, similar to Figure 10 and Figure 12. The distribution contains elements of both earlier plots; the shape of the histogram in the evening hours is similar to that of the top demand hours shown in Figure 10 while the surge in high LOLP hours during the night resembles the top net load hours histogram from Figure 12.

2. Expected unserved energy. For the study time period, expected unserved energy measures the quantity of energy that the system will not meet.

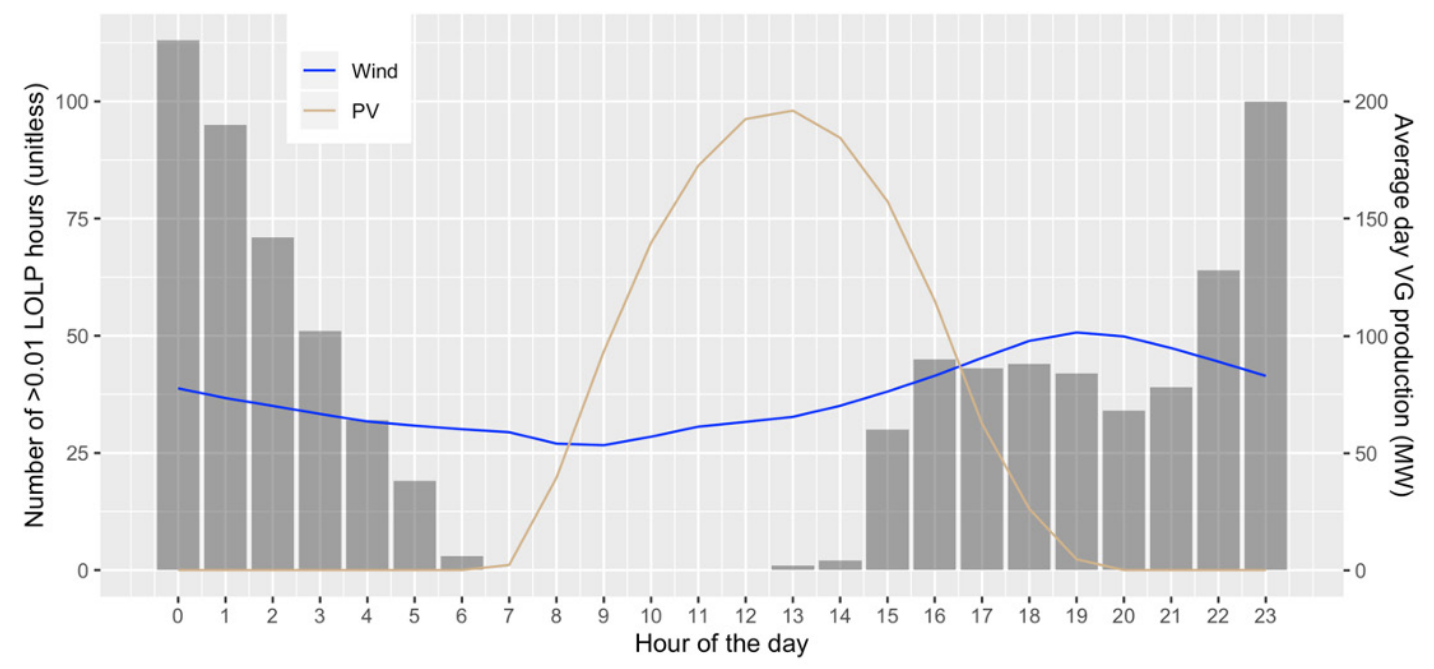

Figure 13. Time-of-day histogram of all hours in a year with a calculated LOLP > 1\% (left axis), overlaid with the annual average wind and solar PV production (right axis). 
Note: The distribution is similar to that of the top $10 \%$ demand hours plotted in Figure 10, but with a heavier emphasis on nighttime hours.

Using these risk-based metrics, planners can procure resources that most effectively increase system reliability in future years. Similarly, the capacity credit of a unit can be determined by examining its impact on system reliability. As mentioned above, a widely used metric called ELCC assesses the additional load a unit could serve while maintaining the same level of system reliability.

\subsubsection{ELCC Method}

To calculate the ELCC of BYPL's new VRE plants, we use the Probabilistic Resource Adequacy Suite (PRAS), NREL's in-house resource adequacy assessment tool (Frew et al. 2019). PRAS determines the LOLP and expected unserved energy of a power system, then uses these metrics to calculate the ELCC of individual generators.

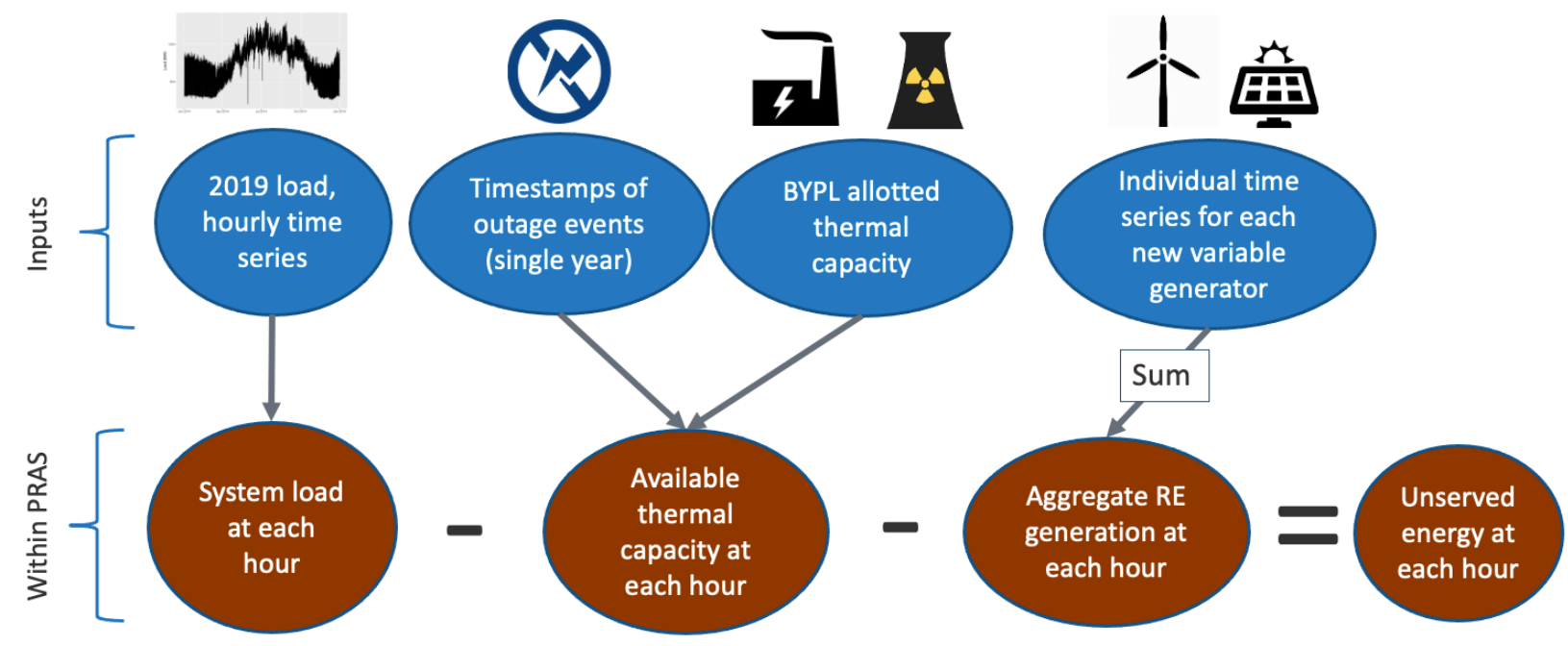

Figure 14. The workflow for NREL's in-house resource adequacy model, PRAS

Note: This diagram has been simplified to only showcase the PRAS capability used in this study, and leaves out transmission flow and storage operations.

Figure 14 illustrates the process PRAS uses to calculate LOLP. The model convolves the probability distribution of thermal outages with the aggregate VRE time series, and then subtracts these from load to find the energy shortfall in each timestep and region. ${ }^{8}$ If nonzero, the energy shortfall is then translated into an LOLP for each hour.

The first step in the PRAS ELCC calculation is the determination of the available generation resources in each hour of the year. The resources consist of thermal capacity and renewable energy generation, represented by the second and third maroon bubbles in Figure 14, respectively. The VRE time series (third bubble) is produced using the SAM model, described above. To produce the hourly time series of available thermal capacity (second bubble), we first derate the nameplate capacity of the thermal generators in BYPL's portfolio so that the modeled nameplate capacities are equal to BYPL's allotted capacity. Next, we associate random outages with each generator. BYPL provided timestamps of outage events, organized by event type, from March 2016 through February 2020. Using these data, we produce

\footnotetext{
${ }^{8}$ If transmission and storage were modeled as well, PRAS would also solve a simplified dispatch problem. It would use the available storage and transmission capacity between regions to alleviate shortfall.
} 
hourly time series of available capacity for each generator. We count mechanical outages because these events are difficult or impossible to predict, as well as outages due to fuel shortages, because these may continue to be exacerbated by increasing demand for limited gas supplies. However, we do not include maintenance outages and derates due to low demand because they have a higher degree of predictability. We run the PRAS model four times, once for each outage year, and average the results. This captures the interannual variability in "random" mechanical outages, as well as annual shifts in fuel shortages.

Importantly, because BYPL's power system operates in tandem with other utilities in Delhi and BYPL contracts only a small percentage of each thermal plant, our PRAS model does not capture all of the power system dynamics typically involved in a full resource adequacy study. Furthermore, we do not model transmission or storage.

Because we are more concerned with calculating relative changes in LOLP rather than absolute figures, we did not use coincident demand and weather years (2014, in this case). Instead, we chose to use 2019 demand in our reliability calculations because the higher demand was more likely to produce a nonzero LOLP. Still, this simplified system did not exhibit any nonzero LOLP. This result may suggest that the system is overbuilt, but with the major caveat that any possible transmission congestion is ignored. To produce a nonzero expected unserved energy and LOLP, we uniformly scale load by $15 \%$. This, along with removing low-capacity factor generators, is a common practice for finding nonzero LOLP in overbuilt systems (Gord et al. 2020).

After calculating LOLE, we find the ELCC of each generator. Figure 15 illustrates PRAS' method for calculating ELCC. System reliability is shown as a curve, because LOLE and load are positively correlated for a given infrastructure. First, PRAS removes the generator from the system and calculates the system LOLE. This represents Point 1. PRAS then adds the generator back to the system and repeats the LOLE calculation. The additional generator increases system-wide firm capacity and resource adequacy, so the curve shifts down to Point 2. The system LOLE is now lower than it was before (reliability is higher), and so it can accommodate more load at the previous LOLP (Point 4). The additional load that can be accommodated represents the generator's ELCC. In Figure 15, the generator in question allows the system to serve $400 \mathrm{MW}$ more load while remaining at the same reliability level $(\mathrm{LOLE}=0.1$ days/year). Its ELCC is therefore $400 \mathrm{MW}$. If the nameplate capacity of this generator was $1,000 \mathrm{MW}$, it would have a capacity credit of $40 \%$. 


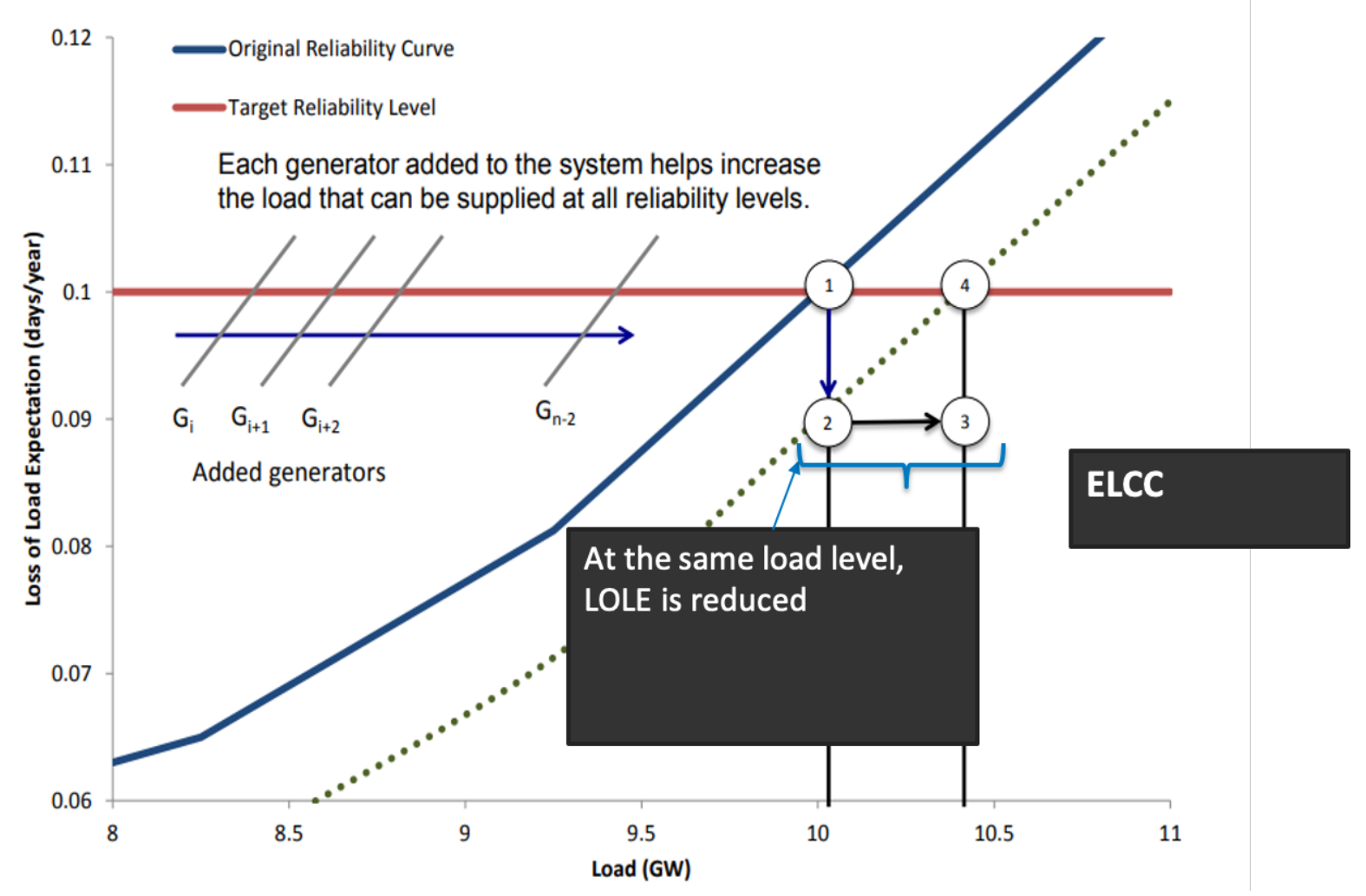

Figure 15. Generic representation of ELCC calculation

The various capacity credit methods described here involve a trade-off between ease-of-use and robustness. On the simple end of the spectrum, the capacity factor approximation can be calculated using only a spreadsheet tool and the only data requirements are time synchronous load and RE output profiles. As discussed in Sections 2.1-2.3, RE output profiles can be produced with NREL's open-source System Advisor Model software. However, the simplicity of the approximation requires numerous assumptions. For instance, it is deterministic (as opposed to probabilistic), neglects thermal outages and transmission, assumes that a unit's historical performance during high-risk hours will continue in future years, and does not reflect the effects of increasing RE penetration.

By contrast, the ELCC method can consider the dynamics of the entire system, including thermal outages, transmission, and storage behavior. ${ }^{9}$ Instead of assessing a plant's historical performance during high-risk time periods, this method computes the likelihood of unserved energy in the system and then assesses the potential of a particular plant to reduce this likelihood. Therefore, it is more robust and better reflects the system as a whole. It also captures the effect of increased renewable energy penetration, as shown below in Section 2.7. But these additional benefits come at a cost; the ELCC method requires a complex resource adequacy model powered by complex data such as forced outage rates of thermal plants and network topology.

${ }^{9}$ Although PRAS has this capability, we neglect transmission and storage in this study due to lack of data and relevance for BYPL's system. 


\subsection{Capacity Credit Results}

Table 4 reports the capacity credit values for each of the seven VRE plants in BYPL's portfolio, as calculated with each of the three methods described above. Capacity credit for individual solar PV plants is $17 \%-18 \%$ when calculated with the top $10 \%$ load hours capacity factor approximation, but it drops to almost zero when assessed with the resource adequacy model. However, the ELCC method finds the aggregate solar PV time series to be higher than that of an individual plant. This suggests that despite the homogeneity of the solar resource in Rajasthan, the geographic distribution of these four particular plants leads to some complementarity in their profiles. In other words - at least based on the 2014 weather year - when some of these plants have low output due to cloud cover, the other PV plants tend to have a relatively higher output. The impact of geographic diversity of PV plants on the aggregate output - an effect known as "geographic smoothing"- has been characterized at different timescales in Gujarat (Klima and Apt 2015).

When comparing the capacity factor approximation to the ELCC method, wind capacity credit reduces somewhat. This reduction is largely due to the timing of the average daily peak in wind output, which lines up more consistently with peak load than with the top LOLP hours. However, because the diurnal fluctuations in wind production are much flatter than those of solar PV, wind capacity credit remains relatively high.

Overall, the VRE has a capacity credit of 29\%, meaning these seven plants can add a total of $160 \mathrm{MW}$ of firm capacity to the planning reserve stack shown in the last stack in Figure 8. These results, when compared against other system operators, are low for solar PV, high for wind, and similar for aggregated VRE. For instance, the Pennsylvania-New Jersey-Maryland (PJM) Interconnection in the eastern United States assigns solar PV a capacity credit of $38 \%$ and wind a capacity credit of $13 \%$ (Jenkin et al. 2016). The Southwest Power Pool assigns overall VRE a capacity credit of 28.3\% (Haley, 2019). 
Table 4. Capacity Credit Results for Each Calculation Method by Plant

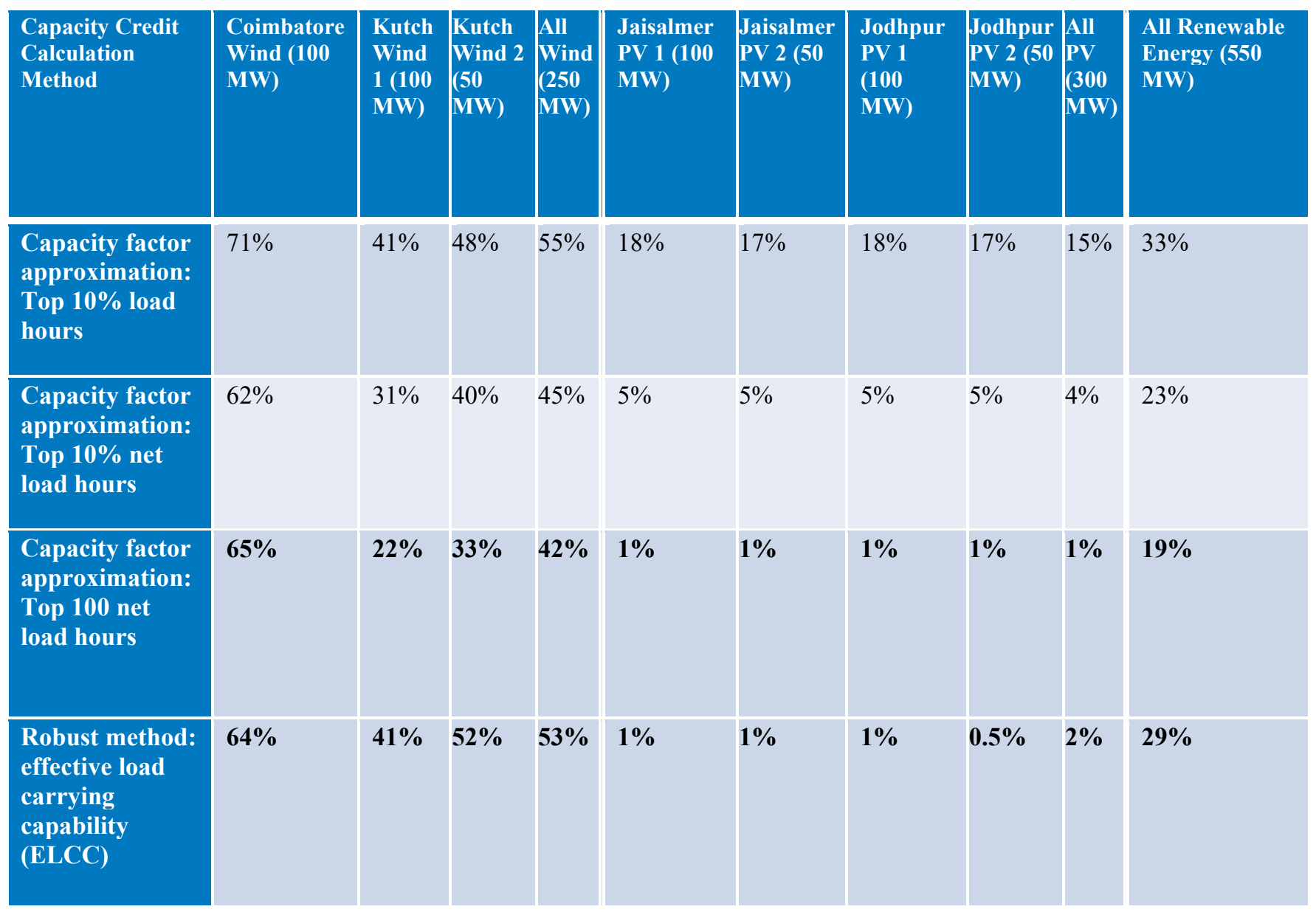

\subsection{Renewable Energy Penetration Scenarios}

COVID-19 has delayed the timeline for BYPL's new renewable energy procurement. Accordingly, we scale the renewable energy penetration level to produce several PRAS models that match different potential deployment scenarios for the near future. Table 5 summarizes these scenarios. Each scenario models the same seven renewable energy plants with different installed capacities. 


\section{Table 5. Renewable Energy Penetration Scenarios}

Note: The purpose of these scenarios is to showcase the effect of increasing renewable energy penetration on renewable energy capacity credit.

\begin{tabular}{|c|c|}
\hline Scenario Name & Capacity Breakdown \\
\hline High Renewable Energy (90\% penetration) & $\begin{array}{l}\cdot 600 \mathrm{MW} \text { wind in Tamil Nadu } \\
\cdot 900 \mathrm{MW} \text { wind in Gujarat } \\
\cdot 1,800 \mathrm{MW} \text { solar PV in Rajasthan }\end{array}$ \\
\hline Medium Renewable Energy ( $30 \%$ penetration) & $\begin{array}{l}\text {-200 MW wind in Tamil Nadu } \\
\cdot 300 \text { MW wind in Gujarat } \\
\text { •600 MW solar PV in Rajasthan }\end{array}$ \\
\hline $\begin{array}{l}\text { Original: } 550 \mathrm{MW} \text { new renewable energy } \\
\text { capacity ( } 15 \% \text { penetration by generation) }\end{array}$ & $\begin{array}{l}\cdot 100 \mathrm{MW} \text { wind in Tamil Nadu } \\
\cdot 150 \mathrm{MW} \text { wind in Gujarat } \\
\cdot 300 \mathrm{MW} \text { solar PV in Rajasthan }\end{array}$ \\
\hline Low Renewable Energy ( $7.5 \%$ penetration) & $\begin{array}{l}\cdot 50 \mathrm{MW} \text { wind in Tamil Nadu } \\
\cdot 75 \mathrm{MW} \text { wind in Gujarat } \\
\cdot 150 \mathrm{MW} \text { solar PV in Rajasthan }\end{array}$ \\
\hline $\begin{array}{c}\text { Minimal Renewable Energy Penetration (1.5\% } \\
\text { penetration) }\end{array}$ & $\begin{array}{l}\cdot 10 \mathrm{MW} \text { wind in Tamil Nadu } \\
\cdot 15 \mathrm{MW} \text { wind in Gujarat } \\
\cdot 30 \mathrm{MW} \text { solar PV in Rajasthan }\end{array}$ \\
\hline
\end{tabular}

For all scenarios, we use BYPL's actual load profile from 2019, as this results in the highest amount of unserved energy. BYPL expects its load shape to remain relatively stable and only its magnitude to grow, so we take 2019 to be a representative load year. The stability of the load shape over the past half decade is shown in Figure 1. As discussed above, we use a 2014 weather year to produce wind and solar PV hourly profiles.

Table 6 and Figure 16 show the penetration scenario results, aggregated for all wind, all PV, and all VRE. As illustrated in the workflow diagram in Figure 14, each PRAS model was run four times; once for each thermal outage year between 2016 and 2020. The error bars in Figure 16 represent the maximum and minimum values in this 4-year span, and the points show the mean values. 
Table 6. Results from PRAS Renewable Energy Penetration Scenarios

\begin{tabular}{|c|c|c|c|}
\hline Capacity Credit (ELCC) & All Renewable Energy & Wind & PV \\
\hline $\begin{array}{l}\text { High Renewable Energy } \\
\text { (90\% penetration) } \\
\text { REPLACE }\end{array}$ & $\begin{array}{l}\text { 2016: } 19.6 \%, 2017: 20.1 \% \\
\text { 2018: } 20.1 \%, 2019: 18.6 \% \\
\text { Mean: } 19.9 \%\end{array}$ & $\begin{array}{l}\text { 2016: } 40.5 \%, 2017: 42.2 \% \\
\text { 2018: } 42.3 \%, 2019: 38.2 \% \\
\text { Mean: } 40.1 \%\end{array}$ & $\begin{array}{l}\text { 2016: } 0.0 \%, 2017: 0.0 \% \\
\text { 2018: } 0.0 \%, 2019: 0.0 \% \\
\text { Mean: } 0.0 \%\end{array}$ \\
\hline $\begin{array}{l}\text { Medium Renewable } \\
\text { Energy (30\% penetration) }\end{array}$ & $\begin{array}{l}\text { 2016: } 25.2 \%, 2017: 26.4 \% \\
\text { 2018: } 27.5 \%, 2019: 23.5 \% \\
\text { Mean: } 25.6 \%\end{array}$ & $\begin{array}{l}\text { 2016: } 49.4 \%, 2017: 51.4 \% \\
\text { 2018: } 53.6 \%, 2019: 44.8 \% \\
\text { Mean: } 49.8 \%\end{array}$ & $\begin{array}{l}\text { 2016: } 0.0 \%, 2017: 0.0 \% \\
\text { 2018: } 0.0 \%, 2019: 0.0 \% \\
\text { Mean: } 0.0 \%\end{array}$ \\
\hline $\begin{array}{l}\text { Original: } 550 \mathrm{MW} \text { New } \\
\text { Renewable Energy } \\
\text { capacity (15\% penetration } \\
\text { by generation) }\end{array}$ & $\begin{array}{l}\text { 2016: } 28.7 \%, 2017: 29.8 \% \\
\text { 2018: } 30.7 \%, 2019: 26.9 \% \\
\text { Mean: } 29.0 \%\end{array}$ & $\begin{array}{l}\text { 2016: } 52.8 \%, 2017: 54.4 \% \\
\text { 2018: } 55.8 \%, 2019: 48.0 \% \\
\text { Mean: } 53.0 \%\end{array}$ & $\begin{array}{l}\text { 2016: } 0.0 \%, 2017: 0.07 \% \\
\text { 2018: } 7.0 \%, 2019: 0.0 \% \\
\text { Mean: } 1.9 \%\end{array}$ \\
\hline $\begin{array}{l}\text { Low Renewable Energy } \\
\text { (7.5\% penetration) }\end{array}$ & $\begin{array}{l}\text { 2016: } 31.6 \%, 2017: 32.4 \% \\
\text { 2018: } 32.7 \%, 2019: 29.8 \% \\
\text { Mean: } 31.6 \%\end{array}$ & $\begin{array}{l}\text { 2016: } 56.0 \%, 2017: 56.8 \% \\
\text { 2018: } 58.4 \%, 2019: 51.2 \% \\
\text { Mean: } 56.0 \%\end{array}$ & $\begin{array}{l}\text { 2016: } 6.6 \%, 2017: 6.6 \% \\
\text { 2018: } 9.3 \%, 2019: 5.3 \% \\
\text { Mean: } 7.0 \%\end{array}$ \\
\hline $\begin{array}{l}\text { Minimal Renewable } \\
\text { Energy Penetration }(1.5 \% \\
\text { penetration) }\end{array}$ & $\begin{array}{l}\text { 2016: } 30.9 \%, 2017: 30.9 \% \\
\text { 2018: } 30.9 \%, 2019: 29.1 \% \\
\text { Mean: } 30.5 \%\end{array}$ & $\begin{array}{l}\text { 2016: } 52.2 \%, 2017: 52.2 \% \\
\text { 2018: } 56.0 \%, 2019: 48.0 \% \\
\text { Mean: } 52.2 \%\end{array}$ & $\begin{array}{l}\text { 2016: } 10.0 \%, 2017: 10.0 \% \\
\text { 2018: } 10.0 \%, 2019: 10.0 \% \\
\text { Mean: } 10.0 \%\end{array}$ \\
\hline
\end{tabular}

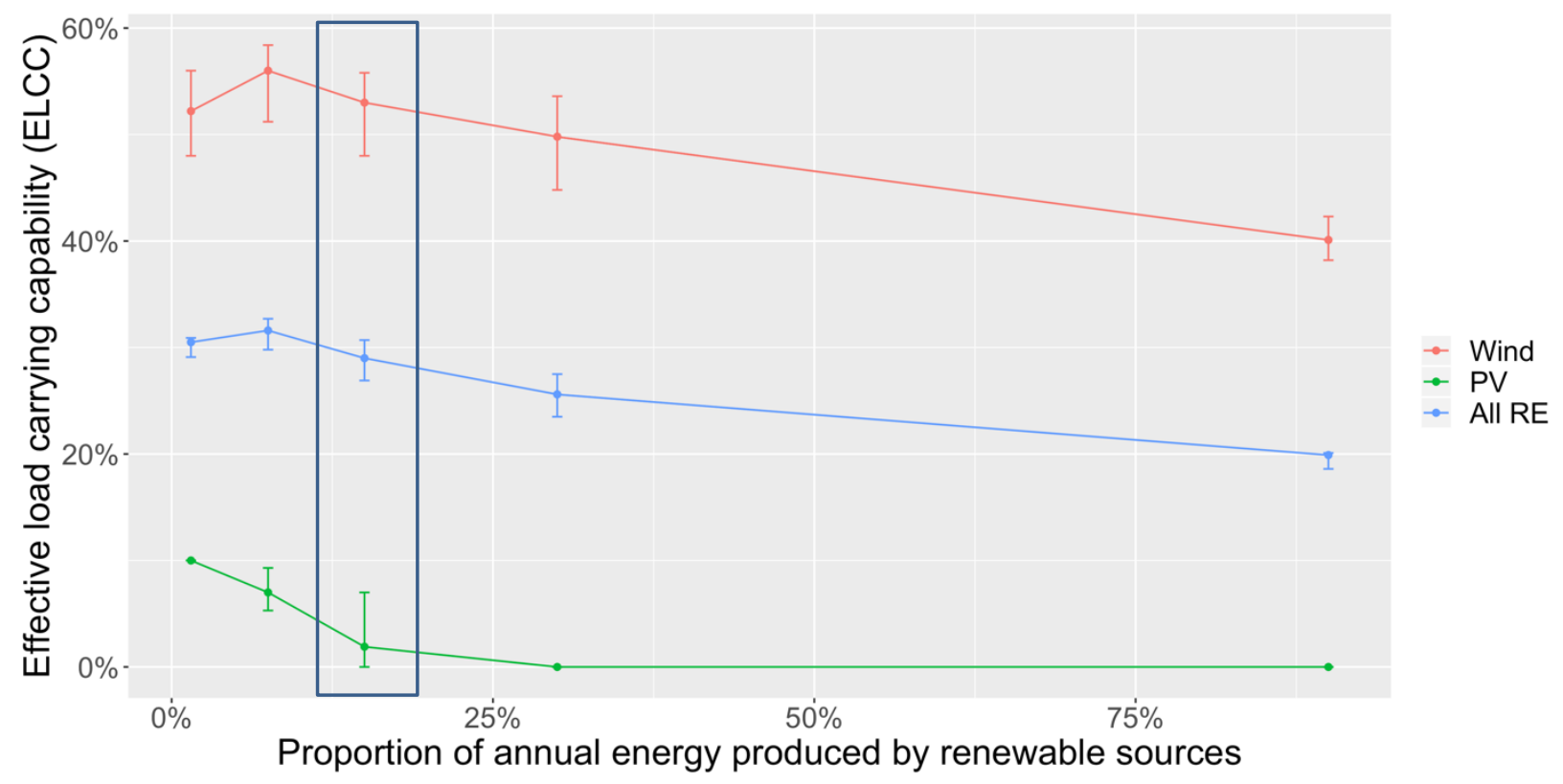

Figure 16. Renewable energy penetration PRAS scenario results for ELCC

Note: The purple box highlights the original 550-MW plan. The error bars represent the range of outputs generated from running each scenario four times, each with a different outage year. 
At minimal penetrations, solar PV provides 10\% capacity credit. However, its ELCC drops off dramatically at even moderate penetrations, and drops to zero by $30 \%$ penetration. This further highlights the fact that while Rajasthani solar energy can be helpful in providing energy services to BYPL in the future, it will not be able to participate in the capacity stack or provide planning reserves at high VRE penetrations.

By contrast, the ELCC of wind and aggregate RE remain steady even at very high renewable energy penetrations. Their capacity credit peaks just below $10 \%$ renewable penetration before gradually tapering off. This pattern, which has been thoroughly studied, is largely due to the diminishing marginal value of additional variable generation that relies on the same weather patterns (Denholm et al. 2016). It can be minimized by taking advantage of geographic smoothing as mentioned as mentioned above, but only to a certain extent (Klima and Apt 2015).

This smoothing occurs not only geographically, but also in the technology dimension. As shown by the error bars in Figure 16, the capacity credit of overall renewable energy has less variability than wind and solar PV individually. This suggests that combining different types of variable generation technologies in a high penetration future would lead to less variable aggregate output and a more precise renewable energy capacity credit. By taking advantage of geographic and technological diversity, the capacity credit of variable generation (the top three blocks in the rightmost stack in Figure 8) will have more definite values. Hybrid power plants have garnered more interest in recent years because they provide this technological smoothing while potentially saving capital cost investment by sharing interconnection infrastructure (Dykes et al., 2020). 


\section{DERs: Evolution of Net Load With Increasing Emerging Technologies}

Distribution network is facing a wave of changes as end consumers connect emerging technologies such as distributed solar PV, BESS, and EVs at their premises. This section discusses the models of these individual technologies and how we evaluated their aggregate effects on network planning/operation. The methodologies employed for this evaluation were compiled in the EVOLVE dashboard, which enables distribution utilities to visualize the shift in customer demand. This section provides a detailed description of how EVOLVE was developed. The key modules that build up EVOLVE are listed below:

1. Load disaggregation module

2. Solar PV module

3. EV integration module

4. Battery energy storage module.

For EVOLVE to work, the system-level load behavior needs to be disaggregated in more granular data sets for distribution transformers; Section 3.1 delves into the details on the disaggregation technique used here. Sections 3.2-3.4 describe models developed and used for solar PV, EV, and storage integration, respectively.

\subsection{Data Selection}

NREL and BYPL started with identifying key data for successful development of the dashboard. The data requested from BYPL are listed below.

- Feeder parameters (for 10 diverse feeders)

- EV charger types and growth assessment

- PV consumer details

- Consumer classes and categories

- 32 distribution transformer data, 30 min resolution (2016-2020, three feeders)

- Energy consumption data: monthly, for all customers from three distribution feeders.

We were interested in identifying three diverse distribution feeders for the dashboard development. To select three diverse distribution feeders, we started with a list of 10 of them based on parameters listed in Table 7. The following subsection provides the methodology used to down select three distribution feeders from the initial set of 10 . 
Table 7. List of Parameters Used to Down-Select Three Distribution Feeders from the Initial Ten

\begin{tabular}{|l|}
\hline Distribution feeder attributes: \\
\hline Maximum conductor length from substation \\
\hline Approximate feeder service area dispersion ( $\left.\mathrm{km}^{\wedge} 2\right)$ \\
\hline Customer mix (\% industrial) \\
\hline Customer mix (\% residential) \\
\hline Customer mix (\% commercial) \\
\hline Total number of customers from $2017-2020$ \\
\hline Mean load (kW) \\
\hline Minimum load (kW) \\
\hline Peak load (kVA) \\
\hline Mean load (kVA) \\
\hline Minimum load (kVA) \\
\hline Mean power factor (All customers) \\
\hline Number of distribution transformers \\
\hline Size of largest rated distribution transformer \\
\hline Size of smallest rated distribution transformer \\
\hline Total PV capacity (in kW) \\
\hline Average annual load growth on feeder over last 10 years \\
\hline Age of substation \\
\hline Age of oldest distribution transformer \\
\hline
\end{tabular}

\subsection{Down-Selection of Distribution Feeders}

Out of 10 feeders available, 3 feeders are down-selected for further analysis and will be referred to as Feeder1, Feeder 2 and Feeder3. Feeder 1 is chosen because it has the highest solar PV installed among all 10 , Feeder2 is due to its good mix of domestic, industrial, and commercial customers and also relatively higher number of customers, and Feeder 3 is selected because it is largely dominated by domestic customers and is the longest feeder with highest number of customers. Figure 17 shows the percentages of number of customers in each feeder. 

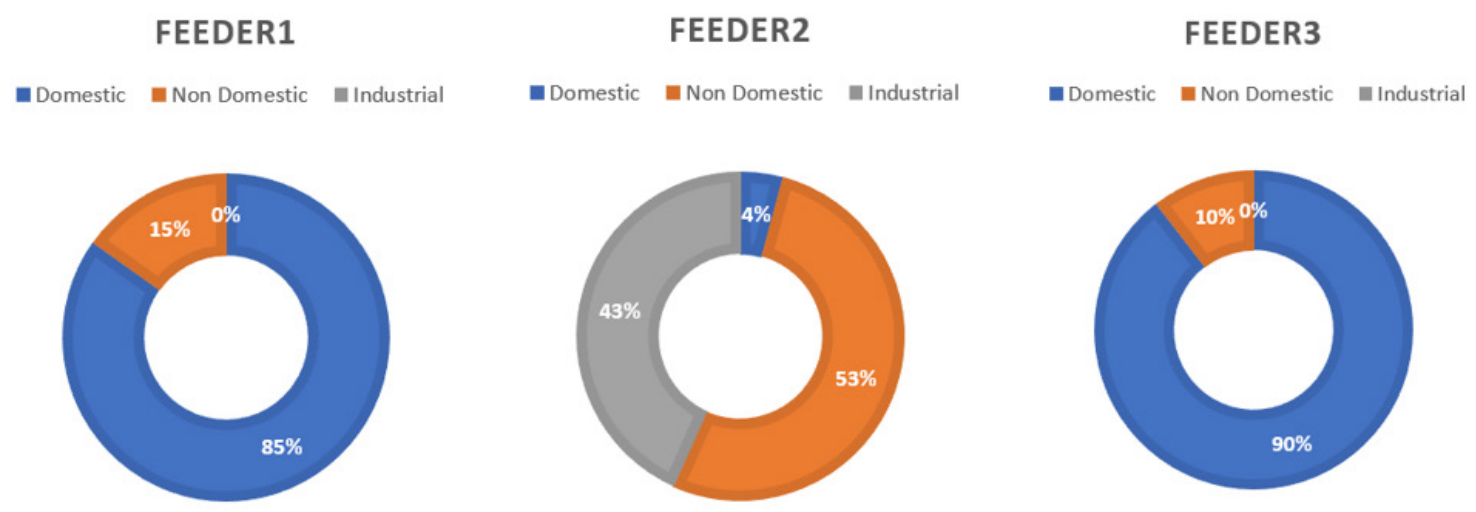

\section{Figure 17. Percentages of customers in domestic, nondomestic, and industrial sectors for three selected feeders}

The total number of customers in each feeder is $3,352,1,002$, and 4,801, respectively. NREL used 4 years of data (from 2016 to 2020) in 30-minute resolution of 30+ distribution transformers belonging to these three feeders to perform a net-load evolution study.

\subsection{Load Disaggregation Module}

Load disaggregation is a process in which we break down the consumption happening at distribution transformers to individual customers. The consumers are classified into three main categories: domestic, nondomestic, and industrial. As a part of the NREL-BYPL net load evolution study effort, a statistical model was developed to disaggregate time series distribution transformer power profiles into these three groups. Knowing the nature of the load profile of the consumers' groups helps the utility understand the role of each group in transformer loading and make policy decisions that benefit both the utility as well as customers.

\subsubsection{Model Description}

The following exogenous variables are used as predictors in an out-linear mixed model to disaggregate the transformer load profile:

- Temperature (in centigrade) and Humidity (in percentage): Weather is one of the major drivers of a consumer's electricity consumption. Temperature and humidity data from Indira Gandhi International Airport (available online at ftp://ftp.ncdc.noaa.gov/pub/data/noaa/) is used in this study to model the transformer power profile. The data was extracted from 2016 to 2020 in 30minute resolution. The variables are designated as Temperature and Humidity in the model.

- Holiday: To capture the effect of holidays on energy consumption, the holiday index is used as a categorical variable in our model. If a day is a holiday, the index is 1, 0 otherwise. The holiday data was obtained online at https://www.officeholidays.com/countries/india/delhi/ for all years. It is designated as Hday in the model.

- Month: To account for seasonal effect on transformer load profile, the type of month is used as another categorical variable in the model. It is designated as Month.

- Consumer's energy consumption data: Monthly energy consumption data for all customers are used to compute the contribution of each of the consumer groups (domestic, nondomestic, and industrial) to the total monthly energy consumption of a distribution transformer. This 
contribution value is represented between 0 and 1 . Note the sum of contribution from all consumers group must be equal to 1 . Because the energy consumption data was available in month resolution, the contribution of a group is assumed same for the whole month. The contribution of each of the group is designated as Domestic, NonDomestic, and Industrial in the model.

- Half-hour index: To account for the fact that each half hour is different in a day (half hour index is used because transformer power profile was available in 30-minute resolution), half hour index is also used as one of the categorical variables in the model. The index 0 represents midnight 12 , 1 represents 12:30 a.m., and so on. It is designated as Hhindex in the model.

The linear mixed model used to model the time series power profile of the distribution transformer is given in Equation 1. Note that, in this model, only domestic contribution is used, because it will be used to estimate the aggregated profile of domestic consumers only by setting the contribution to unity after fitting the model.

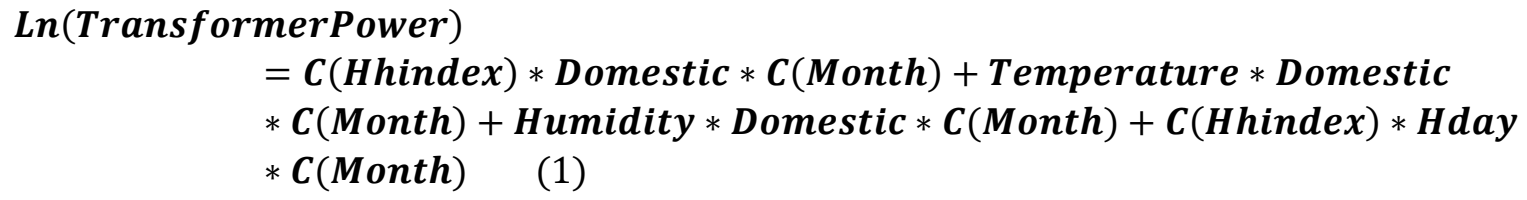

Natural log is used with transformer profile to avoid estimating negative values. Any variable wrapped around parenthesis and prefixed by $\mathrm{C}$ means it is a categorical variable and presence of * indicates interaction term in the model. The interaction term is important in a linear mixed model because it helps to differentiate the impact of one variable when the other interacting variable takes different values.

Equations 3 and 4 can be used to estimate a time series load profile for a nondomestic and industrial group of customers.

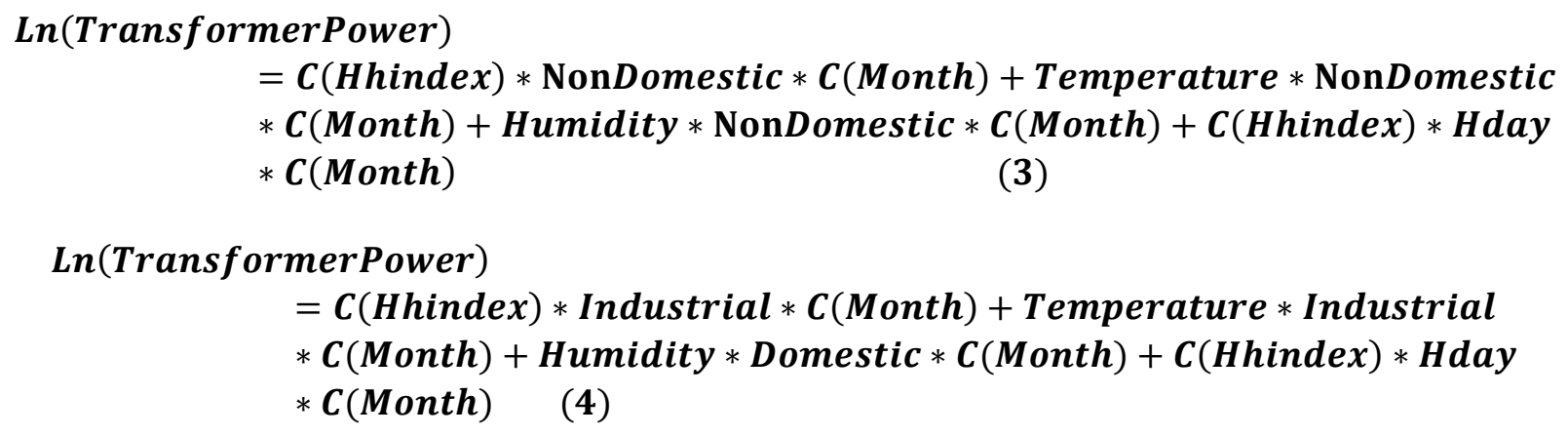

The model was developed and solved using the statsmodel package in Python programming language.

\subsubsection{Model Outputs}

Two distribution transformer load profiles from 2019 were used to validate the model. The first transformer (DT1) is dominated by domestic customers, and the second transformer (DT2) has a mix of nondomestic and industrial customers. Table 8 gives the number of customers in each group for these distribution transformers. 
Table 8. Number of Customers in Each Customer Category for Four Distribution Transformers Considered in Disaggregation Model Testing

\begin{tabular}{|l|l|l|l|}
\hline Distribution Transformer & $\begin{array}{l}\text { Number of Domestic } \\
\text { Customers }\end{array}$ & $\begin{array}{l}\text { Number of Nondomestic } \\
\text { Customers }\end{array}$ & $\begin{array}{l}\text { Number of Industrial } \\
\text { Customers }\end{array}$ \\
\hline DT1 & 71 & 1 & 0 \\
\hline DT2 & 0 & 29 & 50 \\
\hline
\end{tabular}

Figure 18 shows the result for distribution transformer DT1. Note that there is no industrial profile, and because this transformer does not have any industrial customers. Figure 19 and Figure 20 show similar results for the summer week and winter week, respectively. As seen in the figures, summer peaks occur during night and late afternoon, whereas winter peaks occur during morning and evening; overall load is much higher during summer than in winter for this distribution transformer. The profile shape for both domestic and nondomestic customers are almost similar in both summer and winter because the energy consumption data available was in much higher resolution (monthly), compared to the resolution of transformer load (30-minute resolution). Figure 21 shows the plot of residuals (the difference between $\log$ of original profile and log of predicted profile because the model uses $\log$ ) against the predicted load of the transformer (after log transformation). The plot shows an almost homoscedastic nature, which means residuals tend to follow constant variance, validating the developed model.
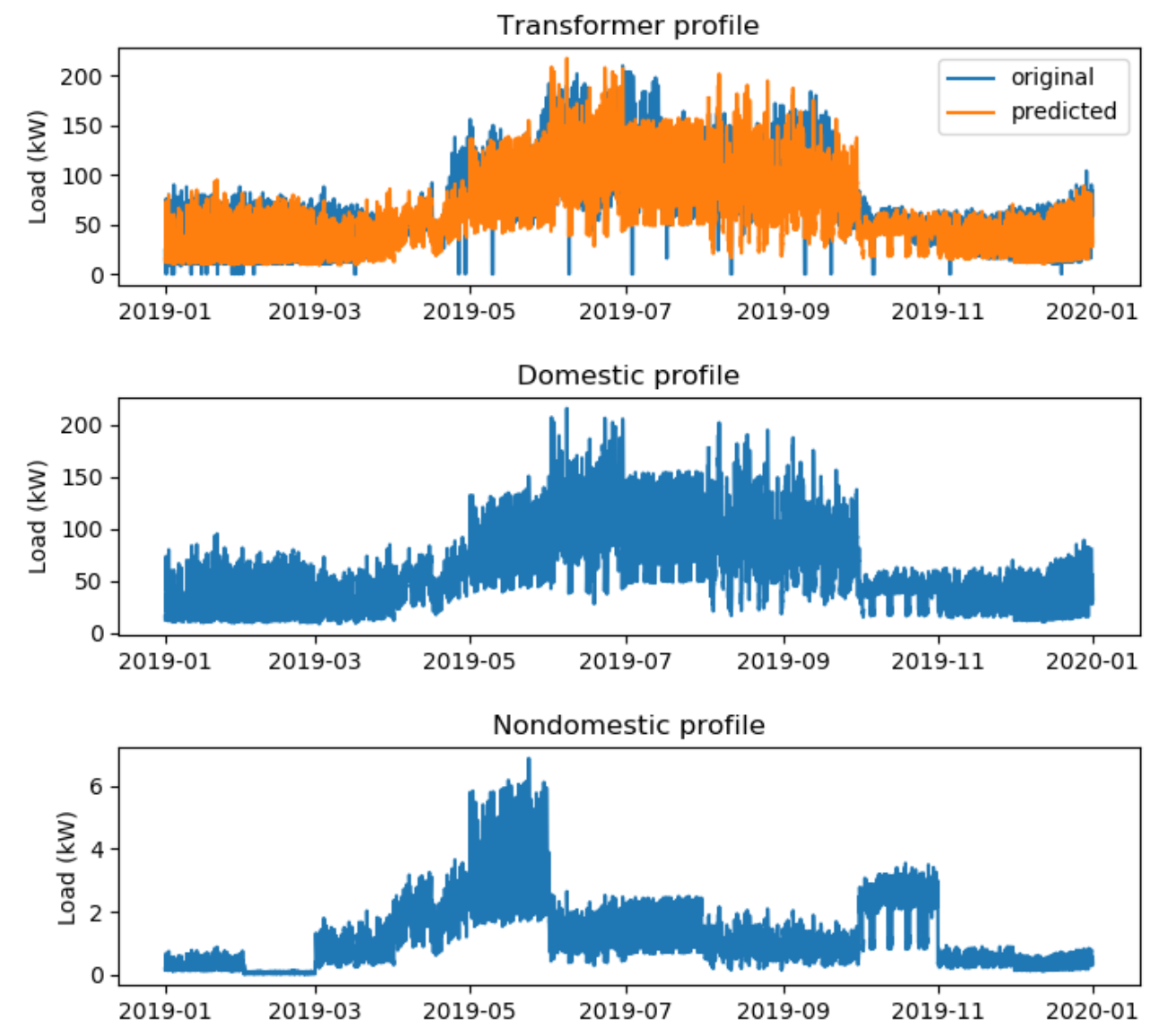

Figure 18. Disaggregated profiles of DT1 transformer with original profile for 2019 

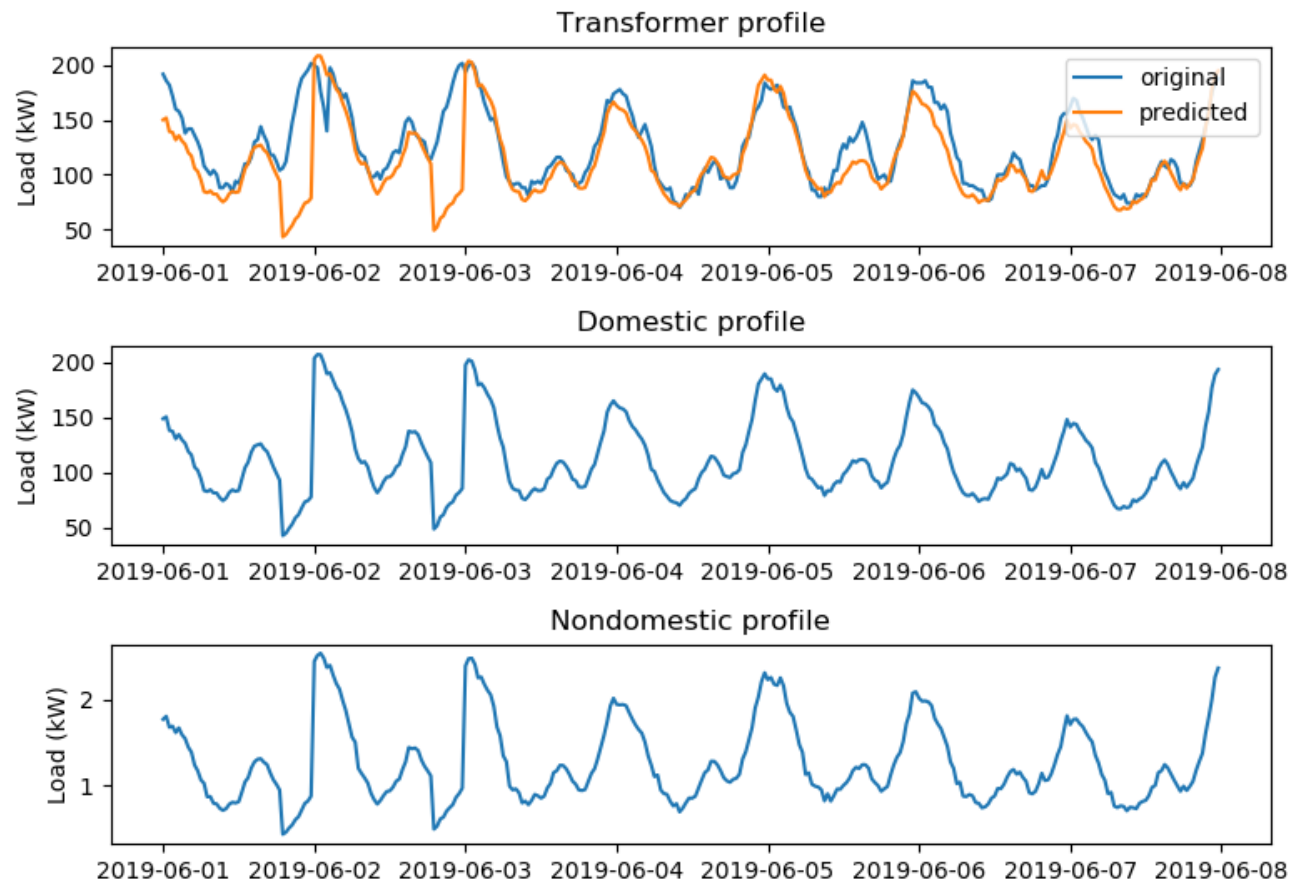

Figure 19. Disaggregated profiles of DT1 transformer with original profile for summer week of 2019
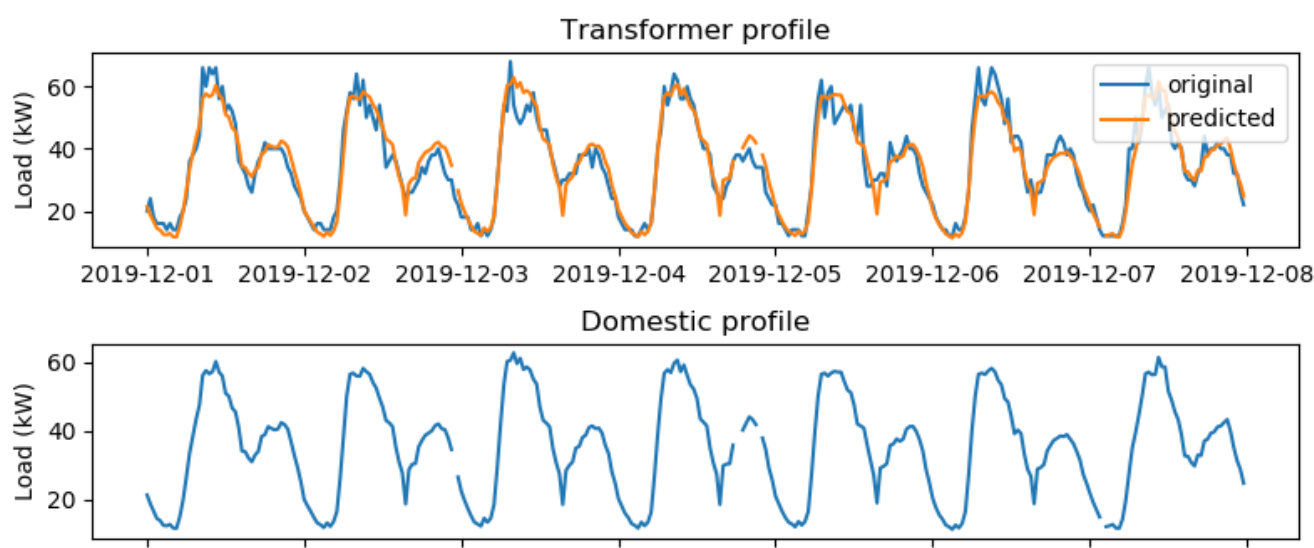

2019-12-01 2019-12-02 2019-12-03 2019-12-04 2019-12-05 2019-12-06 2019-12-07 2019-12-08

Nondomestic profile

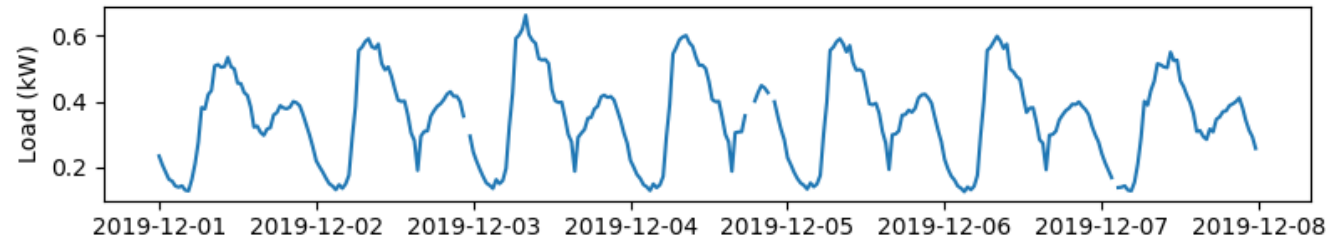

Figure 20. Disaggregated profiles of DT1 transformer with original profile for winter week of 2019 


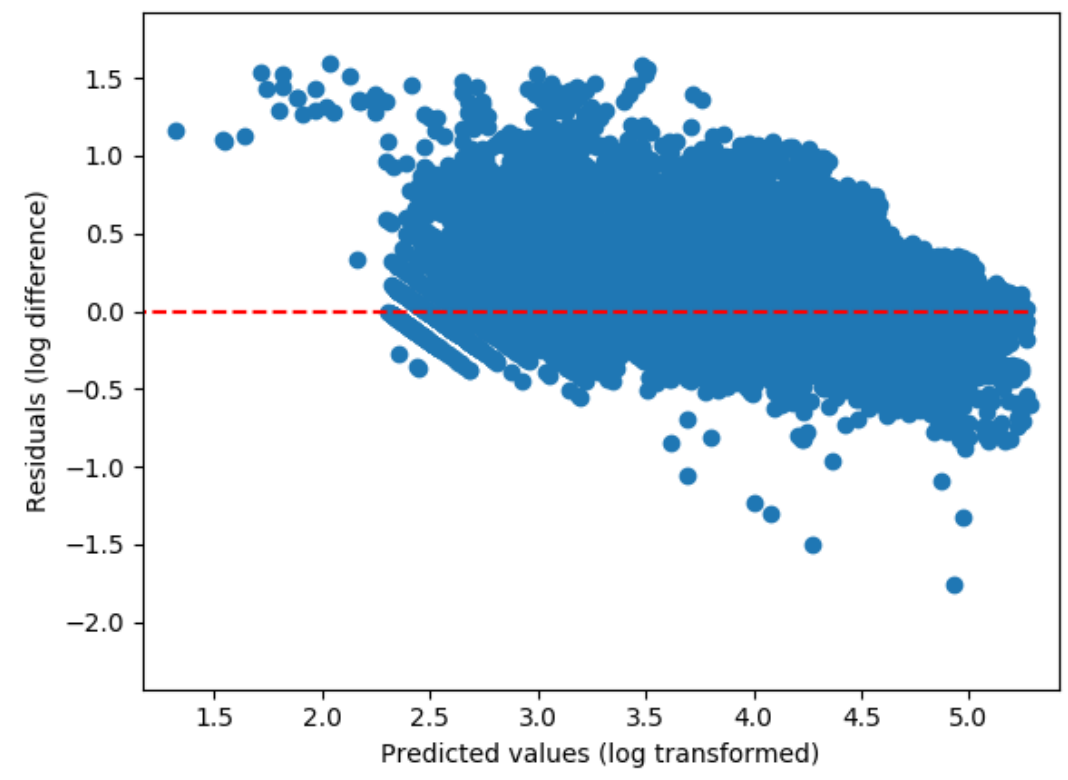

Figure 21. Plot of residuals for DT1

The result for distribution transformer DT2 is shown in Figure 22. The summer week and winter week profiles for this transformer are shown in Figure 23 and Figure 24, respectively. The difference in load magnitudes between the summer and winter months is much less in DT2 compared to DT1, because DT2 is dominated by commercial and industrial customers. Note that DT2 has 0 domestic customers. The residual plot for DT2 is shown in Figure 25. 

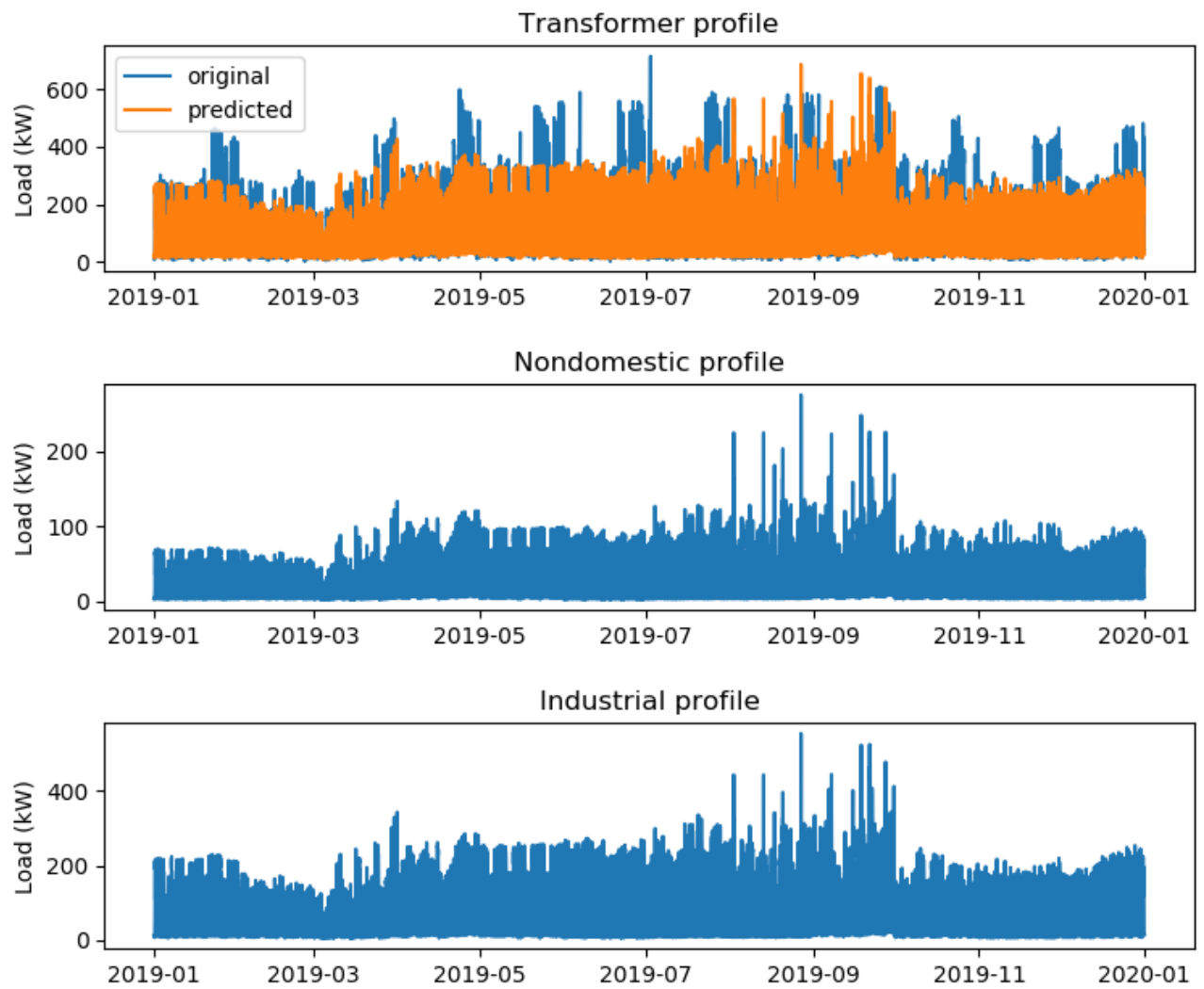

Figure 22. Disaggregated profiles of DT2 transformer with original profile for 2019
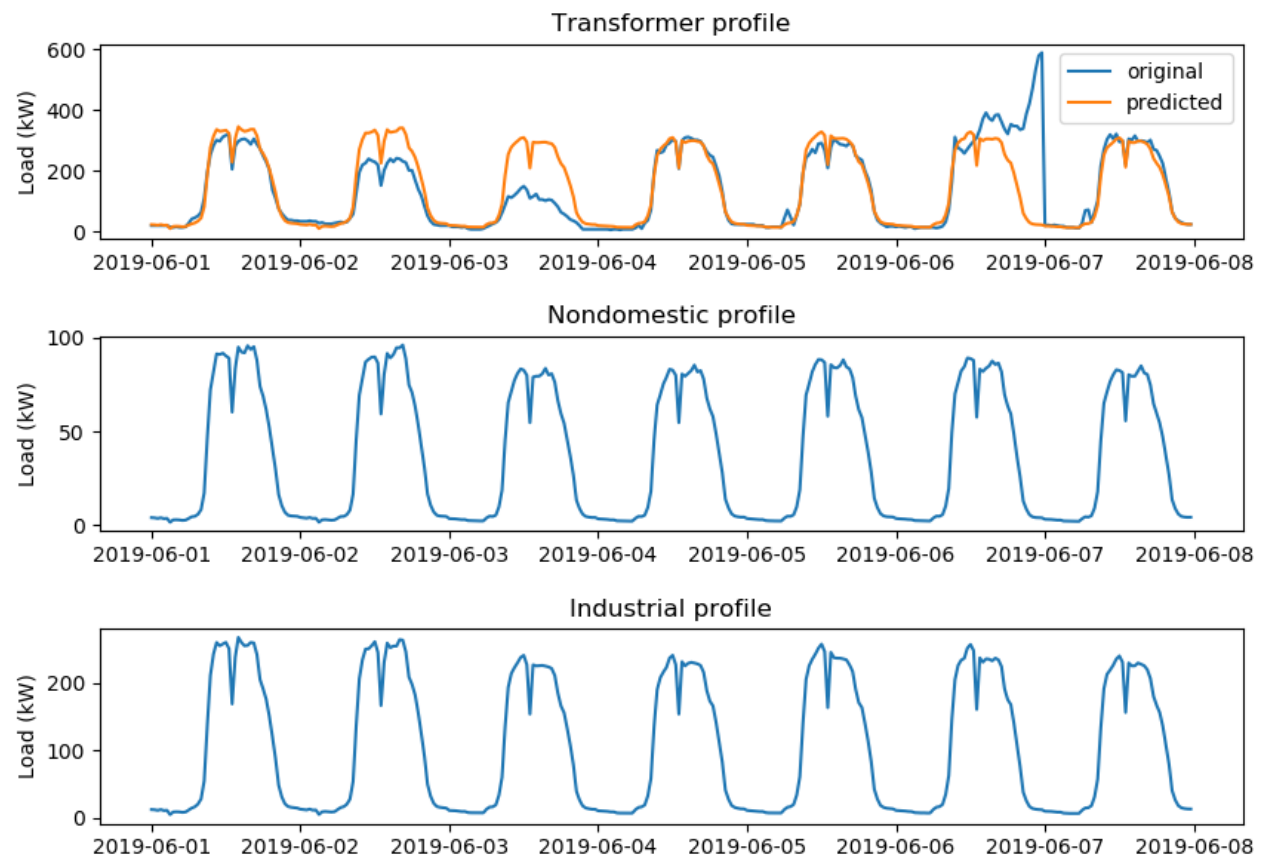

Figure 23. Disaggregated profiles of DT2 transformer with original profile for summer week of 2019 

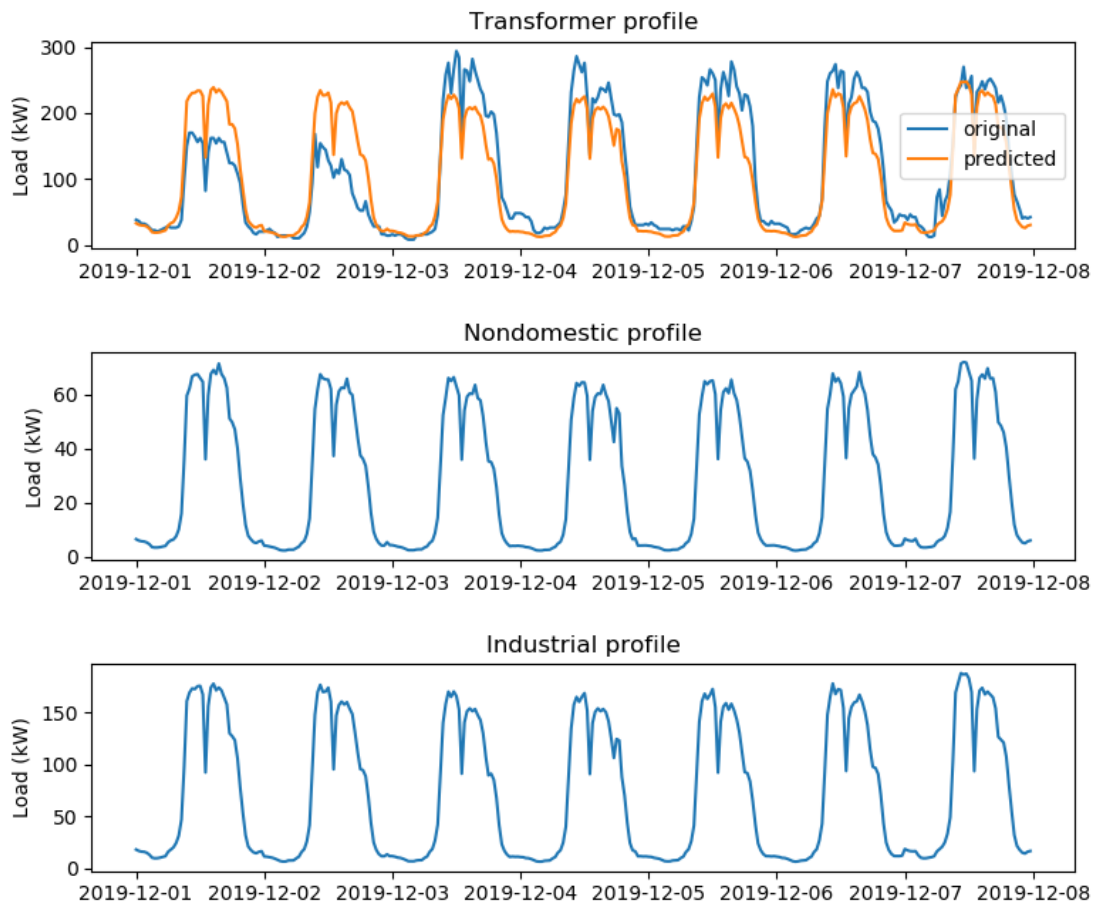

Figure 24. Disaggregated profiles of DT2 transformer with original profile for winter week of 2019

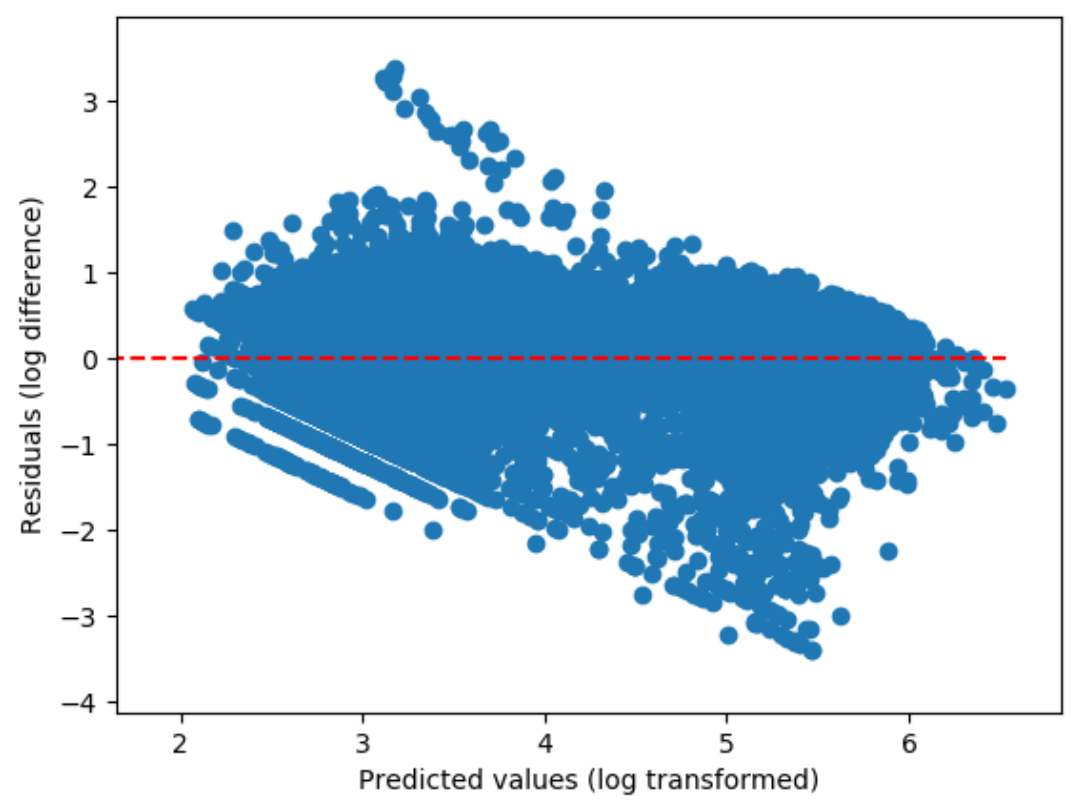

Figure 25. Plot of residuals for DT2 


\section{Solar PV Module}

The EVOLVE dashboard can take solar PV penetration as user input and distribute solar PV to customers. The solar irradiance data for the study is obtained from NREL's National Solar Radiation Database at https://nsrdb.nrel.gov/.

The NREL team analyzed three feeders in BYPL territory to assess the impact of solar on their net load profiles from 2016 to 2020. Four parameters are considered for this analysis. All these parameters are analyzed on monthly basis from 2016 to 2020 . The solar irradiance data for the study is obtained from https://nsrdb.nrel.gov/.

Assumptions made during analysis:

- Note that, because of the unavailability of the irradiance data after 2014 for BYPL territory, we are using 2014 irradiance data for all years, assuming irradiance has not changed significantly.

- Locational benefit of solar panel has not been modeled (i.e., power flow study is not a part of this study).

- All solar installations are lumped at a single point and we assumed that every time maximum available power will be generated.

\subsubsection{Average Power-to-Peak-Power Ratio}

The average-to-peak-power ratio is an indicator of resource utilization efficiency. Higher average-to-peak ratio means that generating resources are utilized efficiently during the period under consideration. Deployment of solar in the power grid reduces the total energy purchased from power utilities. If the power generation from solar is small or none during the system peak, the average power-to-peak-power ratio drops significantly. 

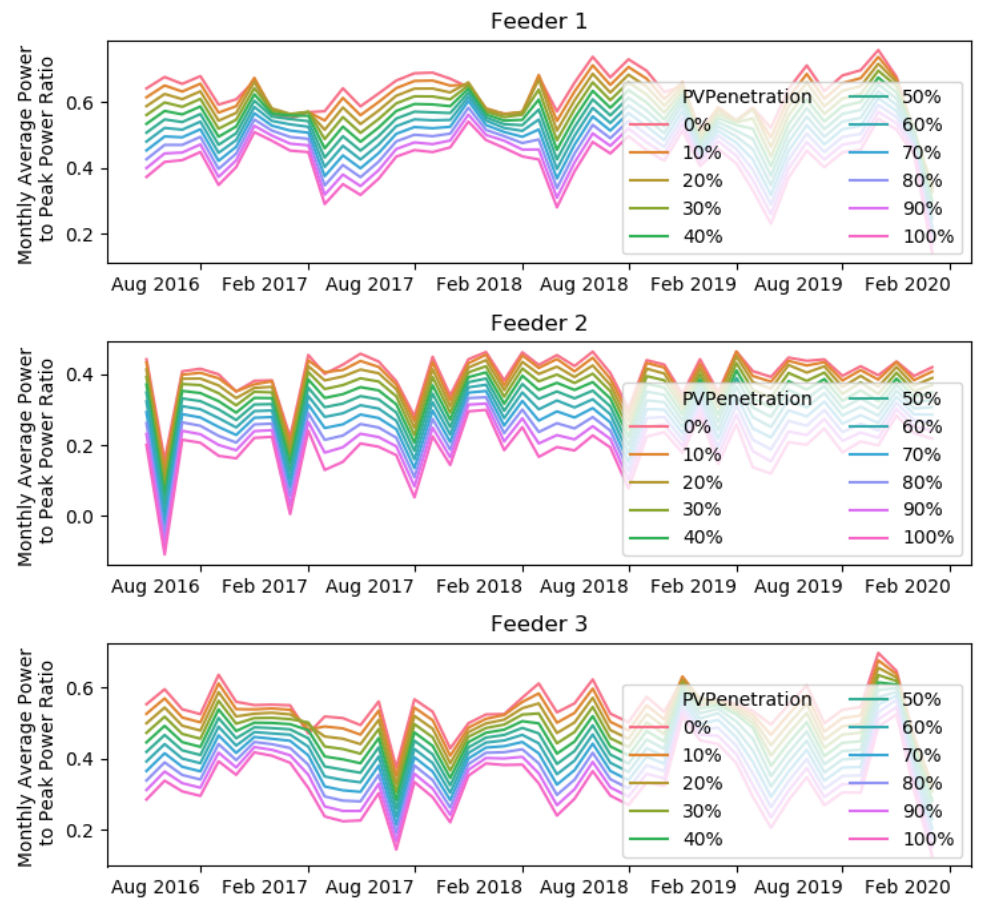

Figure 26. Monthly average power-to-peak-power ratio for three BYPL feeders from 2016 to 2020 for $0 \%$ to $100 \%$ PV penetration level in a step of $10 \%$

Figure 26. shows the monthly average power-to-peak-power ratio for three BYPL feeders from 2016 to 2020, with each line representing different PV penetration levels. The PV penetration percentage is based on annual peak load of the feeder. It is found that feeders dominated by residential customers have a higher average power-to-peak-power ratio (Feeder1 and Feeder3) than the feeder dominated by nondomestic and industrial feeders. The reason is higher energy consumption during office hours and significantly low consumption in other hours. The average power-to-peak-power ratio reduced with increasing PV penetration levels for all three feeders for all years. No significant seasonal variations in average power-to-peak-power ratio were observed in all three feeders.

\subsubsection{Percentage Peak Power Reduction}

Peak power reduction is associated with capacity value of solar. One of the benefits solar may provide is reduction in peak power purchase cost by providing solar generation at a time of peak power consumption. However, the degree of benefit is different in different months. 
Feeder 1

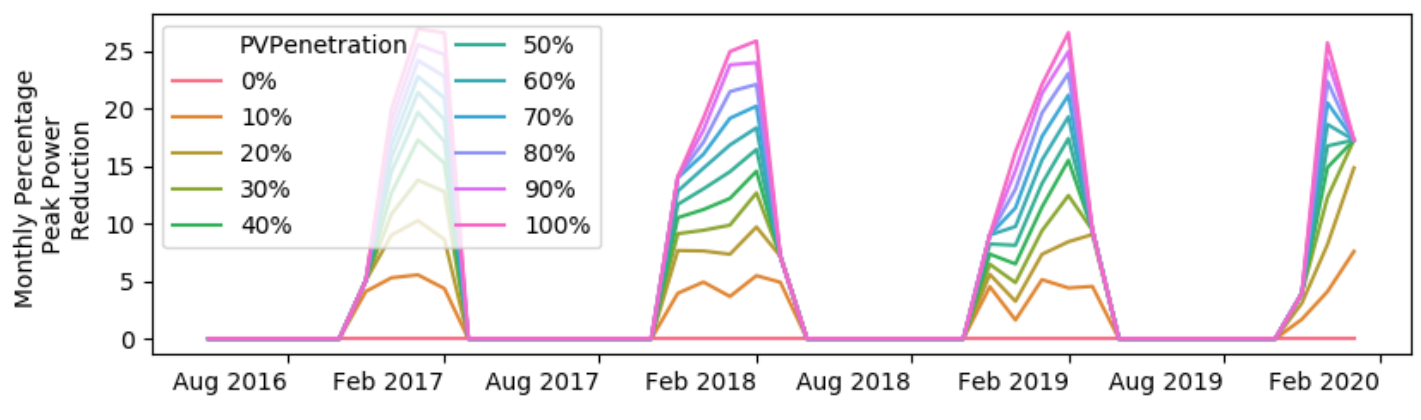

Feeder 2
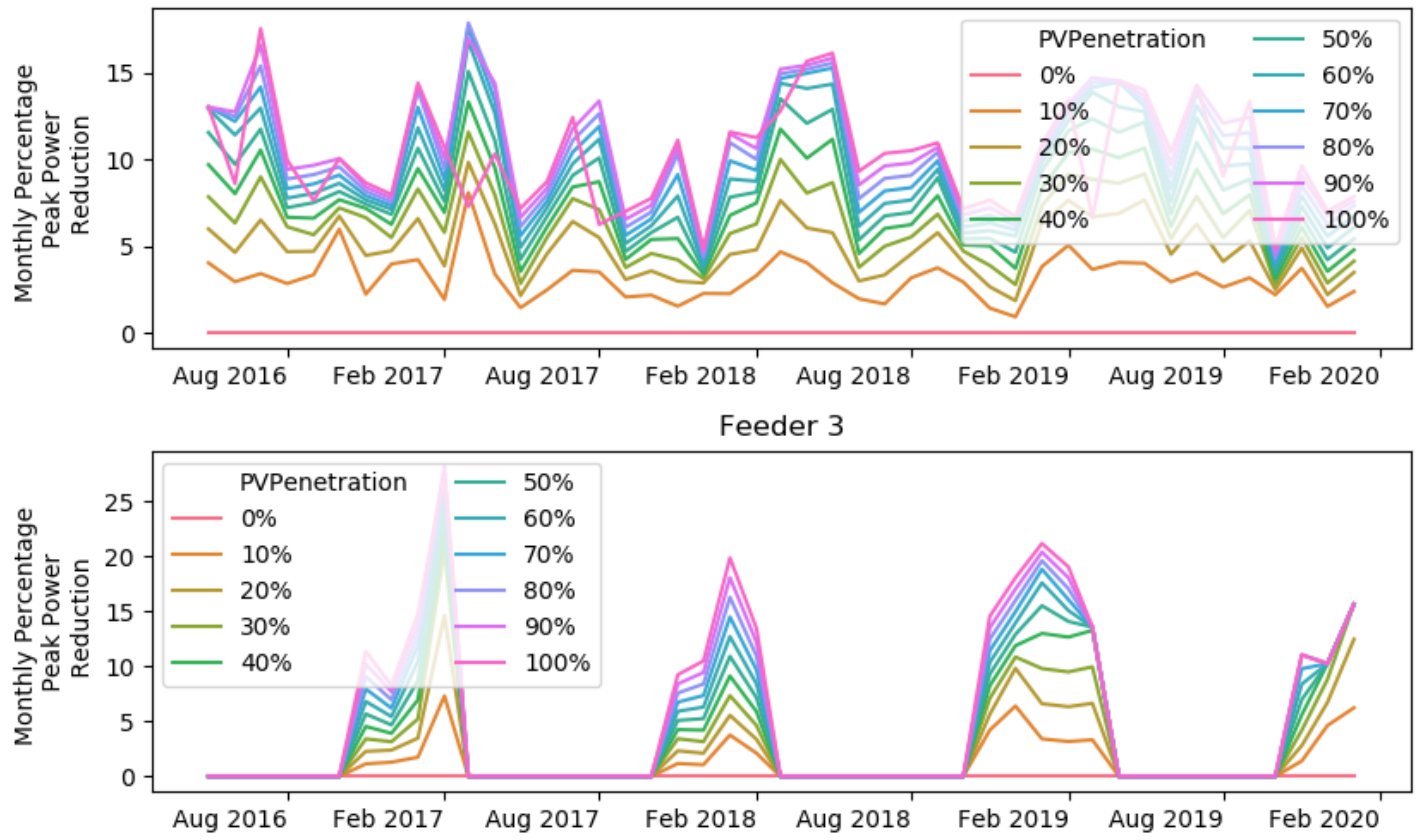

Figure 27. Monthly percentage peak power reduction for three BYPL feeders from 2016 to 2020 for $0 \%$ to $100 \%$ PV penetration level in a step of $10 \%$

Figure 27. shows the plot of monthly percentage peak power reduction for three BYPL feeders from 2016 to 2020, with each line representing different PV penetration levels. It is found that feeders dominated by domestic customers (Feeder1 and Feeder3) can achieve peak reduction during winter months only - not during summer months. The reason for this is that system peak occurs at night during summer when there is no solar generation, whereas during the winter, the peak occurs during the morning. Feeder2, which is dominated by nondomestic and industrial customers, can achieve peak power reduction in all months as the peak occurs only during a day for all months.

\section{Percentage Energy Consumption Reduction:}

Solar helps reduce the energy purchase from a power utility for electricity consumers reducing their electricity bills. Solar generation is different during different months. 
Feeder 1

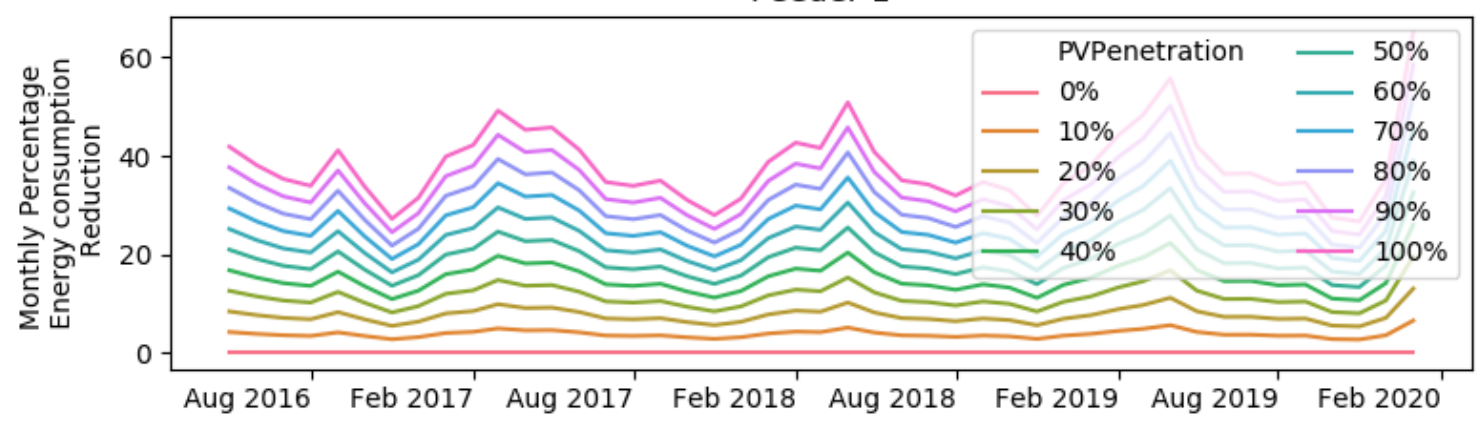

Feeder 2

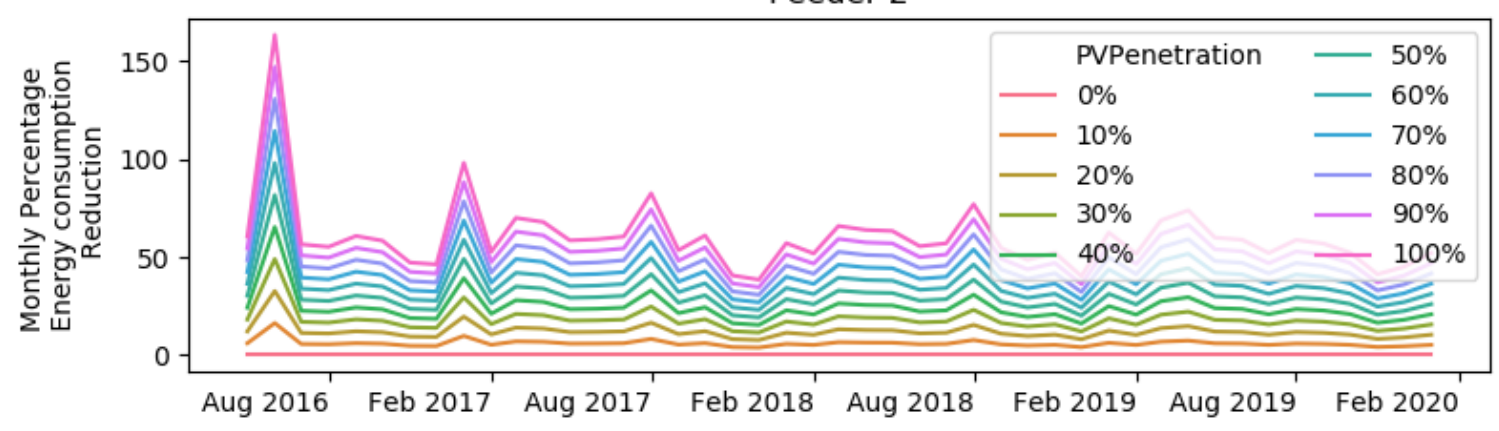

Feeder 3

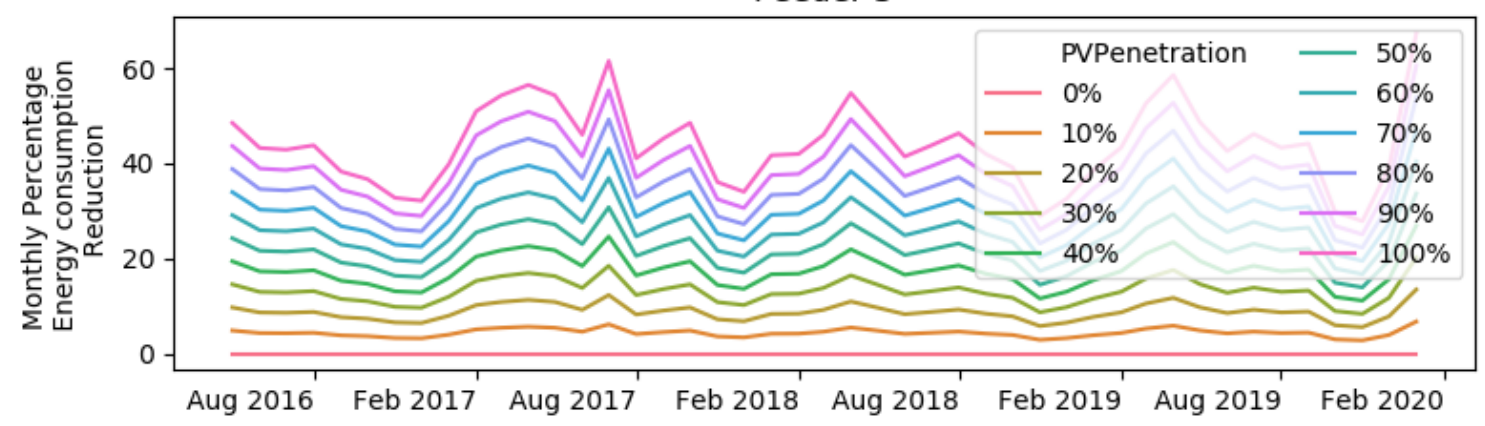

Figure 28. Monthly percentage of energy consumption reduction for three BYPL feeders from 2016 to 2020 for $0 \%$ to $100 \%$ PV penetration level in a step of $10 \%$

Figure 28. shows the plot of monthly percentage energy consumption reduction for three BYPL feeders from 2016 to 2020, with each line representing different PV penetration levels. The percentage of energy consumption reduction increases with an increase in PV penetration levels. The reduction is again slightly higher during months of higher solar irradiance.

\section{Maximum Change in Energy Consumption:}

Every generator has a ramp rate that limits the amount of power that can be increased or decreased in an hour. Studying maximum change in energy consumption every hour (or maybe less) can give us an indication of whether solar will support or adversely impact generators. 

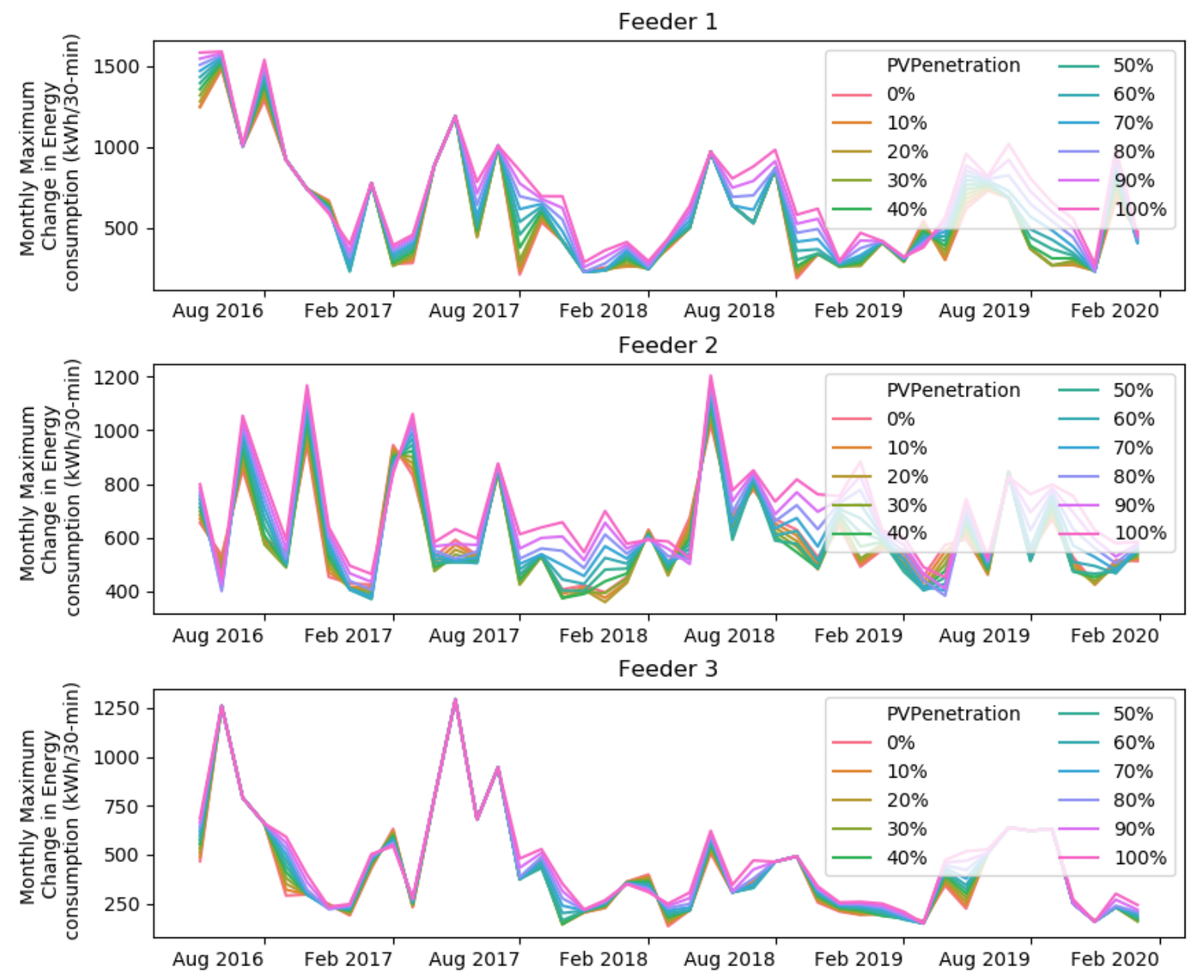

Figure 29. Monthly maximum change in the energy consumption in a 30 -minute interval for three BYPL feeders from 2016 to 2020 for $0 \%$ to $100 \%$ PV penetration level in a step of $10 \%$

Figure 29 shows the monthly maximum change in energy consumption in a 30-minute interval for three BYPL feeders from 2016 to 2020, with each line representing a different PV penetration level. The maximum change in energy consumption shows some seasonal pattern, especially in feeders with a high number of domestic customers (Feeder1 and Feeder2) - higher in the summer and lower in the winter. The effect of increasing PV penetration level is also different in different months and in different feeders, but in general the medium PV penetration level reduced the maximum change in energy consumption most of the time.

\subsection{EV Integration Module}

The global trend of transportation electrification is hitting the Indian market slowly but surely. Although India is in its early stages of adoption as of 2020, there has been a significant development in the EV arena, with two-to-four-wheelers launched by automobile players over the last few years. Several factors, such as national level policy-making and the need to improve air quality, have contributed to this growth, and these factors are expected to lead to the exponential growth of EVs in India. 
Keeping this growth curve in mind, this section describes the development and implementation of EV integration scenarios within the net load evolution framework. Impacts of the changing EV landscape can be evaluated under this framework, in terms of the grid-connected EV loads in a distribution

feeder/transformer. Modeling this framework is conducted by following an object-oriented approach (i.e., an individual EV, charging station, and single charger are treated as separate objects with corresponding static properties). Key parameters to formulate this EV integration module are listed below.

- Number of EVs: This parameter determines how many light-duty EVs need to be modeled for the geographical area that the feeder/transformer serves. Based on location and levels of EV adoption, this number would vary. Initial assumptions are to distribute a number of EVs in a metro area to feeder topology footprint area, but this can be modified based on feeder characteristics (such as urban versus rural or commercial versus residential zones).

This number represents the fleet that is likely to connect to the feeder/transformer being considered. The fleet can again have different compositions, such as more e-rickshaws and fewer e-motorbikes. Individual EV types are considered in this work in terms of varying charging behaviors/preferences, battery capacities, and driving ranges. Initial results presented in the subsequent sections assume a heterogeneous fleet dominated by e-rickshaws (70\%). Battery capacities of E-rickshaws are smaller than e-cars or ebikes, but they need to charge every day because of the frequent usage pattern in daily commutes.

Charging preferences, namely when a driver plugs in and how long they charge for, vary randomly within an adjustable predefined set. Figure 30 depicts how individual charging events would be different in this model as the battery sizes and vehicle uses vary (four-wheelers or e-cars do not charge as often as erickshaws but with the same kind of charger, such as a $3.3 \mathrm{~kW}$ Level 1 charger, they would require longer charging sessions as their battery capacities are larger).

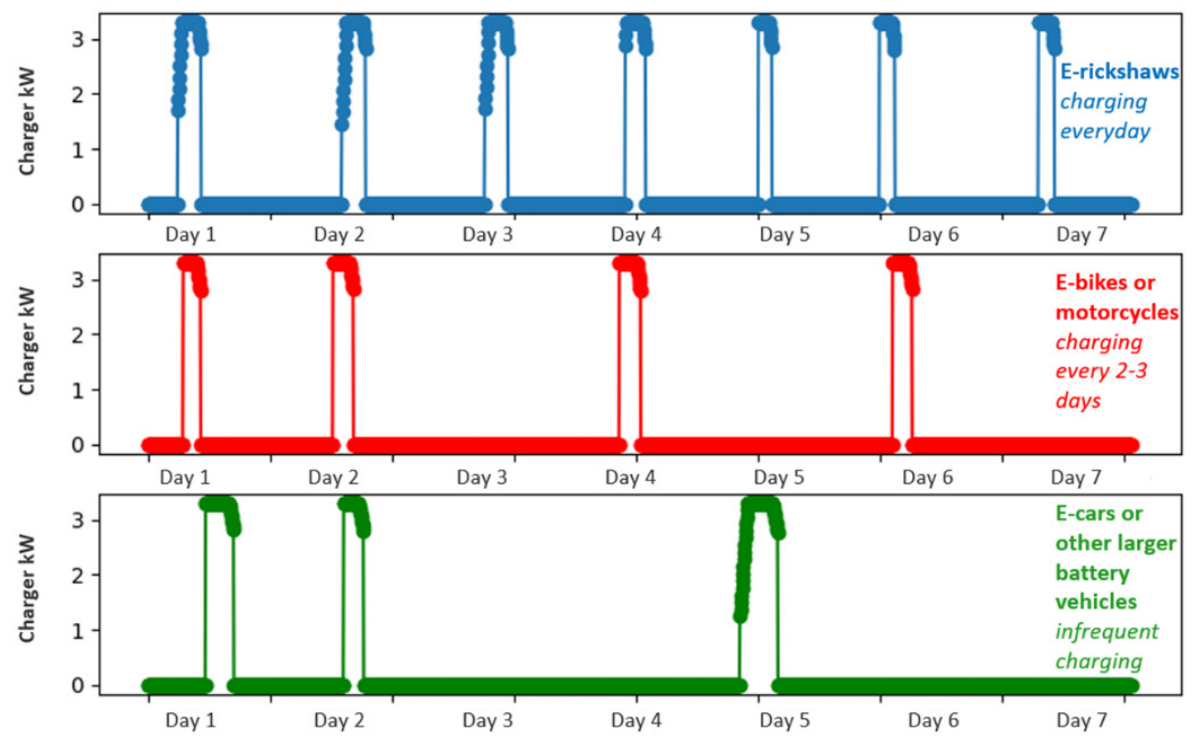

Figure 30. Charging events for different types of vehicles (sampled for one week)

- Charging scenarios: Two dominant charging modes are studied in the framework: (1) residential/individual charger-dominant, and (2) public/commercial/private charging stationdominant. These modes help the framework determine how many chargers are required to charge the total number of EVs or the entire vehicle fleet. With individual or residential charging mode, the required number of chargers is almost equal to the number of total EVs, and the charging events mostly take place overnight. For charging stations, a smaller number of chargers can be considered sufficient because of the underlying time-sharing concept. However, with charging stations, overnight EV charging load would be distributed throughout the day, emulating the traffic that a conventional 
gas/petrol filling station would draw. Table 9 shows the types of chargers considered in this analysis, and Figure 31 shows the types of charging stations.

Table 9. Charger Types Considered for the Delhi Use Case

\begin{tabular}{|l|l|l|}
\hline Charger Type & Charger Capacity & Voltage/Current Parameters \\
\hline Bharat AC-001 & $10 \mathrm{~kW}$ & $230 \mathrm{~V}$ \\
\hline AC, Type 2 & $22 \mathrm{~kW}$ & $415 \mathrm{~V}$ \\
\hline AC (Level 1) & $3.3 \mathrm{~kW}$ & $230 \mathrm{~V} / 15 \mathrm{~A}$ \\
\hline DC, Bharat DC-001 & $15 \mathrm{~kW}$ & $48 / 72 \mathrm{~V}$ \\
\hline DC (Fast), Combined CCS/CHAdeMO & $50 \mathrm{~kW}$ & $200 \mathrm{~A} \max$ \\
\hline
\end{tabular}

\begin{tabular}{|c|c|c|c|}
\hline Private & • & $22 \mathrm{~kW}$ & $15 \mathrm{~kW}$ \\
\hline Govt & • & $15 \mathrm{~kW}$ & \\
\hline Captive - BYPL & - $22 \mathrm{~kW}$ & $10 \mathrm{~kW}$ & $15 \mathrm{~kW}$ \\
\hline $\begin{array}{l}\text { E-rickshaw Charging } \\
\text { Station }\end{array}$ & • & $3.3 \mathrm{~kW}$ & $50 \mathrm{~kW}$ \\
\hline $\begin{array}{l}\text { Individual Charging } \\
\text { (Residential) }\end{array}$ & & $3.3 \mathrm{~kW}$ & \\
\hline
\end{tabular}

Figure 31. Types of charging stations

\subsubsection{Modeling Overview}

Individual or residential charging events are modeled based on three different variables:

- Arrival time

- Arrival state of charge

- Type of vehicle/battery capacity.

Arrival times may randomly vary from the late afternoon to evening timeframe, and arrival state of charge levels will be on the lower end. For residential charging mode, the desired or final state of charge is assumed to be $100 \%$ (i.e., the battery would complete a full charging cycle).

With charging stations, the model mimics the behavior of a filling station-where EV arrival/waiting can be modeled along with individual charging events. Figure 32 shows the process flow considered for a charging station model. The model comes with its static numbers of chargers (how many and $\mathrm{kW}$ capacity) and size of queues (how many vehicles can wait in the queue depending on the physical space of the station). With each time step, a new flock of EVs is assumed to arrive at the station with their own initial state of charge and desired state of charge (or time duration) preferences. If the charging slots are all occupied, the vehicle waits, and as soon as one frees up, it can plug in and start charging. At a given point, the chargers feeding power to connected vehicles determine the total consumption of the station. 


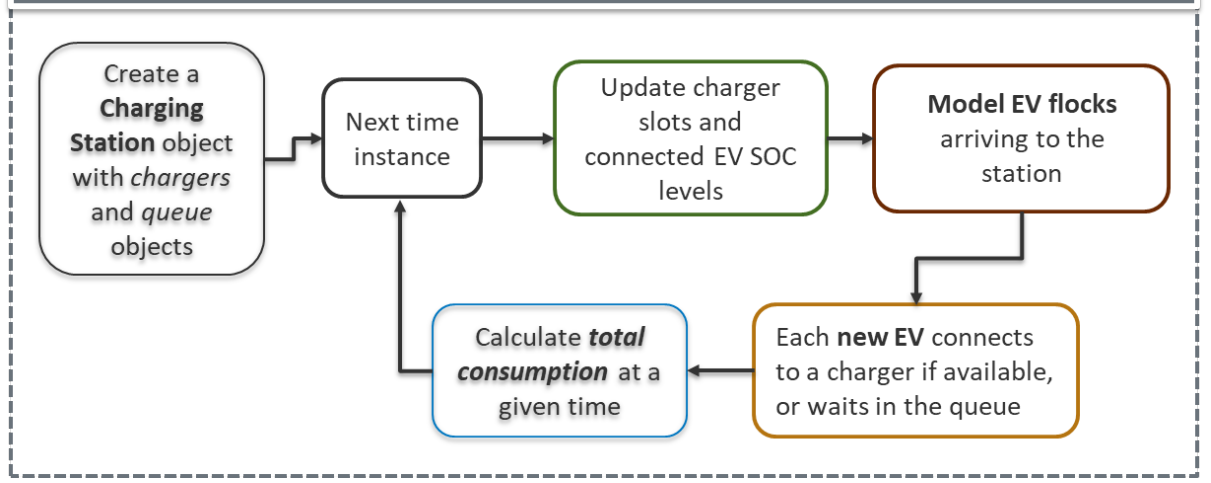

Figure 32. Charging station model workflow

\subsubsection{Scenario Highlights}

This section provides some initial results of different charging modes. Figure 33 shows the net EV load considering $\sim 330 \mathrm{EVs}$ and all charging individually using $3.3-\mathrm{kW}$ AC chargers. The peak consumption happens at different times throughout the night, although it is lower than maximum capacity $(330 * 3.3=$ $1,090 \mathrm{~kW}$ ). This phenomenon reflects the underlying assumption; without any control mechanisms such as a rate structure, not all the vehicles will charge every day, and charging time duration will get distributed throughout the night. A time-of-use rate structure may guide the users to charge at a particular time, which would result in sharper peak consumption for the whole feeder/transformer.

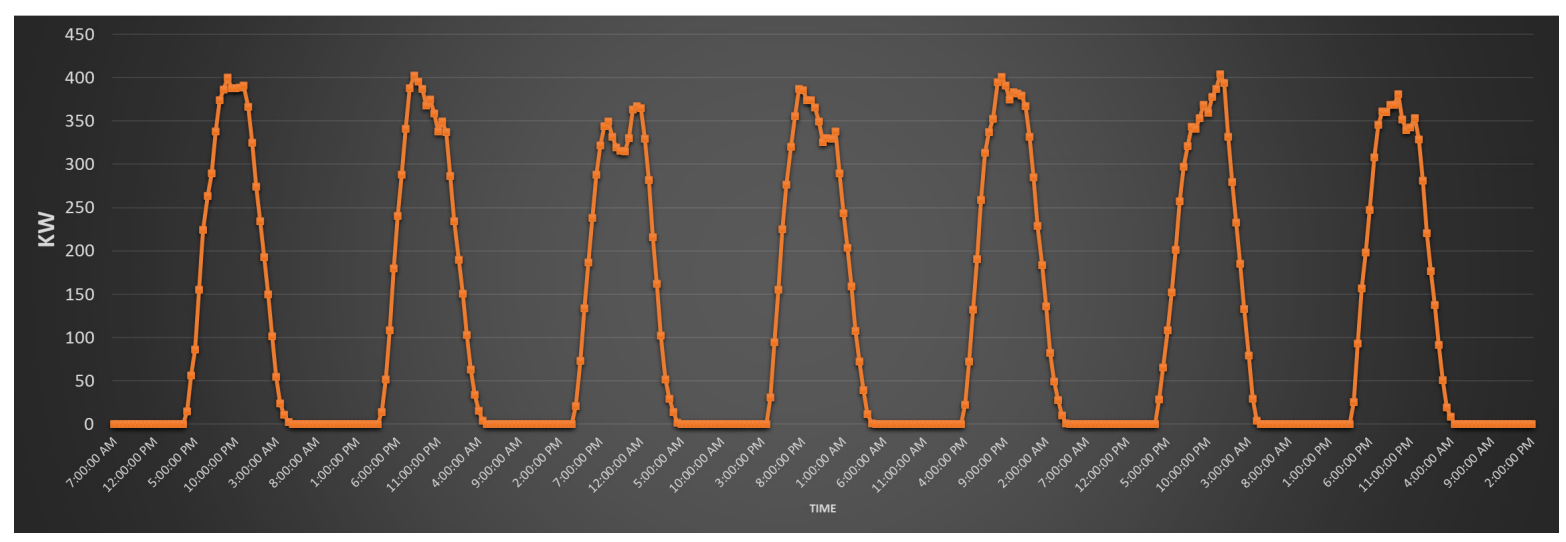

Figure 33. Resultant net EV load profile for all-residential charging scenario

On the other hand, Figure 34 and Figure 35 show the operation only of a charging station for a day. This station has 10 slots, each rated at $15 \mathrm{~kW}$, and reaches its maximum load of $150 \mathrm{~kW}$ in the morning and late evening timeframes. 

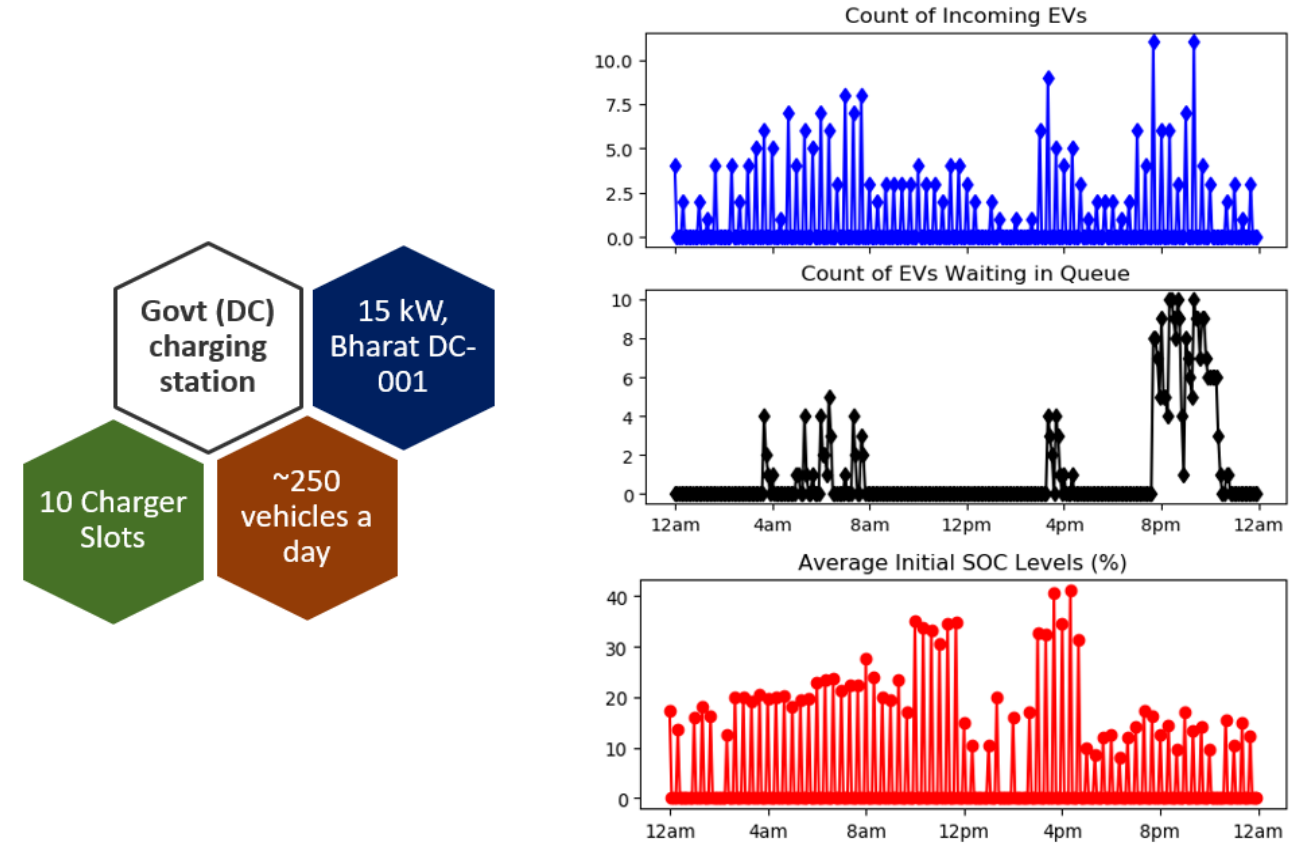

Figure 34. Key parameters for charging station operation for one day
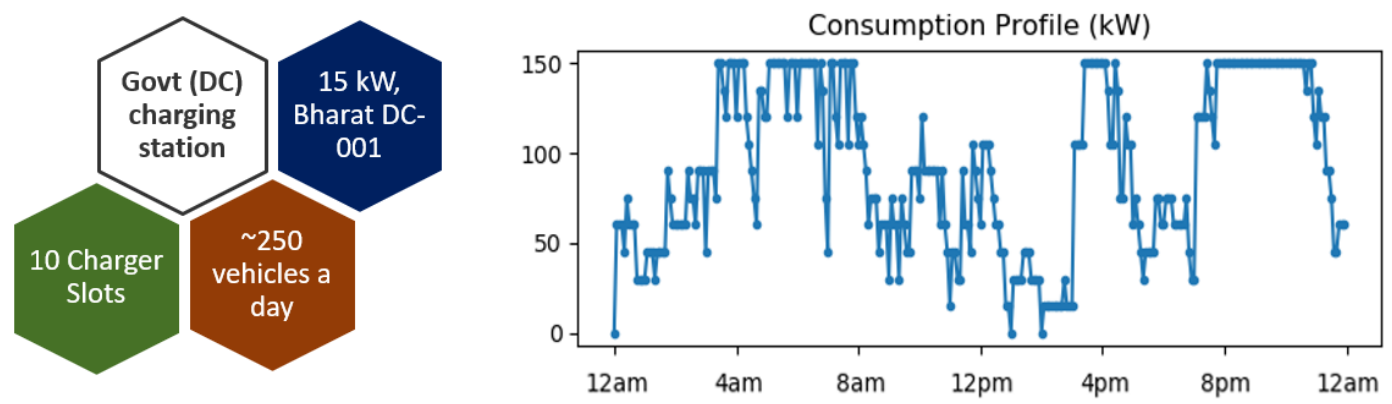

Figure 35. Net load profile for charging station operation for one day

Figure 36 depicts how changing the charging modes affects the net load profiles. With only residential charging, there are overnight peaks, but with $100 \%$ nonresidential charging, the net load gets distributed. A mix of these two fills in the valleys in EV load profiles and reduces the overnight peaks. 


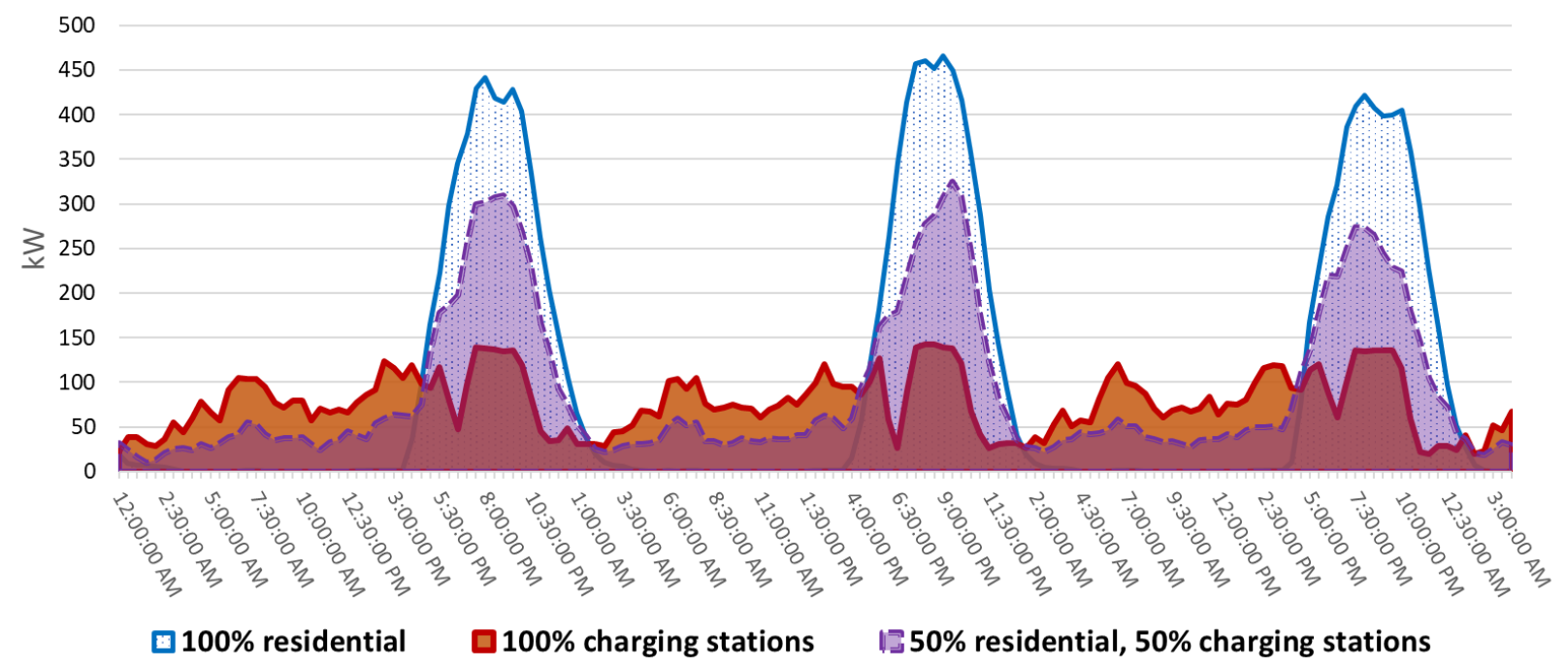

Figure 36. Net EV charging load profile for charging station operation for one day

\subsection{BESS Sizing Algorithm}

The power rating and energy capacity of a BESS are the two key paraments that together define the size of the battery system. The sizing requirement of the BESS is dictated by the application for which that system will be utilized. For example, a utility-scale BESS meant for either peak shaving or load leveling might require a BESS with a high-power rating but would not necessarily require a large energy capacity. Sizing a BESS larger than necessary for an application offers a few advantages, the most significant of which is that the asset owner can be confident that the BESS will have sufficient power or energy to be useful in even the most extreme of loading conditions. But oversizing a BESS results in a disadvantageous situation in which some portion of the system capacity will be unused for most of its operating life, corresponding to wasted capital expense and lost economic opportunity. Thus, there exists some optimal BESS sizing based on a planned application. During this work, two distinct BESS sizing algorithms are developed to determine the ideal BESS size for several planned applications; distribution grid service applications and behind-the-meter applications.

The most expected operating application for distribution grid services is peak shaving, in which the BESS is utilized to reduce the maximum loading state on a targeted distribution transformer. In the distribution grid services application, the BESS would be installed and operated on the secondary side of the distribution transformer but before any customer connections. Thus, the BESS for grid services applications will directly impact the loading point on the distribution transformer, modifying the aggregate loading of all customers serviced by that distribution transformer. This is intended to extend the operating life of the distribution transformer and to defer system upgrades.

The expected operating strategies for behind-the-meter applications are: (1) maximizing self-consumption (i.e., minimizing energy supplied by the utility grid); and (2) minimizing the total energy cost for a customer by charging when time-of-use rates are relatively low and discharging when time-of-use rates are relatively high. BYPL does apply a $20 \%$ surcharge during peak hours (2 p.m. -5 p.m. and 10 p.m. -1 a.m.) from May through September each year for nondomestic customers whose sanctioned load is $10 \mathrm{~kW}$ and above. BYPL also applies a 20\% energy rebate during off-peak hours (4 a.m.-10 a.m.) from May through September each year for nondomestic customers whose sanctioned load is $10 \mathrm{~kW}$ and above to incentive load shifting from peak hours to off-peak hours. In a behind-the-meter application, the BESS would be installed and operated behind the utility connection point for a given customer. Thus, the BESS for behind-the-meter application would impact the energy consumption and energy costs of a single 
customer rather than the broader distribution grid. However, if many customers connected to the secondary side of distribution transformer operated a behind-the-meter BESS by following an identical strategy, then the modification to the aggregate loading could be detected at the distribution transformer.

\subsubsection{Peak Shaving BESS Sizing Algorithm}

A method for sizing utility-scale BESS was presented in (Nagarajan et al., 2020). The approach developed follows a statistical analysis of time series data of the apparent power loading on a distribution transformer. This approach is summarized in the following paragraphs.

The objective is to determine a lithium-ion battery size that would be effective for mitigating a significant portion of overloading conditions observed on a distribution transformer. Here, overloading conditions are those where the distribution transformer load is more than $70 \%$ of the rated capacity in KVA, as shown in Figure 37.

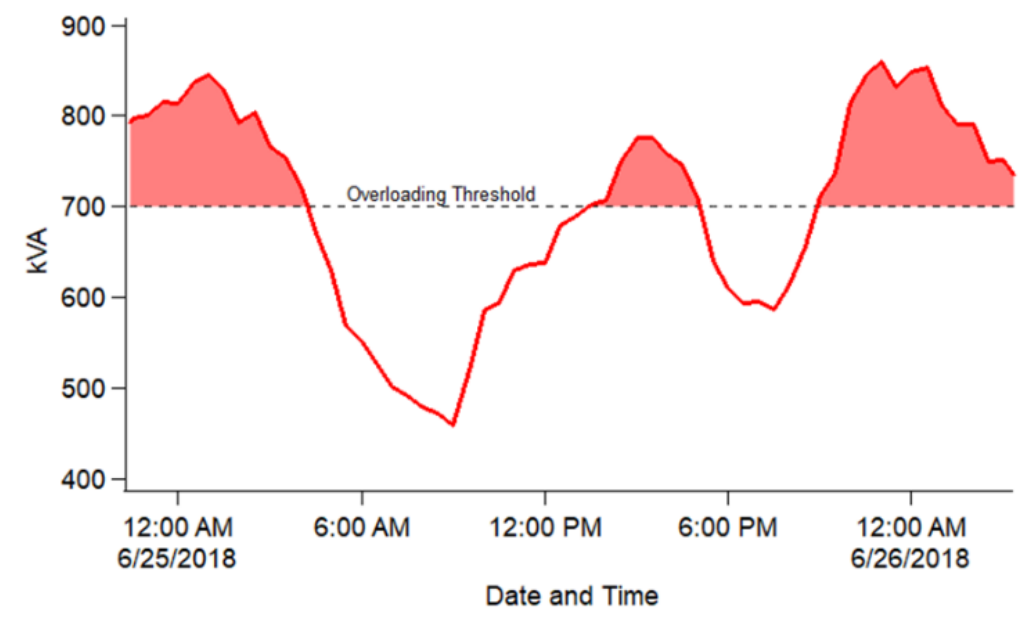

Figure 37. Various overloading conditions observed for a distribution transformer rated at 990 kVA

Note: The overloading threshold is $70 \%$ of the rated capacity.

An overloading occurs through some span of time defined from when the measured loading observed on the distribution transformer transitioned to a state above $70 \%$ of the rated capacity of the distribution transformer to when the measured loading observed on the distribution transformer again transitioned to a state below $70 \%$ of the rate capacity of the distribution transformer. Here, $70 \%$ is assumed for reasons explained in the framework presented in (Nagarajan et al., 2020). An overloading instance is defined by two parameters: the power associated with the overloading condition and the total energy associated with the overloading condition. The total energy associated with the overloading condition can also be measured (shown in the red highlighted areas in Figure 37.). These two parameters can be coupled as a point pair (i.e., $X_{i}=\left(\right.$ power $_{i}$, energy $\left.\left.i\right)\right)$.

\subsubsection{Battery Sizing Map}

A bivariate distribution of overloading power and energy point pairs defined in the previous section can be used to obtain the battery size appropriate for any distribution transformer subject to any loading profile. The bivariate distribution forms a battery sizing map such as the example illustrated in Figure 38 . The point pairs shown in Figure 38 plot the overloading instances observed exceeding $70 \%$ of nominal rating of the distribution transformer (i.e., when the kVA loading of the distribution transformer surpasses a threshold defined as $70 \%$ of the rated capacity of that distribution transformer). In this study, it is assumed that commercially available batteries are either 2-hour or 4-hour batteries. For a 2-hour battery, there would exist a 4:1 ratio between energy and power (e.g., a 5-kW, 10-kWh battery could be readily 
procured and deployed at the distribution transformer). Three points can be defined within the battery sizing map. The first point, the peak power overloading instance point pair shown in red. The second point of interest is the projected peak power point pair to the 4:1 ratio line (for a 4-hour battery), as shown in purple (i.e., mapping at constant energy from the peak power point to the $4: 1$ ratio line). The final point of interest is the 70th percentile point pair, which represents the point on the 4:1 ratio line that would fully mitigate $70 \%$ of the overloading instances observed in the historical record, assuming the battery were fully charged at the beginning of each overloading instance.

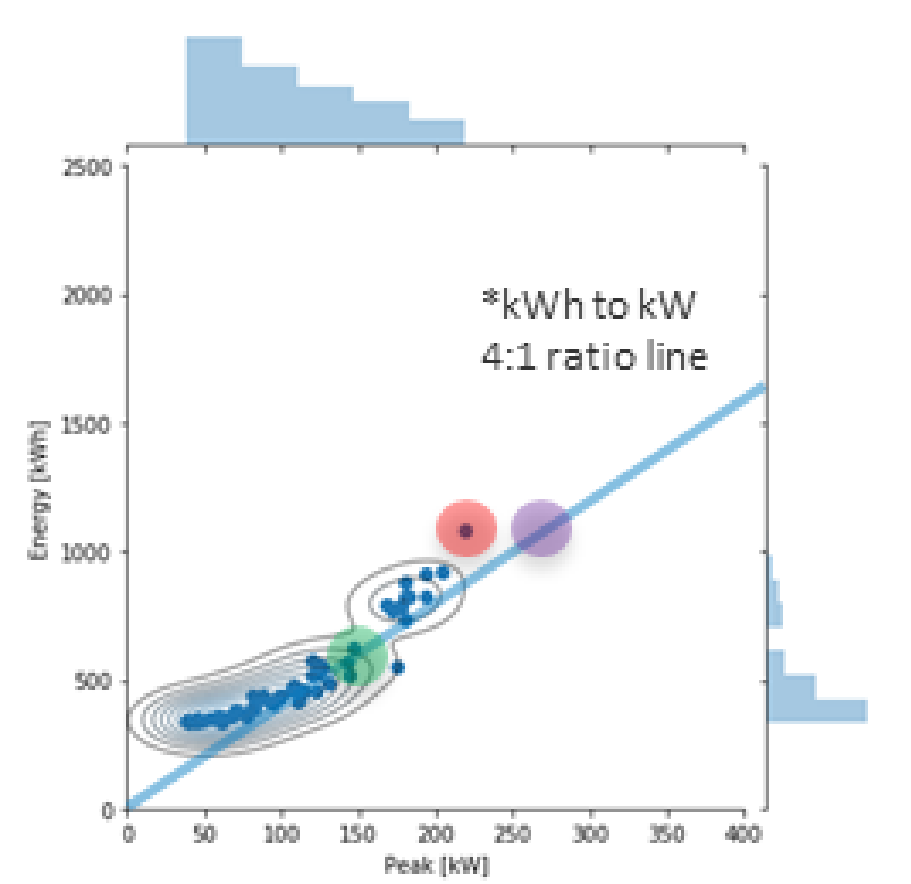

Figure 38. Battery sizing map for a distribution transformer

\subsubsection{Example of Peak Shaving BESS Sizing Algorithm}

Here, an example of the battery-sizing approach for grid service applications is presented for a distribution transformer rated at $660 \mathrm{kVA}$ in Figure 37.. Figure 39 shows the time series data of the distribution transformer loading during one week in September 2019. The periods during which the loading on the distribution transformer is above $70 \%$ of the rated capacity are shown in red; these periods are the overloading instances that can be quantified using the point pair method previously discussed. For the time series data collected in 2019, the point pairs of overloading instances can be obtained and are plotted in Figure 40. The plot also shows the 70th percentile point pair in blue; this is $40 \mathrm{~kW}, 80 \mathrm{kWh}$, which corresponds to a BESS size of $40 \mathrm{~kW} / 80 \mathrm{kWh}$. The overloading instances to the left of the 70th percentile point pair would be fully mitigated by a BESS of that size. Whereas overloading instances, such as those to the right of the 70th percentile point pair, would be only partially mitigated. 


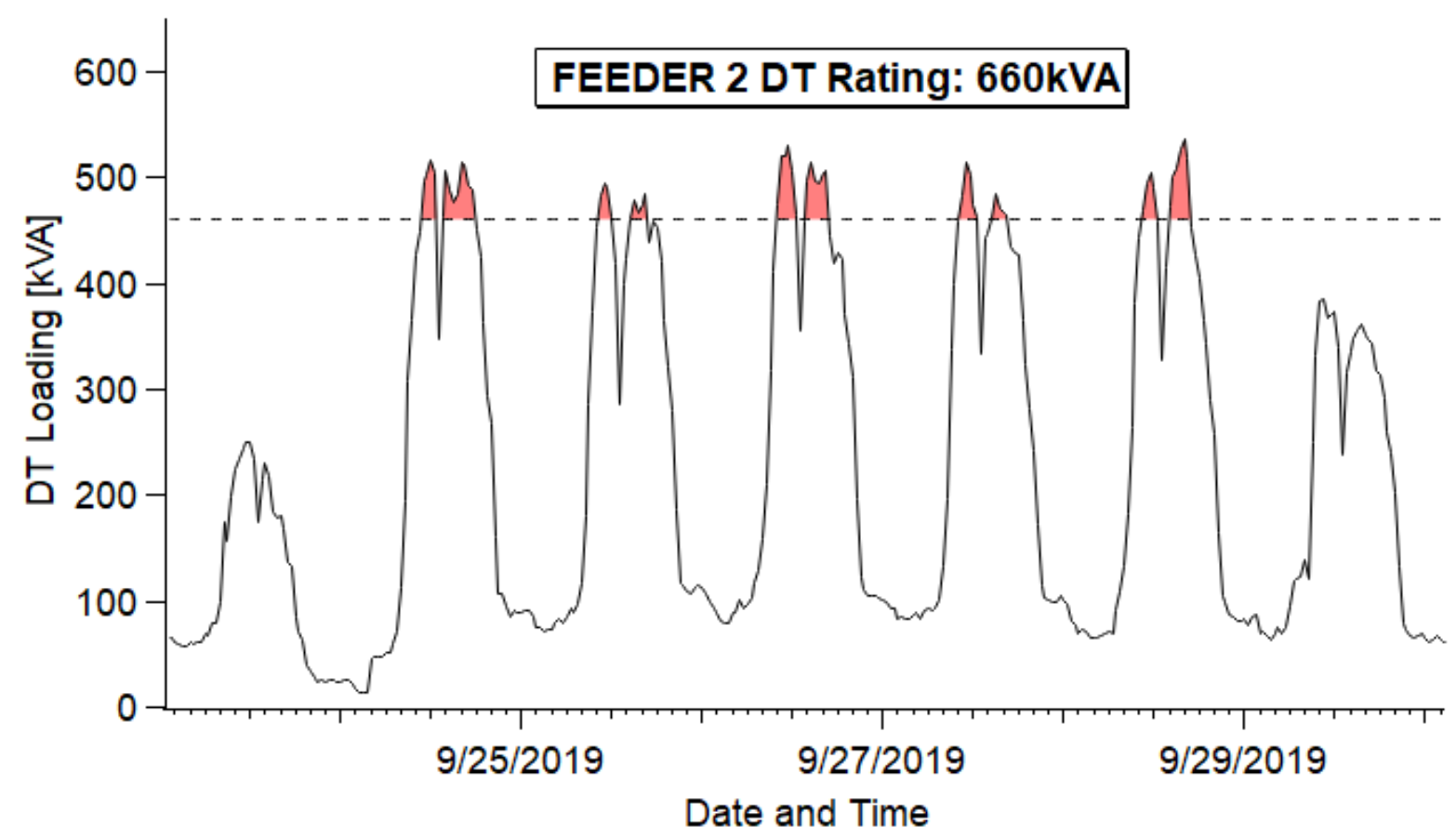

Figure 39. Distribution transformer loading in kVA

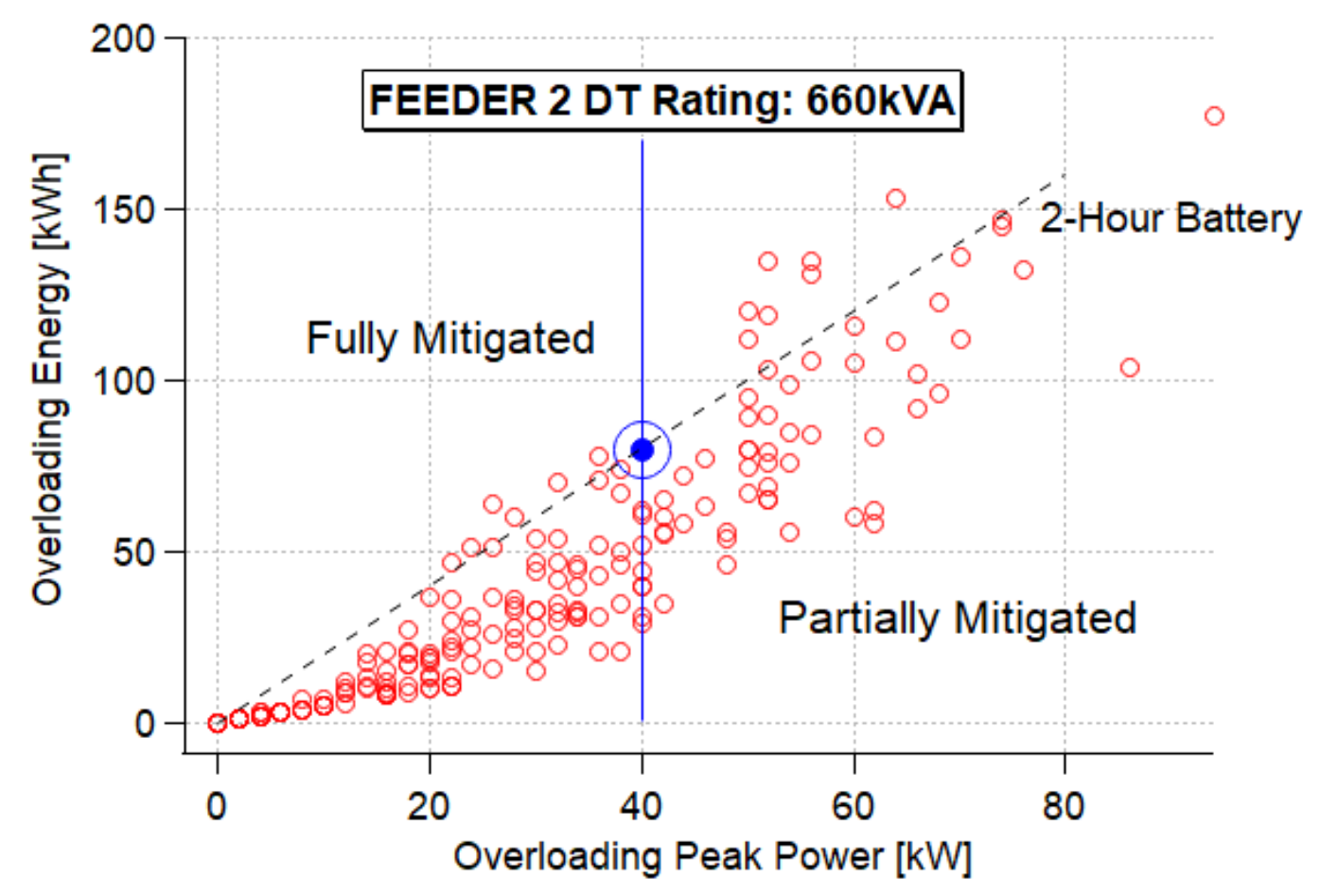

Figure 40. A scatter plot of the overloading instances observed in 2019 


\subsubsection{Behind-the-Meter Applications Sizing Algorithm}

In this subsection, an algorithm for sizing a BESS for behind-the-meter application is described. The algorithm is an iterative battery scheduling optimization problem nested into a sensitivity analysis. During each successive iteration of the algorithm, the battery capacity in the scheduling problem is changed and the objective value is determined. The algorithm terminated when the relative change in the objective value fell below some tunable threshold. The scheduling subproblem is defined as a linear program; this is solved using an interior point method.

\subsubsection{Scheduling Subproblem Formulation}

\section{Variables}

The variables used in the scheduling subproblem are defined as follows:

c $\quad=$ Total cost of energy delivered

$\mathrm{t} \quad=$ Time point

$\mathrm{T} \quad=$ Time domain

$\mathrm{p}_{\mathrm{t}} \quad=$ Price of energy at time $\mathrm{t}$

$\left(\mathrm{B}_{\mathrm{C}}\right)_{\mathrm{t}}=$ Energy flowing into battery at time $\mathrm{t}$

$\left(\mathrm{B}_{\mathrm{D}}\right)_{\mathrm{t}}=$ Energy flowing out of battery at time $\mathrm{t}$

$\varphi \quad=$ Power to Energy Ratio

$\mathrm{E}_{\text {capacity }}=$ Energy capacity of the battery

$\mathrm{E}_{\text {initial }}=$ Initial energy stored

$\mathrm{E}_{\text {end }}=$ Final energy stored

$\mathrm{L}_{\mathrm{t}} \quad=$ Basis load at time $\mathrm{t}$ i. e. customer load less PV generation

\section{Objective Function}

There are two potential interpretations for the objective function that depend on the distribution customer classification. Nondomestic customers that are sufficiently large are subject to a time-of-use surcharge during summer months. For these customers, the unit price of energy changes through time, thus the objective function aims to minimize the total cost of energy to the customer (based on time of use). For all other customers, including domestic customers and nondomestic customers with load less than $10 \mathrm{~kW}$, a flat energy price is assessed. Thus, for these customers, the objective function aims to minimize the total quantity of energy (based on flat pricing). For either case, the formulation of the objective function is the same.

$\min \{c\} \mid c \equiv \sum_{t=1}^{T} p_{t} \cdot\left(\left(B_{C}\right)_{t}-\left(B_{D}\right)_{t}\right)$

\section{Constraint Equations}

There are four types of constraint equations defined in the scheduling subproblem. Those are defined and discussed below.

Energy limiting constraints: These inequality constraints reflect that the battery has a limited energy capacity then cannot be utilized once depleted, nor can the battery be made to store more energy than its rated size.

$$
\sum_{t=1}^{T}\left(B_{C}\right)_{t}-\sum_{t=1}^{T}\left(B_{D}\right)_{t} \leq E_{\text {capacity }}-E_{\text {initial }}
$$




$$
\sum_{t=1}^{T}\left(B_{D}\right)_{t}-\sum_{t=1}^{T}\left(B_{C}\right)_{t} \leq E_{\text {initial }}
$$

Power limiting constraints: These inequality constraints reflect that the battery charging and discharging rate is limited by the power-to-energy ratio of the system.

$$
\begin{aligned}
& 0 \leq\left(B_{C}\right)_{t} \leq \varphi E_{\text {capacity }} \forall t \in T \\
& 0 \leq\left(B_{D}\right)_{t} \leq \varphi E_{\text {capacity }} \forall t \in T
\end{aligned}
$$

Load relational constraint: This inequality constraint bounds the battery charging and discharging to the instantaneous demand (from base load and EVs) and surplus energy generated locally (from PV).

$$
\left(B_{D}\right)_{t}-\left(B_{C}\right)_{t} \leq L_{t} \forall t \in T
$$

Cyclic Constraint: This quality constraint ensures that at the end of the period of performance, the state of charge of the BESS will be equal to some target. If this target is selected as half of the rated capacity, then the battery will feature cyclic charging and discharging behavior. If this target were selected as zero, then the battery would deplete by the end of the period of performance.

$$
\sum_{t=1}^{T}\left(B_{C}\right)_{t}+\sum_{t=1}^{T}\left(B_{D}\right)_{t}=E_{\text {final }}
$$

\section{Example of Behind-the-Meter Applications Sizing Algorithm}

An example case of the behind-the-meter sizing algorithm is presented for a domestic customer in Feeder 1 . The period of performance is 1 week in the month of June 2019. The customer's monthly energy consumption is $340 \mathrm{kWh}$, and the customer owns and operates a PV array with a DC rating of $600 \mathrm{~W}$. Here, we assume a DC/AC ratio of 1.2 for the PV inverter. Figure 41 shows the customer's initial load (i.e., their power demand before considering any local PV generation). The figure also shows the basis load, clipped to zero when negative, which corresponds to the initial load less the local PV generation. The figure also shows the battery operation that results from the solution to the battery scheduling problem and the resulting net load for the customer. The solution to the battery scheduling problem is shown in Figure 42. The solution reflects an operation in which the battery is charged during periods of local PV generation and is generally discharged in the evening when no PV generation is possible. The net effect of this optimal operation is a reduction in the peak power demand for this customer of $16.4 \%$, relative to the basis load as summarized in Table 10. The determined BESS size for this example customer is a 4-hour battery rated at $1.375 \mathrm{~kW} / 5.5 \mathrm{kWh}$.

Table 10. Optimal BESS Size and Peak Load With and Without the BESS

\begin{tabular}{|l|l|}
\hline Parameter & Value \\
\hline Optimal BTM BESS Size & $5.5 \mathrm{kWh}$ \\
\hline Peak Without BESS & $0.879 \mathrm{~kW}$ \\
\hline Peak With BESS & $0.735 \mathrm{~kW}$ \\
\hline Peak Reduction & $-16.4 \%$ \\
\hline
\end{tabular}




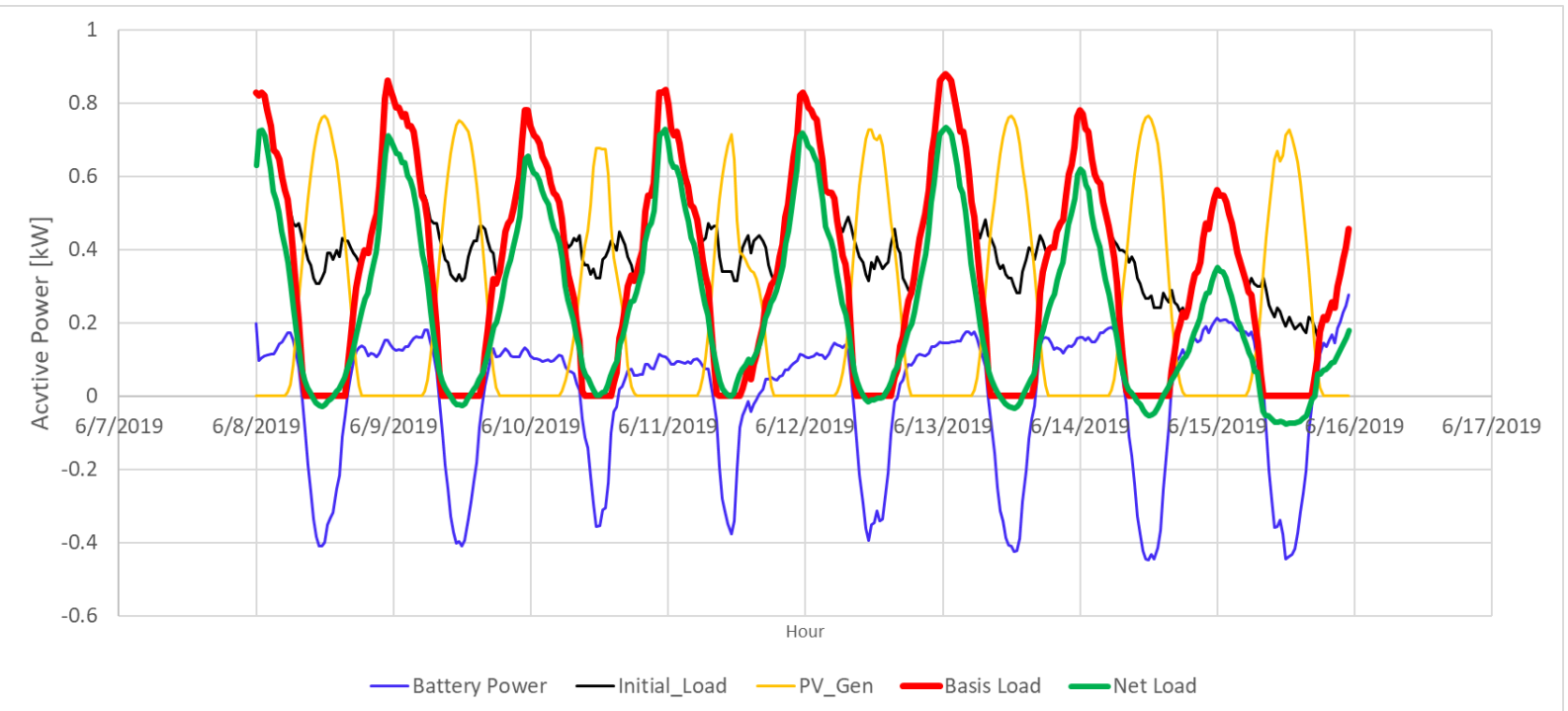

Figure 41. The BESS scheduled operation, the customer load, the PV generation, the basis load, and the resulting net load for a domestic customer

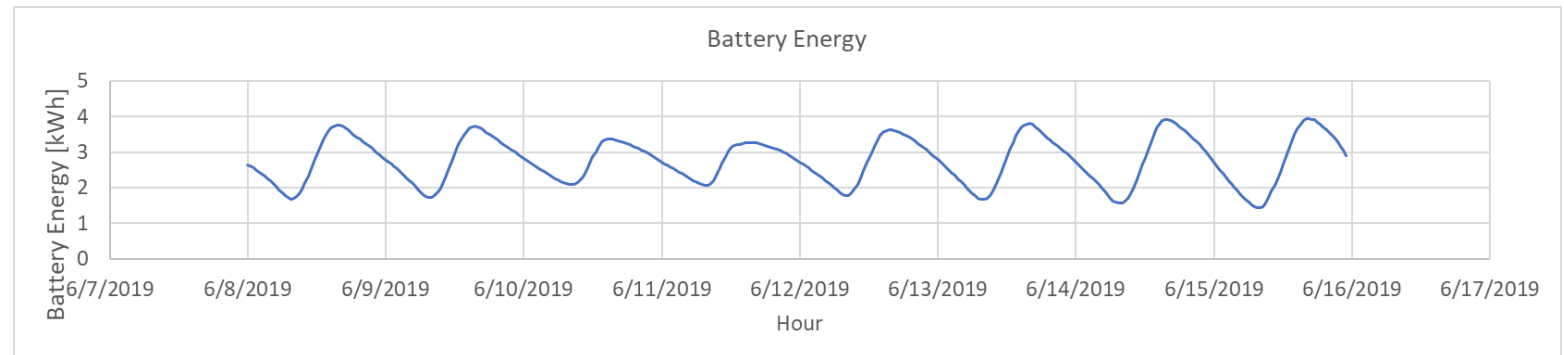

Figure 42. The optimal solution of the battery scheduling subproblem for the example customer

\subsubsection{Charging/Discharging Time and Threshold Selection Algorithm}

There are several strategies for charging and discharging a battery, among which time- and power-based approaches are most common. In a time-based strategy, charging and discharging hours are predefined, whereas in a power-based approach, charging and discharging thresholds are predefined. Determining the best charging/discharging thresholds (for a power-based strategy) and times (for a time-based strategy) is not fully understood and critical for maximizing benefits from energy storage.

NREL developed an algorithm to identify the thresholds for time-based and power-based approaches. The algorithm leverages the historic load profile of a distribution transformer to determine the best charging and discharging hours for a utility-scale battery (assumed to be connected on the secondary side of the distribution transformer). The inputs to the algorithm are battery technical parameters (rated capacity, energy capacity, charging rate, discharging rate, charging efficiency, discharging efficiency, and selfdischarge rate) and historic load profile. 
- The first step in the algorithm is to identify the number of charging and discharging hours.

$$
\begin{aligned}
\text { Num of charging hours } & =\frac{\text { Energy capacity }(\mathrm{kWh})}{\text { Rated capacity }(\mathrm{kW}) \times \text { charging rate }} \\
\text { Num of discharging hours } & =\frac{\text { Energy capacity }(\mathrm{kWh})}{\text { Rated capacity }(\mathrm{kW}) \times \text { discharging rate }}
\end{aligned}
$$

- As the objective in this study is to reduce the peak load, the algorithm finds the hours belonging to peak loads or top loads for discharging and hours belonging to minimum loads or bottom loads for charging. To begin with, let us say the algorithm begins with hours belonging to top $1 \%$ of the top loads and bottom loads. If the number of hours belonging to $1 \%$ of top loads is less than either the number of charging or number of hours belonging to $1 \%$ of bottom loads is less than number of discharging hours, the algorithm will stop and start with the next percentage.

- Now, the possible combinations of charging hours and discharging hours are determined. For example, if the number of hours belonging to top $1 \%$ of loads is $18,19,20,21,22$, and the number of charging hours determined using the previous equation is 4 , then the possible charging combinations are $\{18,19,20,21\} ;\{18,19,20,22\} ;\{18,19,21,22\} ;\{18,20,21,22\}$; and $\{19$, $20,21,22\}$.

- Each combination of charging hours is tested with all combinations of discharging hours by feeding to the battery model, and the peak reduced is determined. The combination of charging hours and combination of discharging hour that resulted in maximum peak reduction is saved.

- The process continues for the next percentage of load hours. At the end, the combination of charging hours and the combination of the discharging hour that resulted in the maximum peak reduction is selected as the best charging hours and discharging hours.

Figure 43 shows the original load profile and new load profile after the energy storage of energy capacity $400 \mathrm{kWh}$, power capacity $200 \mathrm{~kW}$, charging rate 0.5 , discharging rate 0.5 is added to the system, along with battery energy profile for 1 week. The best charging hours and discharging hours determined by the algorithm are $\{1,2,3,4\}$ and $\{9,10,15,16\}$ with a peak reduction of $11 \mathrm{~kW}$. 


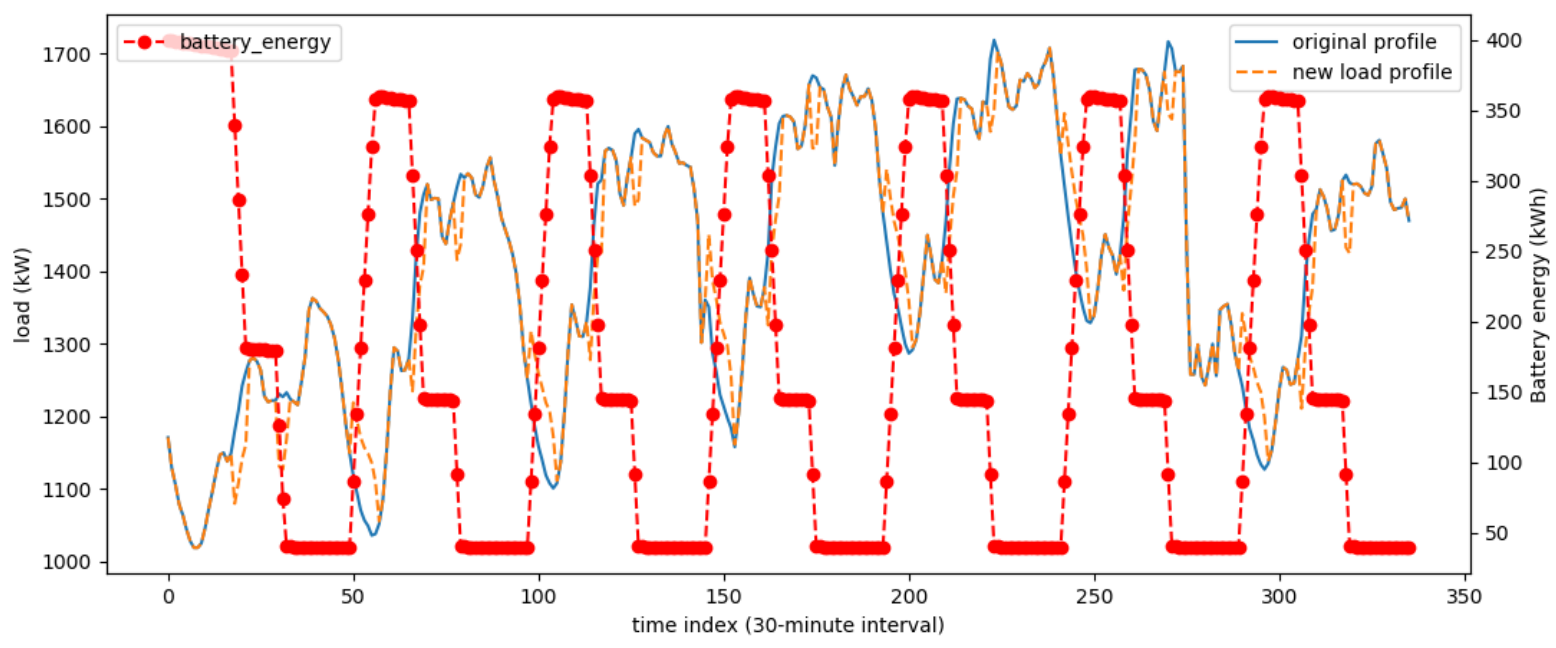

Figure 43. Original and new load profile with battery energy profile after applying algorithm to determine best charging/discharging hours

For a power-based strategy, the process for finding charging and discharging thresholds is similar. Here, the objective is to achieve the maximum peak load reduction. The input to the algorithm is the usual battery technical parameters and number of steps for the algorithm to select the charging and discharging thresholds.

- The first step is to determine the starting thresholds for charging and discharging. Here, the threshold is a value between 0 and 1, which will be multiplied with peak load to determine actual thresholds in $\mathrm{kW}$. If the initial discharging threshold is less than 0.5 , it will be automatically set to 0.5 .

$$
\text { Initial discharging threshold }=\max \left(1-\frac{\text { Discharging rate in } \mathrm{kW}}{\text { Peak load in } \mathrm{kW}}, 0.5\right)
$$

Initial charging threshold = Initial discharging threshold

- Now, between the initial discharging threshold and 1 , the number of discharging thresholds equal to number of steps provided as user input are selected using a linear interpolation technique. For example, if 0.9 is the initial discharging threshold for 5 steps, the discharging thresholds selected are $0.92,0.94,0.96,0.98,1.0$.

- Between 0 and the initial charging threshold, the number of charging thresholds equal to the number of steps provided as user input are selected using linear interpolation technique. For example, if 0.9 is the initial charging threshold for 5 steps, the charging thresholds selected are $0.18,0.36,0.54,0.72,0.9$.

- Each discharging threshold is tested with all of the charging thresholds by feeding to the battery model, and the peak reduced is determined. The combination of charging threshold and discharging threshold that resulted in the maximum peak reduction is then selected as the best charging and discharging thresholds.

Figure 44 shows the original and new load profile of the distribution transformer after adding the energy storage of 400-kWh energy capacity, 200-kW rated capacity, and max discharging rate of $100 \mathrm{~kW}$, along 
with the battery energy profile after applying the algorithm, to determine the best charging and discharging thresholds for the power-based strategy. The charging and discharging thresholds determined are 0.976 and 0.781 , resulting in a $40-\mathrm{kW}$ peak reduction.

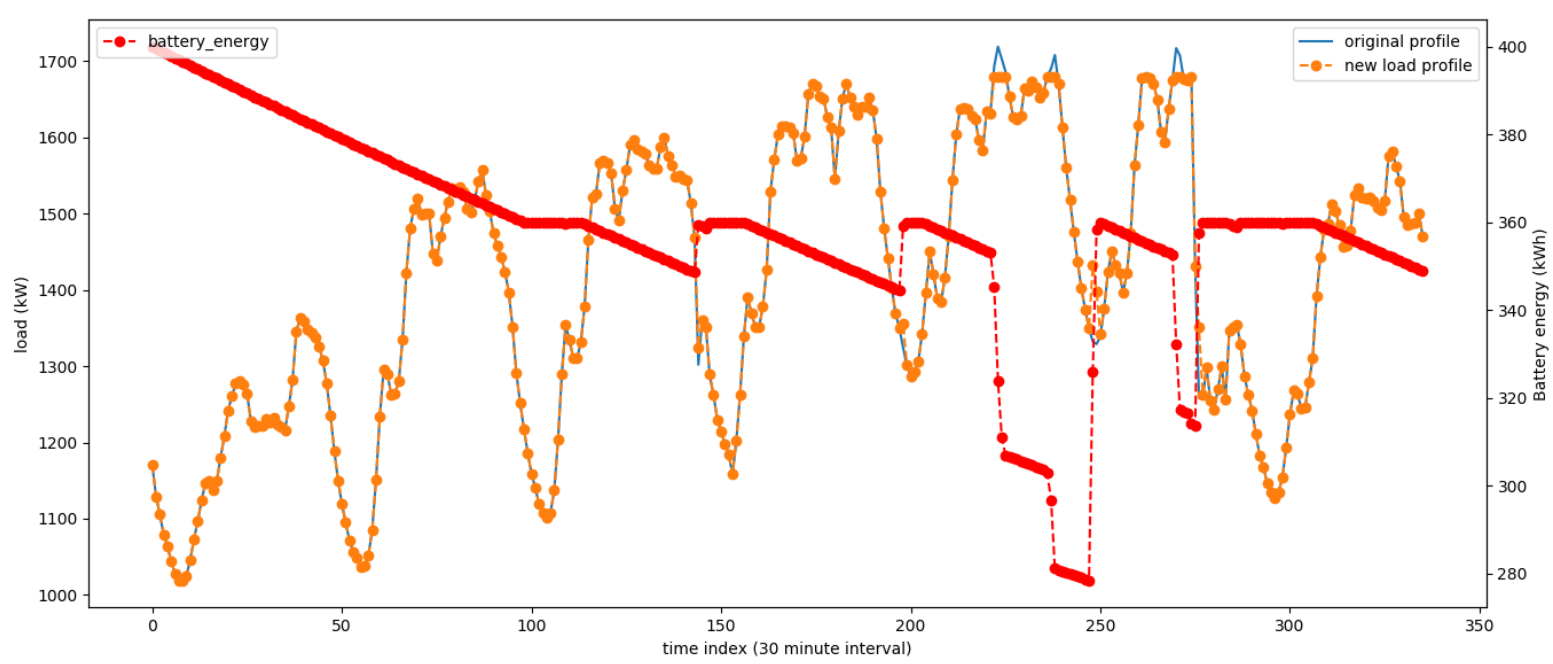

Figure 44. Original and new load profile with battery energy profile after applying algorithm to determine best charging/discharging thresholds (for power-based strategy)

\subsection{Dashboard for Net Load Profile Analysis}

The NREL team developed an easy-to-use dashboard interface, based upon each module described, as a part of a net load evolution study - the EVOLVE tool. Figure 45 shows a snapshot of the dashboard (partial view visible in a desktop mode).

\subsubsection{Dashboard Overview}

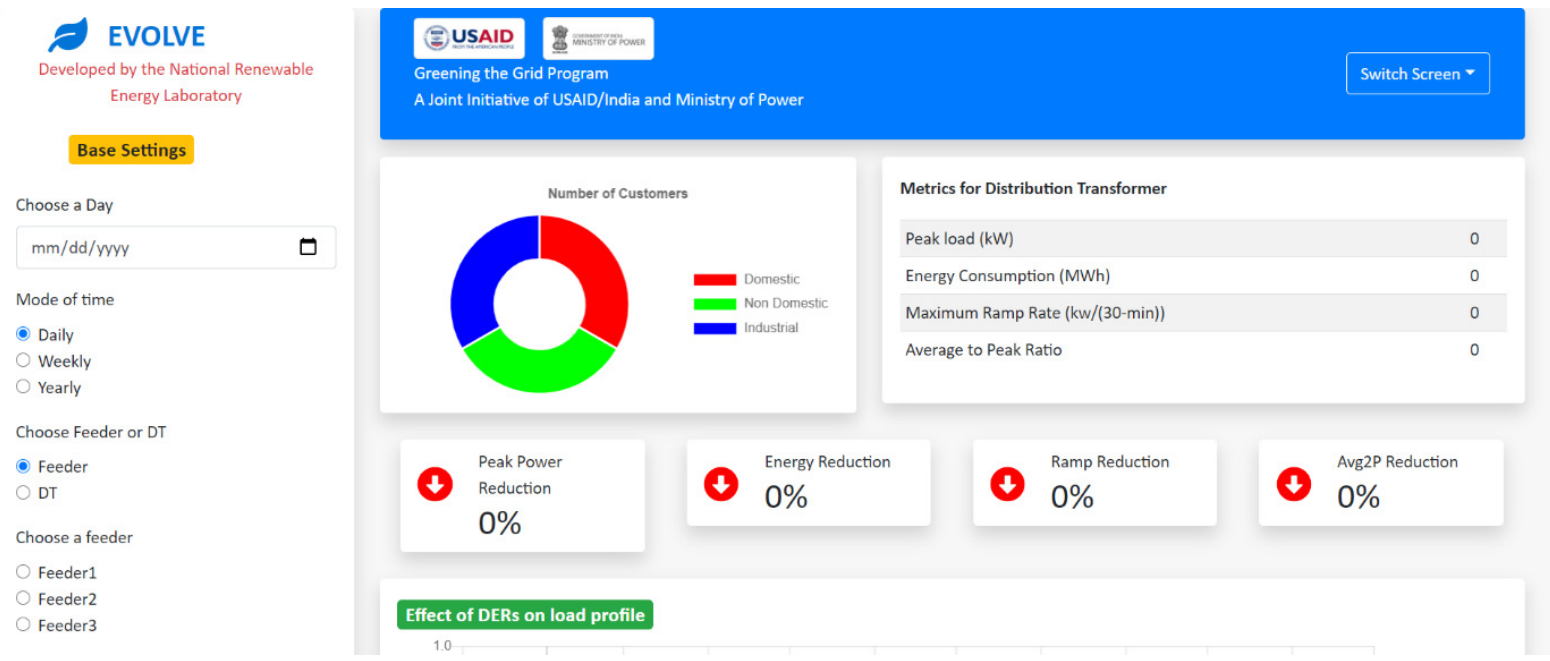

Figure 45. Partial view of dashboard for net load evolution study (EVOLVE)

The front end of the dashboard was built in React (https://reactjs.org/). The left pane of the dashboard collects all the user inputs and sends a POST request to an API to get processed results in response. The schematic of software architecture is presented in Figure 46. Separate modules were developed to process 
individual emerging technologies (currently included are solar, energy storage, and EV) using Python programming language). A higher-level API was developed on top of all modules that the front-end React App uses to communicate with.

Below is the description of all inputs for the dashboard.

- Choose a Day: The input is in $\mathrm{mm} / \mathrm{dd} / \mathrm{yyyy}$ format. It is used as start day for all the modes of time.

- Mode of time: User can pick one of the three modes: daily, weekly, and yearly for a net load evolution study. The time step used for load profile analysis is 30 -minute.

- Choose Feeder or DT: User can choose either feeder or distribution transformer for analysis.

- Choose a Feeder: If a feeder is selected for analysis, the name of the selected feeder will be used for analysis; otherwise, it will remain unused.

- Choose a distribution transformer: If a distribution transformer is selected for analysis, the name of the selected distribution transformer will be used for analysis; otherwise, it will remain unused.

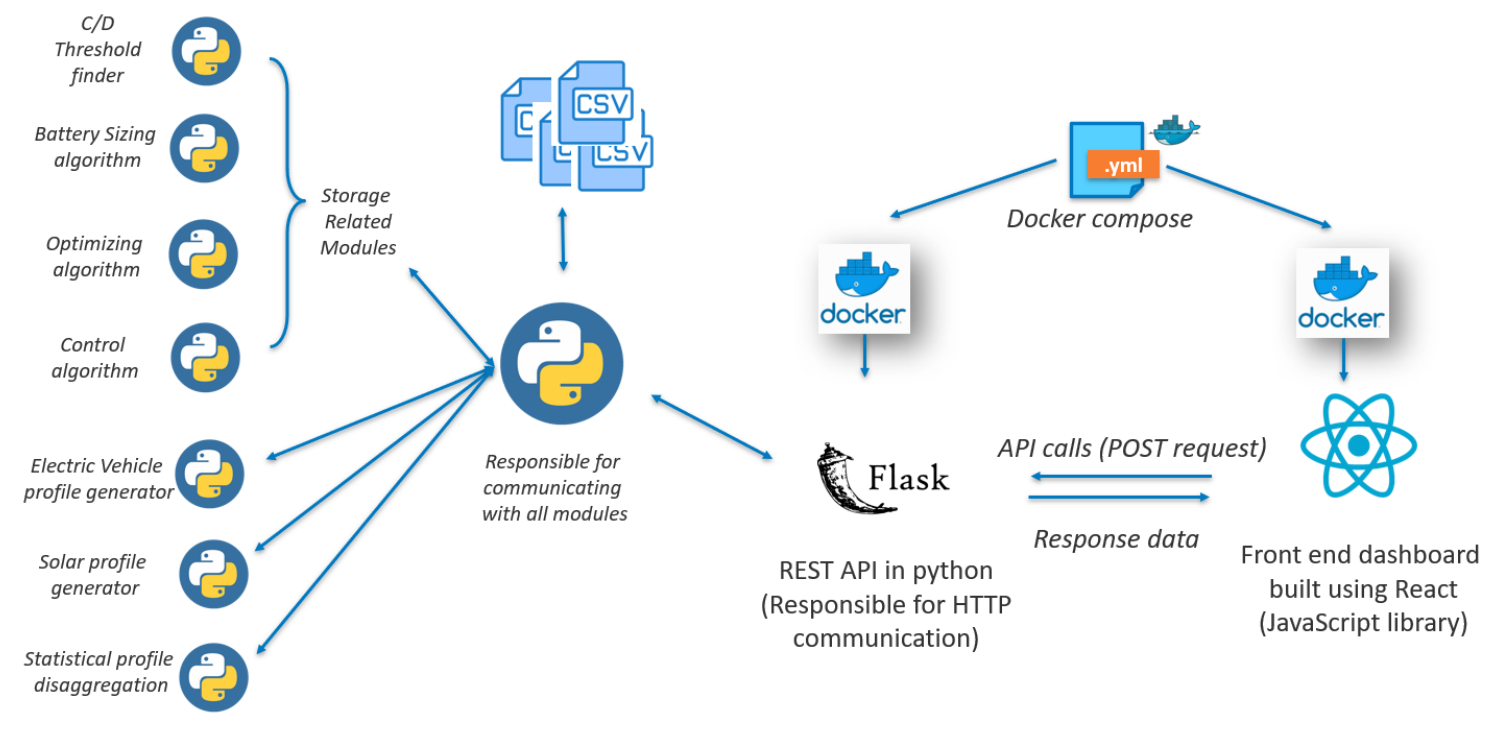

Figure 46. Schematic software architecture for EVOLVE

- Solar Settings:

- Total Capacity $(\mathrm{kW})$ : User can input total installed PV capacity belonging to distribution transformer or feeder, depending on which one is selected.

- Energy Storage Settings:

- Energy Capacity $(\mathrm{kWh})$ : Energy capacity of utility-scale energy storage in kWh

- Rated Capacity $(\mathrm{kW})$ : Rated power capacity of utility-scale energy storage in $\mathrm{kW}$ 
- Check to find size of utility scale battery: If checked, this will automatically compute energy capacity and rated capacity of battery to mitigate more than $70 \%$ overloading instances. Note that manual input for energy capacity and rated capacity will be ignored if this field is true.

- Charging/Discharging Strategy: User can select one of two charging/discharging strategies: time-based and power-based.

- Charging Threshold: If a time-based strategy is chosen, the user should provide hours for charging energy storage separated by commas. Allowed hours are from 0 to 23 . If a power-based strategy is chosen, the user should provide a factor of peak load below which energy storage should be charged. The allowed value is between 0 and 1 .

- Discharging Threshold: If a time-based strategy is chosen, the user should provide hours for discharging energy storage separated by commas. Allowed hours are from 0 to 23. If a power-based strategy is chosen, the user should provide a factor of peak load above which energy storage should be discharged. The allowed value is between 0 and 1 .

- Sweep and find best thresholds: If checked, this will automatically select charging and discharging thresholds depending on the charging/discharging strategy selected.

- Charging Rate (0-1): Rate at which the battery should be charged. The allowed value is between 0 and 1 . This rate will be multiplied with the rated capacity of the battery to compute actual charging $\mathrm{kW}$.

- Discharging Rate (0-1): Rate at which the battery should be discharged. The allowed value is between 0 and 1 . This rate will be multiplied with the rated capacity of battery to compute actual discharging $\mathrm{kW}$.

\section{- EV Settings:}

- Number of vehicles: The user can input the number of vehicles belonging to the selected distribution transformer or feeder.

- Adoption percentage: A percentage increment in the number of vehicles.

\subsubsection{Net Load Evolution Study Use Cases}

A distribution transformer with a peak load of $520 \mathrm{~kW}, 792$ domestic customers, and 89 nondomestic customers was chosen for illustrating five different use cases. A summer week was chosen to present in this report.

\section{Visualizing a Native or Base Load Profile Without Emerging Technologies}

To visualize the base or native load profile without the effect of any emerging technologies, total capacity $\mathrm{kW}$ in solar settings, energy capacity, and rated capacity in energy storage settings, and number of vehicles in EV settings are set to zero. Figure 47 shows the base profile of a representative transformer for the first week of July 2019. Note that the new and base load profiles are the same in this use case. Because this is a summer week, the peak occurs during the night ( 9 p.m. -1 a.m.) and late afternoon (3 p.m. to 5 p.m.). 


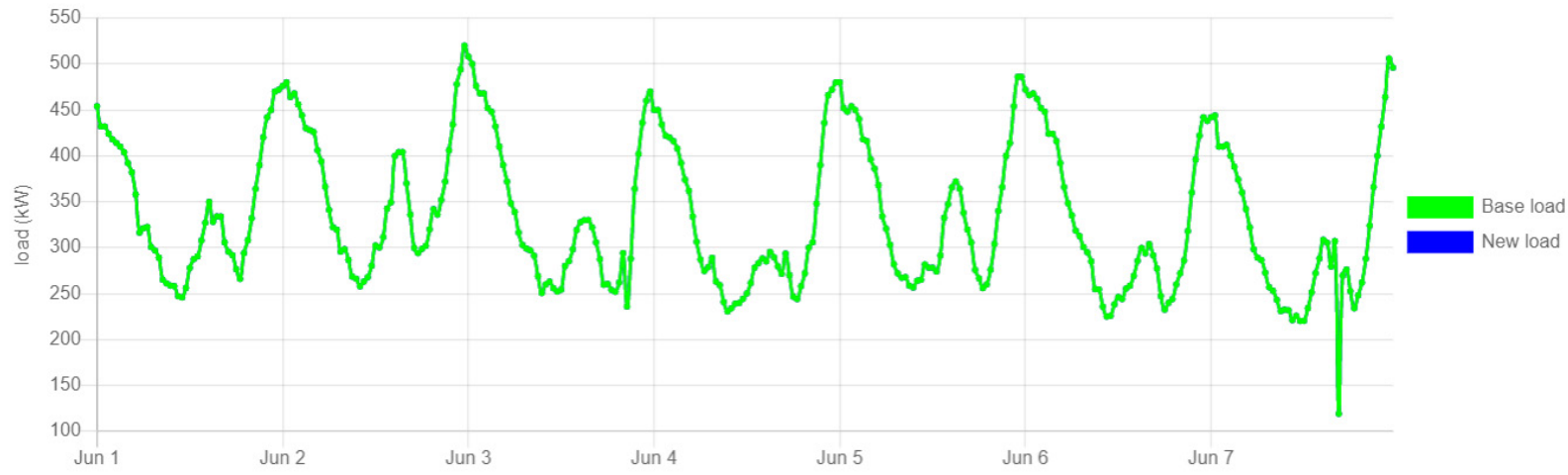

Figure 47. Base or native load profile of summer week in a domestic distribution transformer for 2019

\section{Visualizing a Net Load Profile With Rooftop PV}

To look at the impact of rooftop PV on net load profile of the distribution transformer, $100 \mathrm{~kW}$ of total PV capacity is used in solar settings. As energy is generated only during the daytime, the load will decrease during the daytime, represented by the blue line in Figure 48 . The load remains unaffected at other times, represented by the green line.

\section{Effect of DERs on load profile}

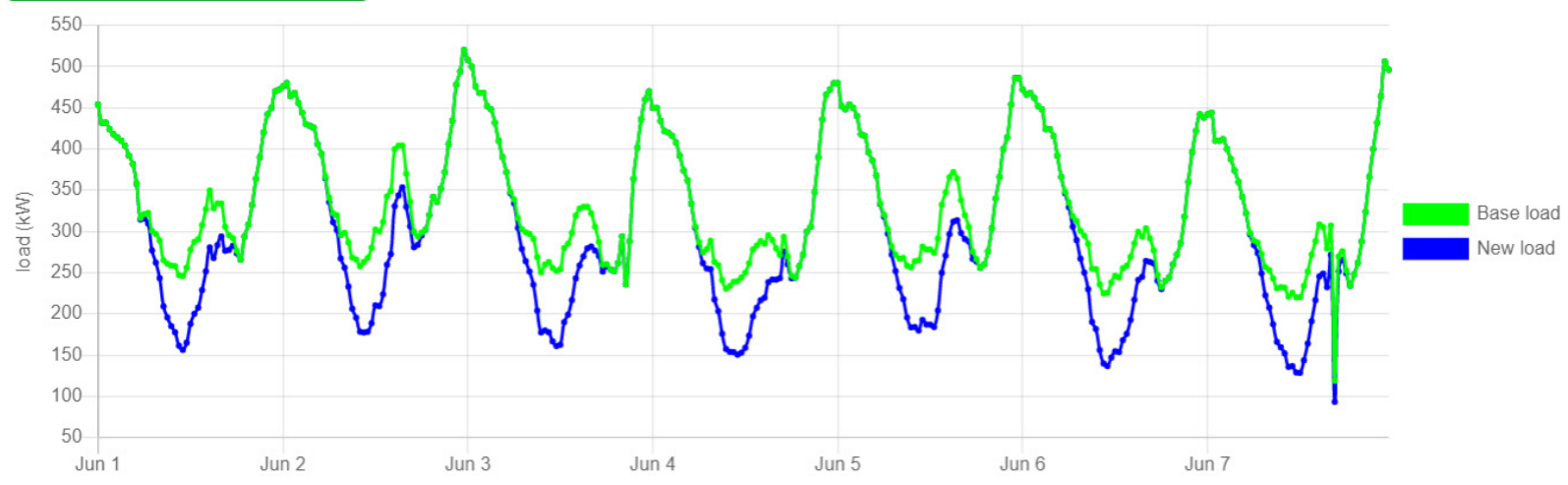

Figure 48. Base and new load profiles after addition of $100 \mathrm{~kW}$ of solar for one week in June 2019

The solar power profile for the same time is shown in Figure 49. Although the maximum power generation from solar is $91 \mathrm{~kW}$, the power generated at the peak time is 0 , because the base peak occurs at night when there is no solar generation. 


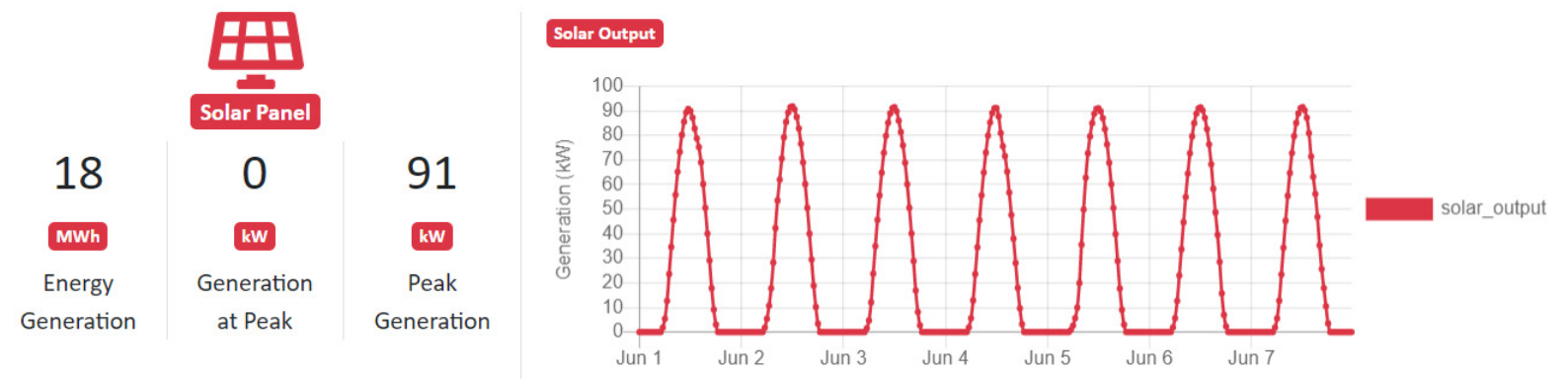

Figure 49. Solar profile and metrics specific to solar energy generation for summer week of 2019

\section{Visualizing a Net Load Profile With EV}

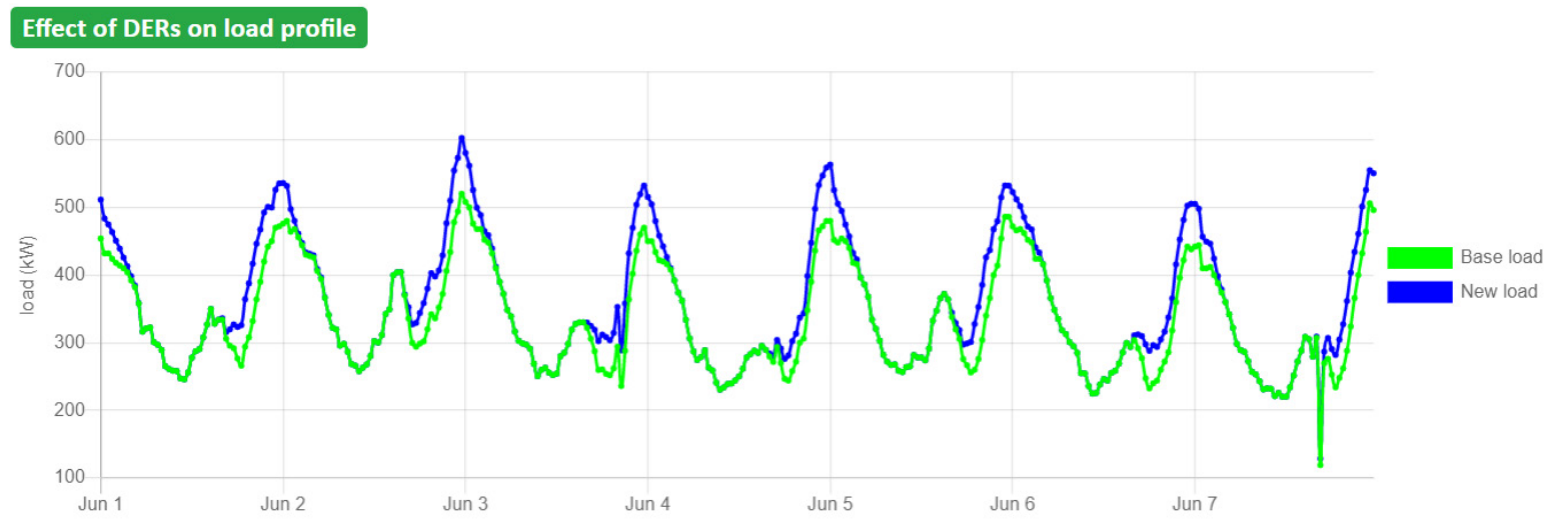

Figure 50. Base and net load profile with 50 EVs for summer week of 2019

To analyze the impact of EVs on the net load profile of the distribution transformer, the number of vehicles in the EV settings is set to 50. As all these EVs are assumed to be using residential chargers, the power consumption increases at nighttime. With $50 \mathrm{EVs}$, the peak for the week is increased by $82 \mathrm{~kW}$. The contribution to the peak load of the system due to EVs using residential charges is much higher during summer.
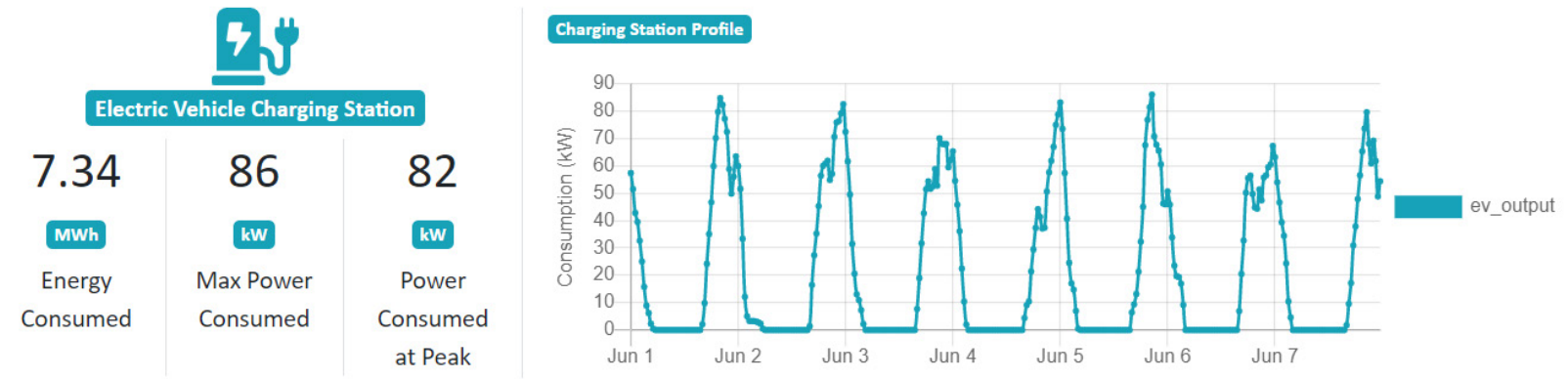

Figure 51. EV power profile and metrics of energy consumption for summer week of 2019

\section{Visualizing a Net Load Profile With Energy Storage}

To analyze the impact of utility-scale energy storage on net load profile of the distribution transformer, a utility-scale battery with an energy capacity of $200 \mathrm{kWh}$ and rated capacity of $100 \mathrm{~kW}$ was chosen. 


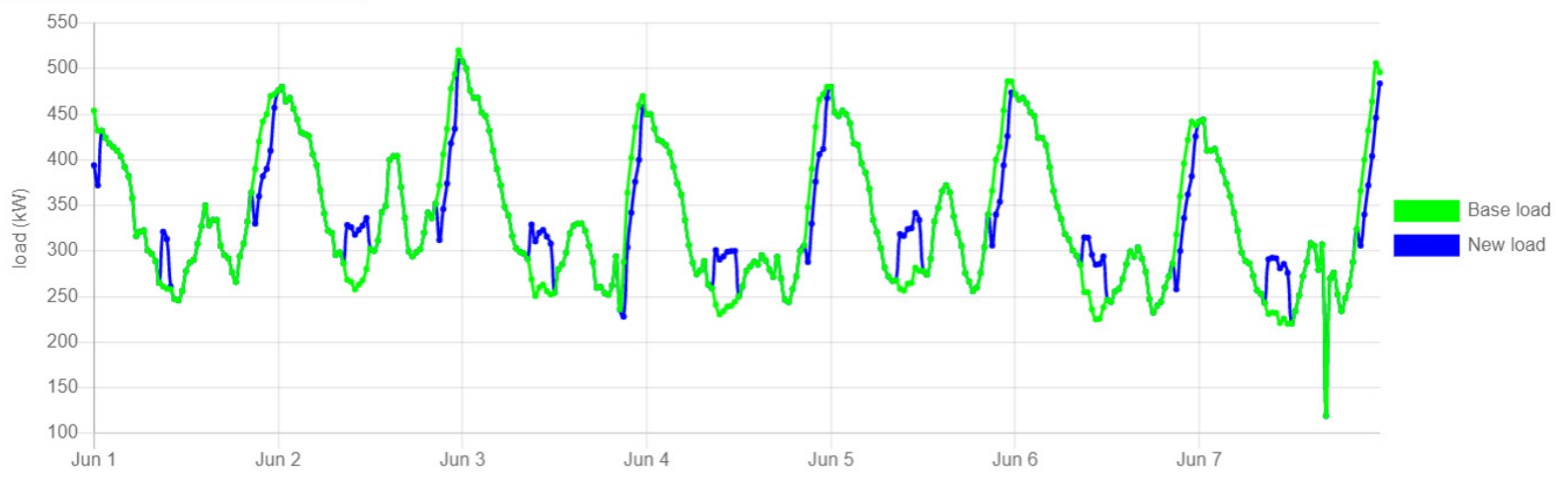

Figure 52. Base and new load profile with energy storage for summer week of 2019

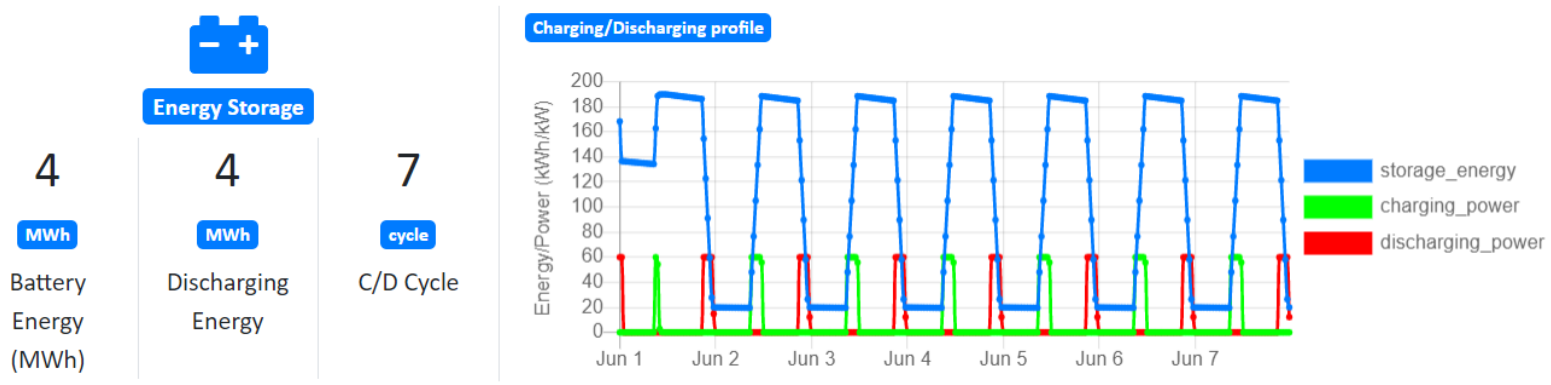

Figure 53. Battery energy, charging/discharging power profile, and metrics for summer week of 2019

The selected discharging hours are 9 p.m. to 1 a.m., and charging hours are 9 a.m. to 11 a.m. For the timebased strategy, the discharging hours are selected with the aim of reducing the peak load, which is around nighttime, and charging hours are selected considering nonpeak hours. Figure 52. shows the base profile and net load profile after the addition of energy storage. Figure 53. shows the battery energy profile, along with charging and discharging power profiles in the blue, green, and red colors, respectively. Although the battery is of a rated capacity $100-\mathrm{kW}$ maximum charging and the discharging power profile is $60 \mathrm{~kW}$ - the reason being that both the charging and discharging rates are 0.6 .

To see the automatic sizing and automatic selection of charging and discharging thresholds in action, both checkboxes under the energy storage settings must be checked, and the resulting base and net load profile with energy storage is shown in Figure 54. The battery energy capacity and rated capacity determined using sizing algorithm are $104.1 \mathrm{kWh}$ and $39.0 \mathrm{~kW}$. The threshold selected for battery charging and discharging by algorithm are 5,6 and 0,23 hours. 


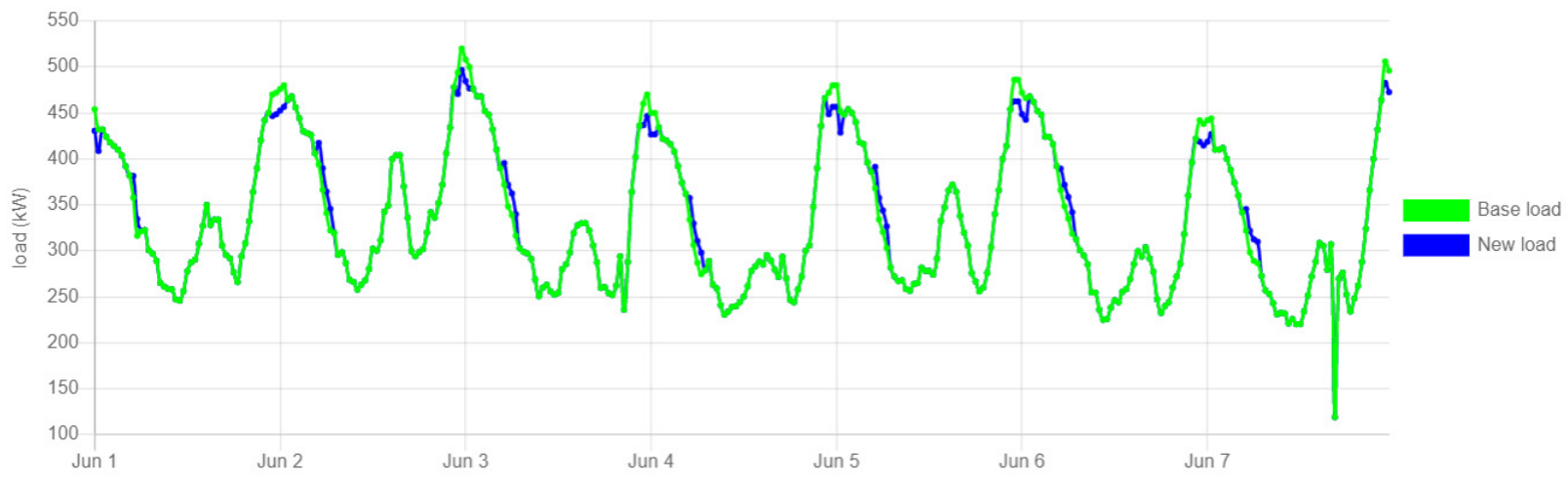

Figure 54. Base and new load profile with energy storage for automatic sizing and threshold selection for summer week of 2019

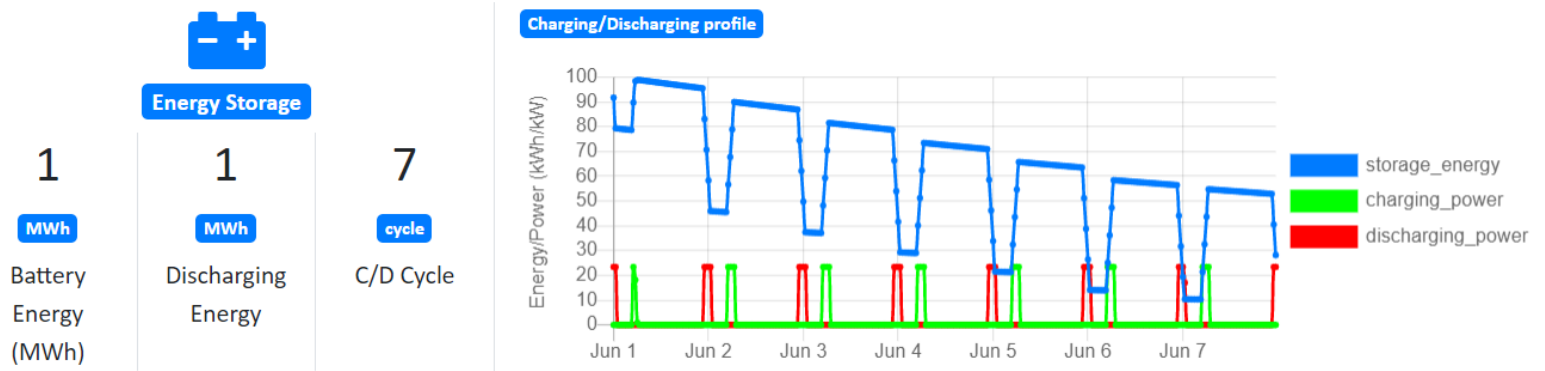

Figure 55. Battery energy, charging/discharging power profiles, and metrics for automatic sizing and threshold selection for summer week of 2019

Visualizing a Net Load Profile With Rooftop PV, EV, and energy storage

Finally, the base and net load profiles with rooftop PV (100 kW), EVs (50), and energy storage with automatic sizing and threshold selection are shown in Figure 56. 


\section{Effect of DERs on load profile}

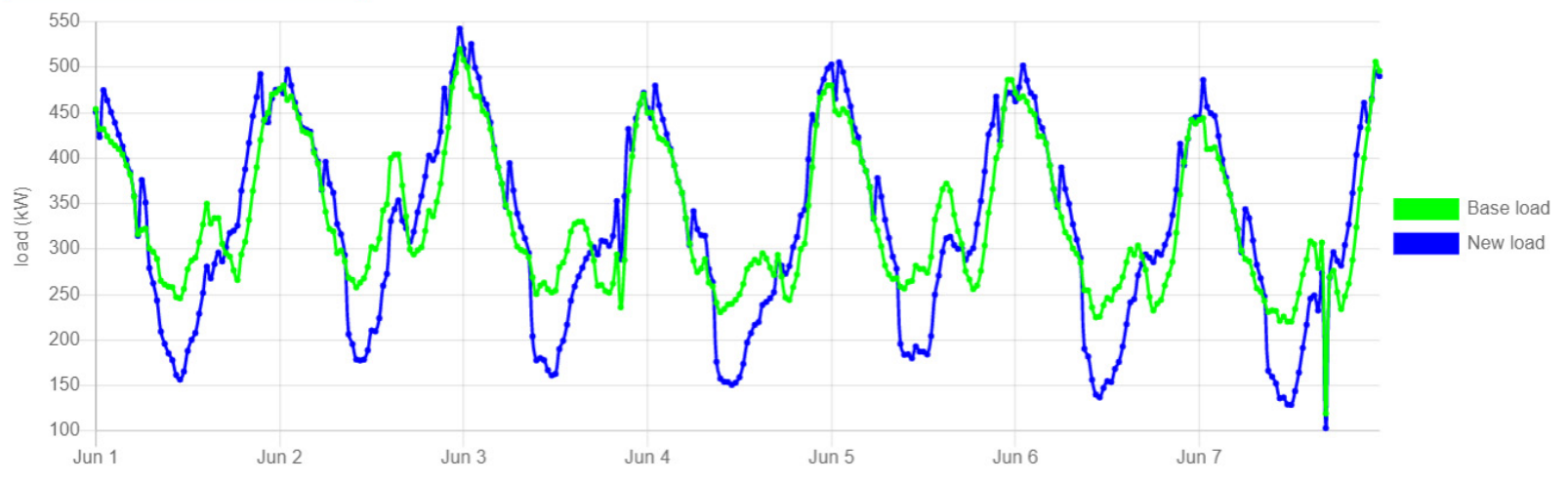

Figure 56. Base and new load profile after adding solar, EV, and energy storage for summer week of 2019

The new energy storage profile along with related statistics is presented in Figure 57. The energy capacity and rated capacity of a new energy storage system are $350.75 \mathrm{kWh}$ and $100.39 \mathrm{~kW}$. The charging and discharging thresholds selected by the algorithm are $6,7,8$ and $0,22,23$, respectively.
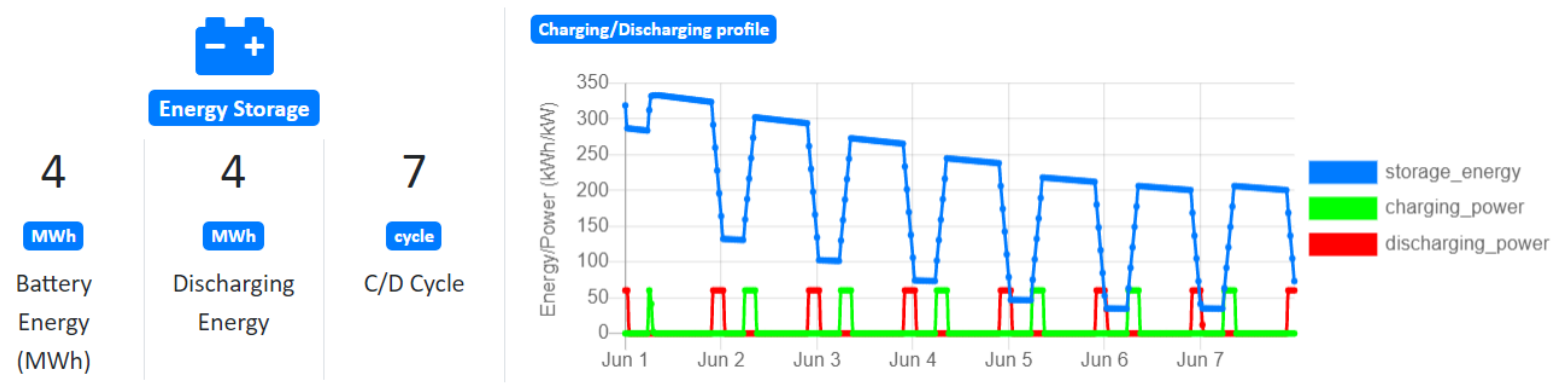

Figure 57. Battery energy, charging/discharging power profile after adding solar and EVs for summer week of 2019 (automatic sizing and threshold selection turned on)

\subsection{Use-Case Analyses on Selected Distribution Feeders}

To analyze the impact on the load profile at feeder level, one summer day of 2019 was chosen. All feeders following the DER's presence is modeled.

- Solar capacity: $1 \mathrm{MW}$ solar capacity is modeled

- Energy storage: 1,000 MWh energy capacity, $500 \mathrm{~kW}$ power capacity with $50 \%$ maximum charging and discharging rate, charging hours considered are low load time periods (8 a.m. to 11 a.m. for Feeder1, 10 a.m. to 2 p.m.), and discharging hours considered are high load time periods (9 p.m. to 1 a.m. for Feeder1, 10 p.m. to 2 p.m. for Feeder2).

- EV: Ten EVs are modeled for all three feeders with $25 \%$ of them being residential chargers.

Figure 58 shows the results for Feeder1, Feeder2, and Feeder3, respectively. Feeder1 and Feeder3 as 

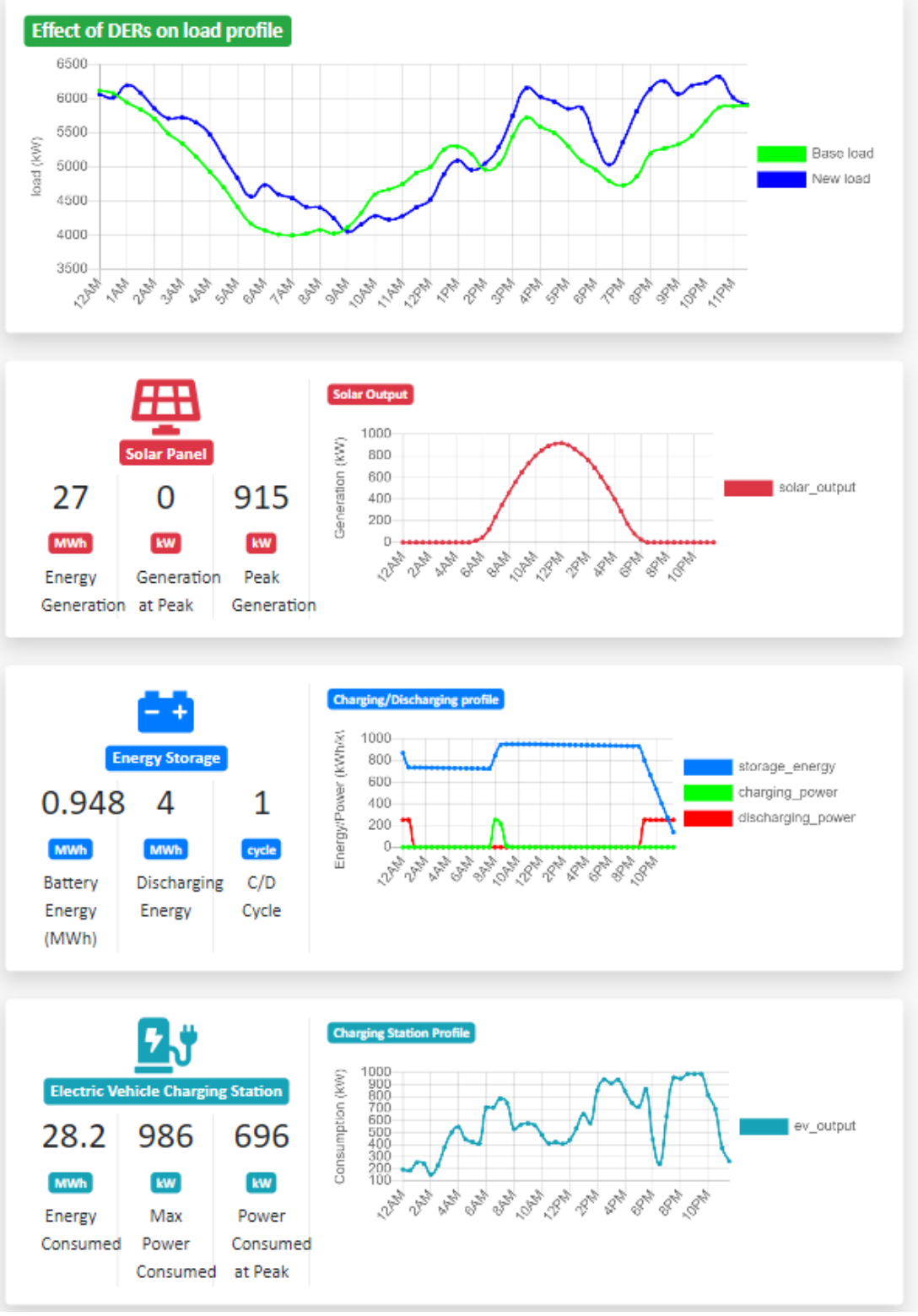

Figure 58. Impact on load profile of Feeder1 due to DERs on summer day of 2019. Starting from the top, first figure shows new and base profile, second figure shows solar generation profile (1 MW solar capacity), third figure shows battery energy, charging and discharging profile $(1,000$ MWh, $500 \mathrm{~kW}$ ), and last figure shows aggregated consumption pattern of EVs (10 vehicles, $25 \%$ residential)

they are dominated by domestic customers; peak occurs are night during summer season and load is lighter during morning time. Introducing solar generation decreases consumption during the daytime when the sun is shining. Notice that for Feeder2, which is dominated by industrial and commercial customers, the peak load occurs during the afternoon, so solar generation can help reduce the peak. But this does not occur in feeders that are dominated by residential customers (such as Feeder1 and Feeder2). The impact of EVs on all three feeders is to increase the load mostly in the late afternoon and evening time, as most of them are nonresidential EVs. The aggregated EV profile is the same because we used same number of EVs with same customer mix. 


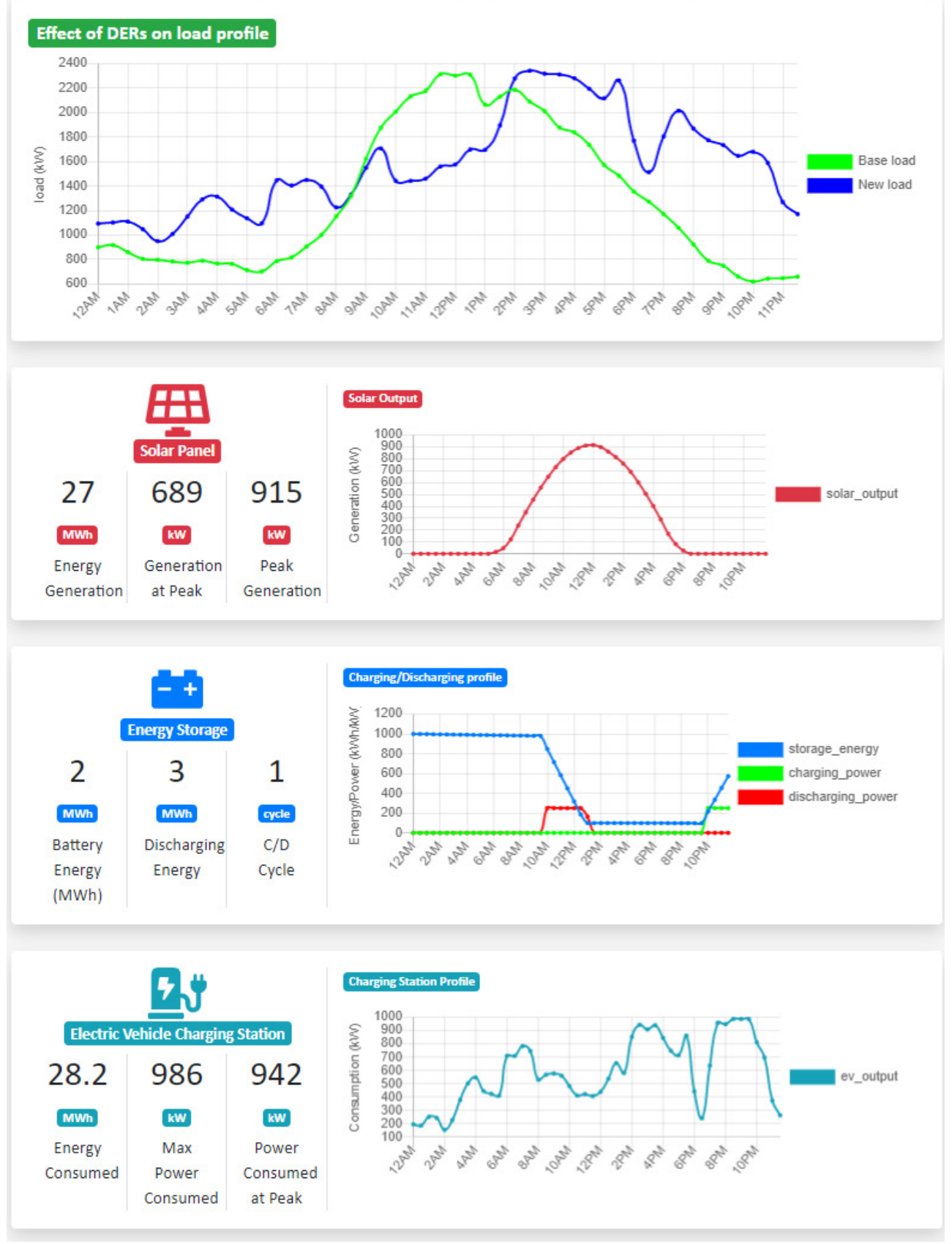

Figure 59. Impact on load profile of Feeder2 due to DERs on summer day of 2019. Starting from the top, first figure shows new and base profile, second figure shows solar generation profile (1 MW solar capacity), third figure shows battery energy, charging and discharging profile $(1,000$ $\mathrm{MWh}, 500 \mathrm{~kW}$ ), and last figure shows aggregated consumption pattern of EVs (10 vehicles, $25 \%$ residential)

Regarding energy storage, charging and discharging hours are selected in such a way that the batteries are charged during a low load period and discharged during a high load period, with the aim of reducing peak demand in all the feeders. Residential EV adoption tends to increase the load during the nighttime, whereas nonresidential EVs tend to increase load during the afternoon and evening. So, feeders dominated by residential customers will see relatively larger increases in the peak when their customers adopt EVs, as consumption coincides with peak time. Solar deployment is mostly beneficial to 
nonresidential feeders for peak reduction. Energy storage can play a significant role in reducing the peak for residential feeders.

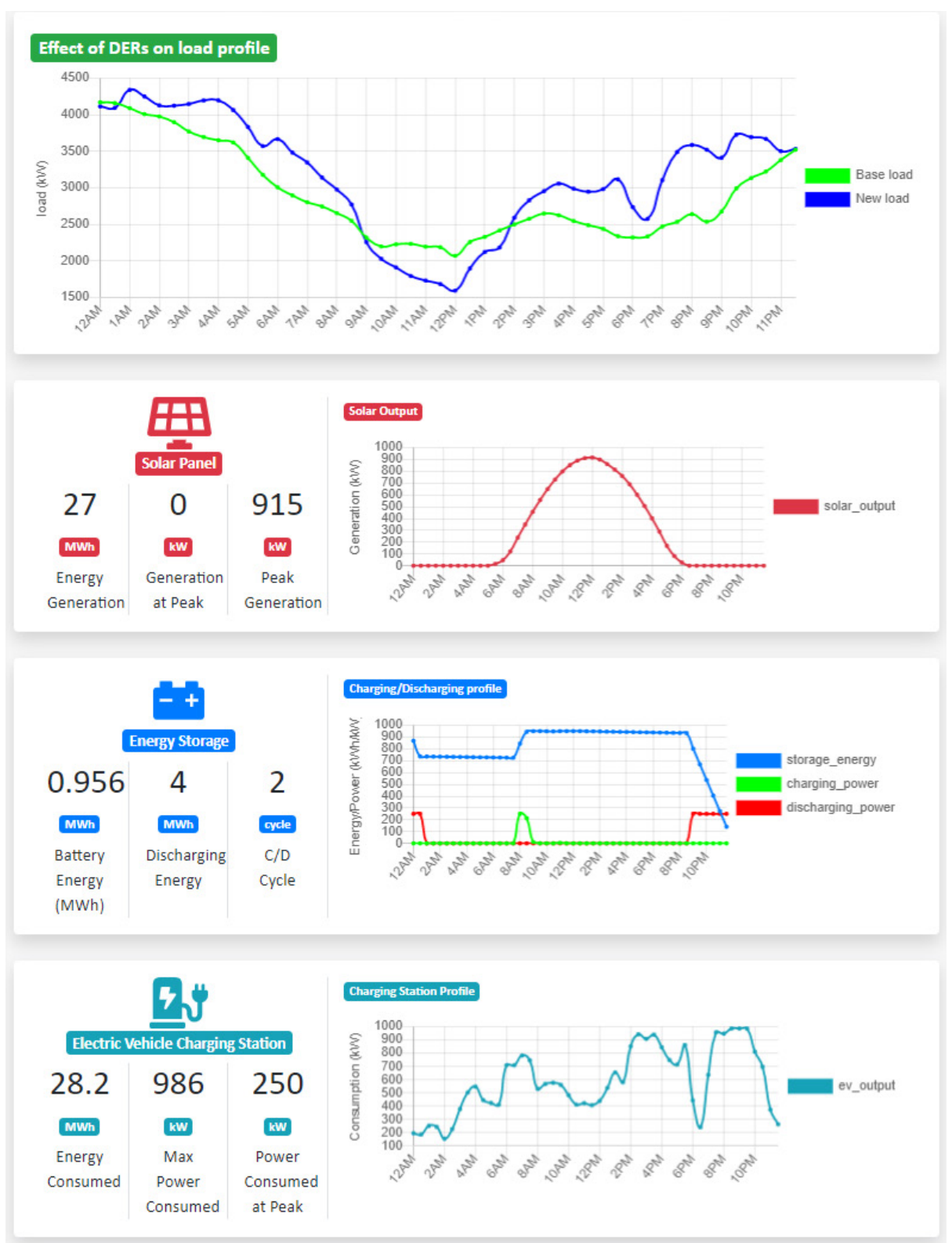

Figure 60. Impact on load profile of Feeder3 due to DERs on summer day of 2019. Starting from the top, first figure shows new and base profile, second figure shows solar generation profile (1 MW solar capacity), third figure shows battery energy, charging and discharging profile $(1,000$ $\mathrm{MWh}, 500 \mathrm{~kW}$ ), and last figure shows aggregated consumption pattern of EVs (10 vehicles, $25 \%$ residential) 


\section{Conclusions}

Over the past decade, solar PV, wind energy, and battery energy storage adoption has increased at all scales (transmission and distribution), as illustrated in Figure ES-1. Furthermore, distribution systems are beginning to experience higher levels of electrification, most notably in the automotive sector. Opportunities and challenges posed by these technologies on the power distribution grid are not yet fully understood. Typically, wind farms are planned and built at large scale (100 MWs to GWs) and interconnected to transmission systems. Solar PV, on the other hand, can either be connected to transmission systems at the GW scale or at rooftops at the $\mathrm{kW}$ scale. Thus, challenges and opportunities vary significantly, depending on the size and point of interconnection. Additionally, the services expected from these assets vary, depending on the point of interconnection - transmission or distribution system. Accordingly, we identified two tracks for research in this paper:

Power procurement: This research track centered on the challenges and opportunities caused by GW scale renewable integration at the transmission level. As new utility-scale wind and solar PV plants start to make up a significant portion of a distribution utility's portfolio, they will accelerate the utility's reliability challenges. NREL utilized open-source, reusable tools to investigate the contribution that utility-scale renewable energy procurement can provide to distribution utilities, from both energy and capacity perspectives.

Specifically, we estimated the energy production and capacity credit of BYPL's recent RE power procurements. These consist of $250 \mathrm{MW}$ of wind and $300 \mathrm{MW}$ of solar PV plants scattered across the country, some of which have recently been commissioned. The production potential of these plants can be summed up with three points:

- Capacity factor for all additional utility-scale renewable energy is estimated to be $27 \%$ in summer (March to October) and $15 \%$ in winter (November to January).

- Wind energy, especially when imported from Coimbatore, can contribute significantly to BYPL's planning reserve. Solar PV supplies minimal benefit to the planning reserve.

○ Wind turbine model and hub height have a significant impact on estimated output and capacity credit.

DERs: In the power procurement research track, utility customers were considered to only be traditional consumers of energy. The DER research track, by contrast, investigated the opportunity of customers to produce and store energy as well. This effort focused on challenges and opportunities caused by many small-scale DER integrations at the distribution systems. At the power distribution systems, utilities face challenges from not only solar technology, but also from battery energy storage and electric vehicles as well. Combined, these three technologies (solar PV, battery energy storage, and EVs) pose unique challenges to distribution utilities. This research focused on assessing the net load evolution that distribution utilities observe as these emerging technologies make their way to the grid.

The DERs research track was set up to help BYPL understand the evolution of customer demand with the growing adoption of emerging technologies. Customer demand evolves incrementally as these DERs are integrated. We found the following:

- Solar integration created a dip during the afternoons

- EVs added to the base load during the night

○ Energy storage reduced load during early morning peaks 
All these incremental updates happening at scale in distribution utilities quickly escalates to a unique shift in consumption at distribution transformers. Aggregated demand shift at distribution transformers lead to a distinct change at distribution feeder head.

These distributed emerging technologies create a small shift in demand, which, when aggregated, quickly escalates into a need for significant overhaul in utility operation and planning. For this purpose, NREL developed an interactive dashboard, which any distribution utility can use to learn the aggregate impacts of customer adoption of distribution emerging technologies. This dashboard, EVOLVE, enables distribution utilities to enter relevant scenarios, observe the shift in customer demand, and help make decisions accordingly. A key outcome from DERs research is an easy-to-use open-source dashboard for learning evolution of net-load with increasing emerging technologies.

Indian distribution utilities like BYPL are beginning to experience unprecedented growth of utility scale wind and solar PV, rooftop solar PV, distribution level battery energy storage, and electric vehicles. In order to maintain reliable electric service, utilities will need to understand how these distribution technologies will reshape their demand curve. Further, they will need to study the degree to which utilityscale, weather-based generation can meet this changing demand curve. In this paper, we showcase several tools to help utilities answer these questions:

- The System Advisor Model (SAM) models individual renewable plants and produces hourly power profiles. The SAM GUI is accessible as a desktop executable.

- Capacity factor approximation provides a simple measure of capacity credit. It can be performed with any spreadsheet editing tool.

- The Probabilistic Resource Adequacy Suite (PRAS) calculates system reliability metrics, as well as effective load carrying capability (ELCC) of individual plants. ELCC provides a robust measure of capacity credit. PRAS is an open-source tool written in the Julia programming language.

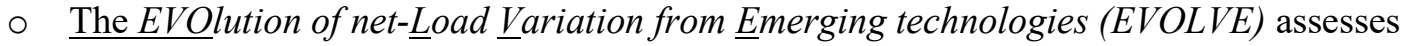
the impact of rooftop solar PV, residential battery energy deployment, and electric vehicle adoption on the load shape time series at various points in the distribution system. EVOLVE is accessible through an interactive browser dashboard.

BYPL and other utilities can use these tools to better understand the evolution of their future load curves, and to also make more informed, data-driven decisions regarding power procurement PPAs. 


\section{References}

Blair, N., Dobos, A.; Freeman, J., Neises, T., Wagner, M., Ferguson, T., Gilman, P.; Janzou, S. (2014).

System Advisor Model, SAM 2014.1.14: General Description. NREL/TP-6A20-61019. National Renewable Energy Laboratory. Golden, CO. https://www.nrel.gov/docs/fy14osti/61019.pdf.

BNEF (BloombergNEF). 2019. New Energy Outlook. New York City: BloombergNEF.

Brown, Maxwell, Wesley Cole, Kelly Eurek, Jon Becker, David Bielen, Ilya Chernyakhovskiy, Stuart Cohen, et al. 2020. Regional Energy Deployment System (ReEDS) Model Documentation: Version 2019. Golden, CO: National Renewable Energy Laboratory. NREL/TP-6A20-74111

Carden, K., Wintermantel, N., and Benson, C. (2020). Duke Energy Carolinas Integrated Resource Plan, Attachment III: 2020 Resource Adequacy Study. Hoover, Alabama: Astrape Consulting.

Cochran, J., Palchak, P. (2017). Greening the Grid: Pathways to Integrate 175 Gigawatts of Renewable Energy Into India's Electirc Grid. Golden, Colorado: National Renewable Energy Laboratory.

Cole, W. (2019). Cost Projections for Utility-Scale Battery Storage. Golden, Colorado: National Renewable Energy Laboratory.

Cox, S., and Leisch, J. E. (2019). The Renewable Energy Data Explorer: Mapping Our Renewable Energy Future. Golden, Colorado: National Renewable Energy Laboratory.

Denholm, P., O'Connell, M., Brinkman, G., and Jorgenson, J. (2015). Overgeneration from Solar Energy in California: A Field Guide to the Duck Chart. Golden, Colorado: National Renewable Energy Laboratory.

Denholm, P., Novacheck, J., Jorgenson, J., and O’Connell, M. (2016). Impact of Flexibility Options on Grid Economic Carrying Capacity of Solar and Wind: Three Case Studies. National Renewable Energy Laboratory.

Draxl, C., Hodge, B. M. Hodge, Clifton, A., and McCaa, J. (2015.) Overview and Meteorological Validation of the Wind Integration National Dataset Toolkit. NREL/TP-5000-61740. Golden, CO: National Renewable Energy Laboratory.

Dykes, K., King, J., DiOrio, N., King, R., Gevorgian, V., Corbus, D., Blair, N., Anderson, K., Stark, G., Turchi, C., and Moriarity, P. (2020.) Opportunities for Research and Development of Hybrid Power Plants. Golden, CO: National Renewable Energy Laboratory. NREL/TP-5000-75026. https://www.nrel.gov/docs/fy20osti/75026.pdf.

Frew, B., Stephen, G.,Sigler, D., Lau, J., Jones, W., and Bloom, A. (2019). Evaluating Resource Adequacy Impacts on Energy Market Prices Across Wind and Solar Penetration Levels. Golden, Colorado: National Renewable Energy Laboratory. United States: N. p., 2019. Web. doi:10.1016/j.tej.2019.106629.

Stephen, G., Hale, H. and Cowiestoll, B. (2020). Managing Solar Photovoltaic Integration in the Western United States: Resource Adequacy Considerations. Golden, CO: National Renewable Energy Laboratory. NREL/TP-6A20-72472. https://www.nrel.gov/docs/fy21osti/72472.pdf. 
Haley, C. (2019). Solar and Wind ELCC Accreditation. Little Rock, Arkansas: Southwest Power Pool, Inc.

Hledik, R. (2017). Stacked Benefits: Comprehensively Valuing Battery Storage in California. Sacramento, California: California Energy Commission.

Jenkin, T., Beiter, P., and Margolis, R. (2016). Capacity Payments in Restructured Markets under Low and High Penetration Levels of Renewable Energy. NREL/TP-6A20-65491. Golden, Colorado: National Renewable Energy Laboratory.

Karmiris, G. a. (2013). Peak Shaving Control Method for Energy Storage. Vasterås, Sweden: ABB.

Klima, K., and Apt, J. (2015). Geographic smoothing of solar PV: results from Gujarat. Environmental Research Letters. Vol. 10, No. 10.

Madaeni, S. H., Sioshansi, R., and Denholm, P. (2012). Comparison of capacity Value Methods for Photovoltaics in the Western United States. Golden, CO: National Renewable Energy Laboratory.

Mai, T., Drury, E., Eurek, K., Bodington, N., Lopez, A., and Perry, J. (2013). Resource Planning Model: An Integrated Resource Planning and Dispatch Tool for Regional Electric Systems. Golden, CO: National Renewable Energy Laboratory. NREL/TP-6A20-56723

Milligan, M., and Parsons, B. (1999). A Comparison and Case Study of Capacity Credit Algorithms for Wind Power Plants. Journal of Wind Engineering. Multi-Science Publishing Co. LTD. Brentwood, Essex, United Kingdom. Vol 23, No. 3.

Milligan, M. and Porter, K. (2005). Determining the Capacity Value of Wind: A Survey of Methods and Implementation. Conference Paper. NREL/CP-500-38062. Golden, Colorado: National Renewable Energy Laboratory.

Nagarajan, A., Ghosh, S., Jain, A. K., Akar, S., Bryce, R., Emmanuel, M., Remo, T., Latif, A., Palchak, D., Cochran, J., Ranjan, A., and Nagpal, N. (2020.) Preparing Distribution Utilities for UtilityScale Storage and Electric Vehicles: A Novel Analytical Framework. NREL/TP-5D00-75973. https://www.nrel.gov/docs/fy20osti/75973.pdf.NREL. (2019). Annual Technology Baseline. Golden, Colorado: National Renewable Energy Laboratory.

Sengupta, M., Xie, Y., Lopez, A., Habte, A., Maclaurin G., and Shelby, J. (2018.) The National Solar Radiation Data Base (NSRDB)." Renewable and Sustainable Energy Reviews 89 (June): 51-60.

Stephen, O. a. (2014). Geospatial Modeling of Electricity Distribution Network In Ife Central Local Government Area, Osun State, Nigeria. Science Journal of Environmental Engineering Research, $1-7$.

Yang, M. Y. (2004). Efficient Operation Regions of Power Distribution Transformers. IEEE Transactions on Power Delivery, 1713-1717. 


\section{Appendix A: Correlations Between Utility-Scale Wind, Solar PV, and Demand}

The full year correlogram between wind, PV, and load is shown in Figure A-1. Wind correlates well with peak load on average, but solar PV does not. We expound on this relationship by finding the Pearson correlations between these quantities for each hour of the year. These values reveal a significant positive correlation between wind and load $(+0.642)$ and very little correlation between PV and either quantity.

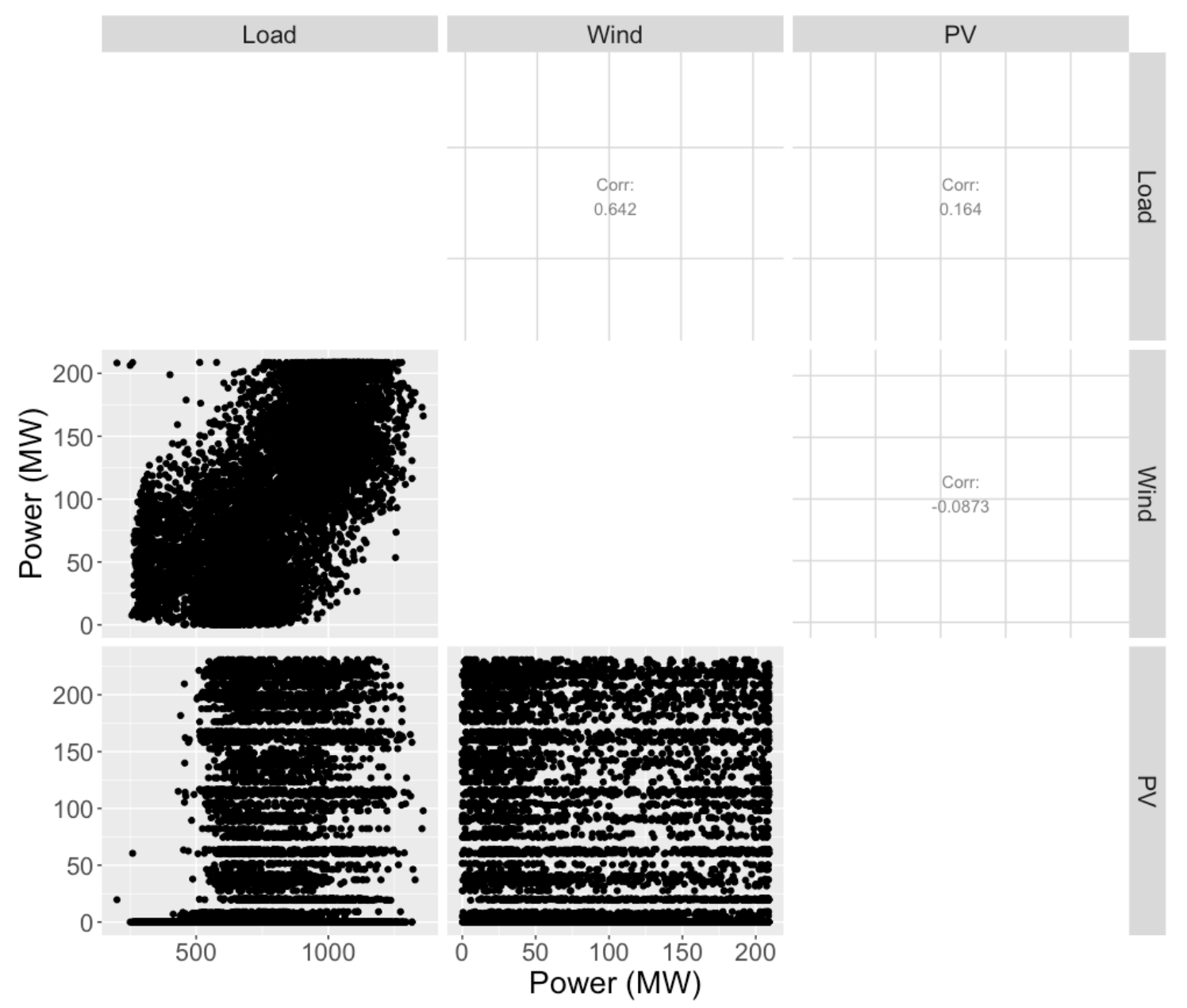

Figure A-1. Correlogram for wind, solar PV, and load for every hour of the year

Figure A-2 plots the same data, divided into the winter and summer seasons as defined by BYPL. We find that almost all the previous correlations between wind and load occurs in the summer months when both quantities are relatively high. This has significant implications for the capacity credit of wind.

In Figure A-3, we divide the wind and load data into months. We see that the yearly correlation is higher than the correlation in any individual month. This suggests that the inter-month relationship between wind and load is stronger than their intra-month relationship. For instance, wind and load are both generally low in the winter and high in the summer. This pattern is more significant than the day-to-day relationship of wind and solar in, for example, the winter month of November. 


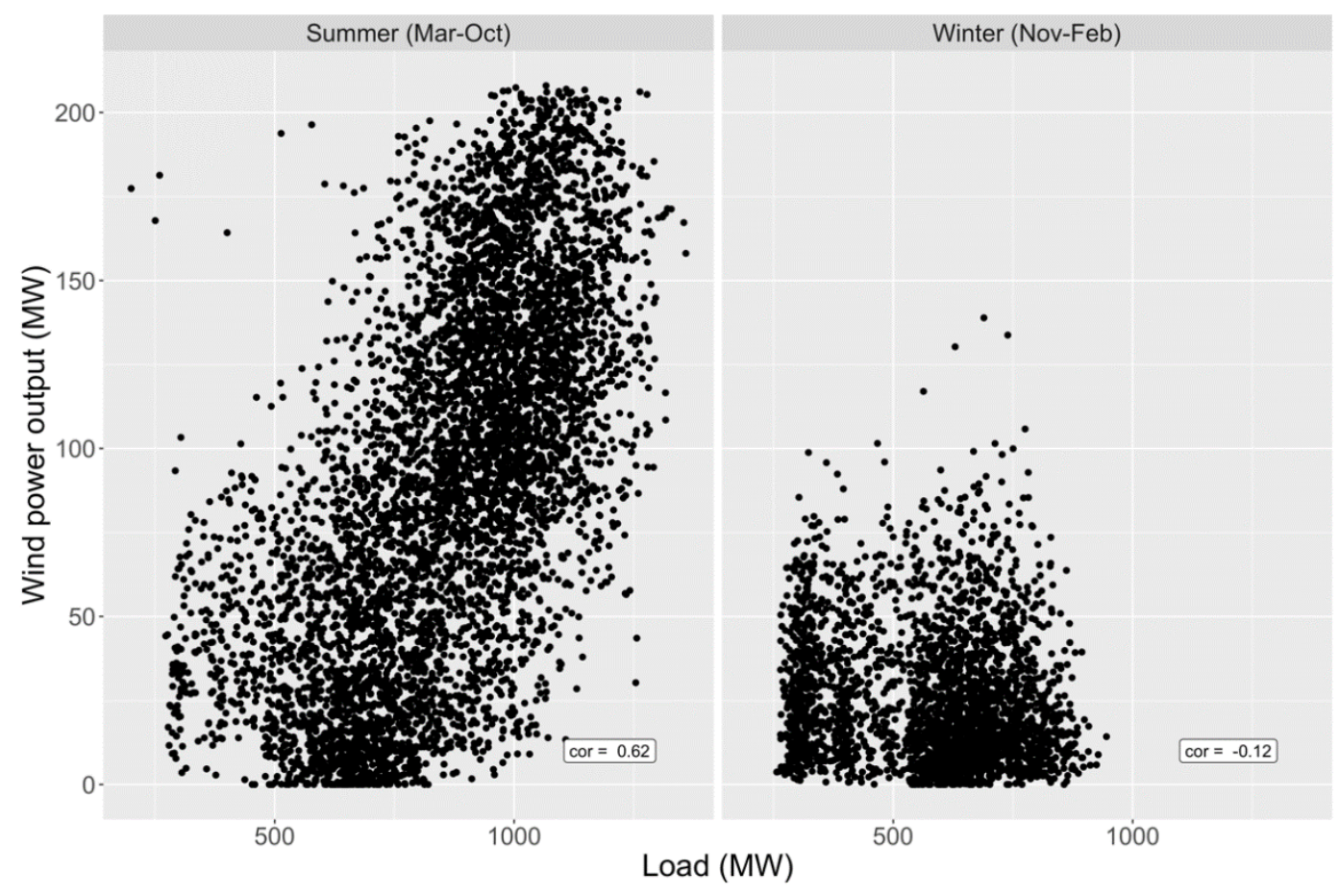

Figure A-2. Seasonal correlation of wind and load

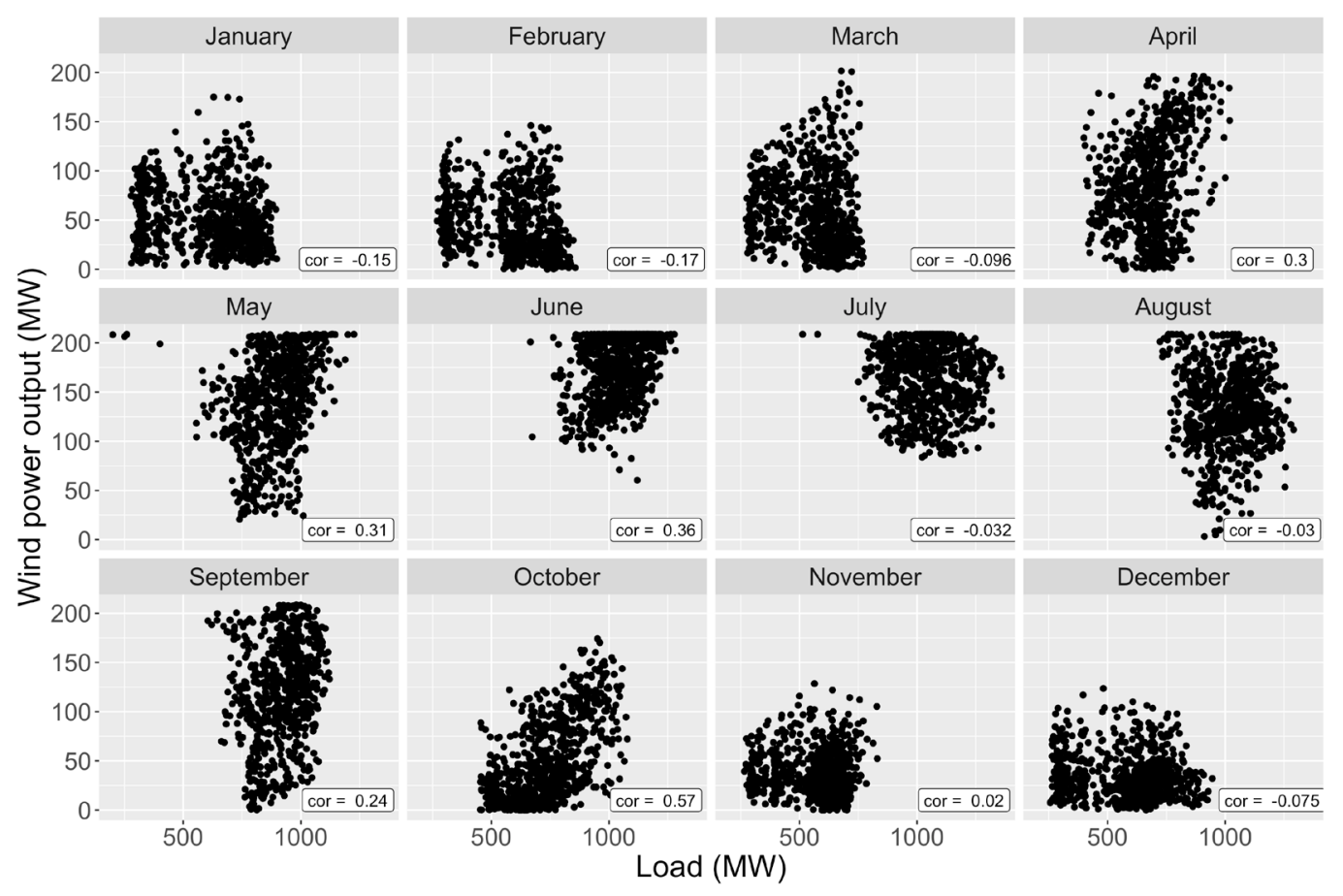

Figure A-3. Monthly correlation of wind and load 


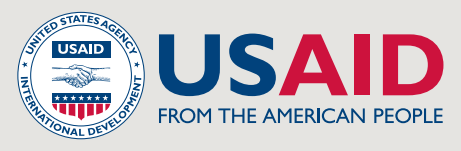

GOVERNMENT OF INDIA MINISTRY OF POWER

\begin{abstract}
About USAID
The United States Agency for International Development (USAID) is an independent government agency that provides economic, development, and humanitarian assistance around the world in support of the foreign policy goals of the United States. USAID's mission is to advance broadbased economic growth, democracy, and human progress in developing countries and emerging economies.
\end{abstract}

\section{About the Ministry of Power, Government of India}

The Ministry of Power is primarily responsible for the development of electrical energy in the country. The Ministry is concerned with perspective planning, policy formulation, processing of projects for investment decision, monitoring of the implementation of power projects, training and manpower development, and the administration and enactment of legislation in regard to thermal, hydro power generation, transmission, and distribution.

\section{About NREL}

The National Renewable Energy Laboratory (NREL) is the U.S. Department of Energy's (DOE's) primary national laboratory for renewable energy and energy efficiency research. NREL deploys its deep technical expertise and unmatched breadth of capabilities to drive the transformation of energy resources and systems.

\section{Disclaimers}

This report was prepared as an account of work sponsored by an agency of the United States government. Neither the United States government nor any agency thereof, makes any warranty, express or implied, or assumes any legal liability or responsibility for the accuracy, completeness, or usefulness of any information, apparatus, product, or process disclosed, or represents that its use would not infringe privately owned rights. Reference herein to any specific commercial product, process, or service by trade name, trademark, manufacturer, or otherwise does not necessarily constitute or imply its endorsement, recommendation, or favoring by the United States government or any agency thereof. The contents of this report are the sole responsibility of National Renewable Energy Laboratory and do not necessarily reflect the views of the United States Government or the Government of India.
This report is available at no cost from the National Renewable Energy Laboratory (NREL) at www.nrel.gov/publications.

Available electronically at SciTech Connect, http:/www.osti.gov/scitech

Available for a processing fee to U.S. Department of Energy and its contractors, in paper, from:

U.S. Department of Energy

Office of Scientific and Technical Information

P.O. Box 62

Oak Ridge, TN 37831-0062

OSTI http://www.osti.gov

Phone: 865.576 .8401

Fax: 865.576.5728

Email: reports@osti.gov

Available for sale to the public, in paper, from:

U.S. Department of Commerce

National Technical Information Service

5301 Shawnee Road

Alexandria, VA 22312

NTIS http://www.ntis.gov

Phone: 800.553 .6847 or 703.605 .6000

Fax: 703.605.6900

Email: orders@ntis.gov

NREL/TP-6A20-79069

NREL prints on paper that contains recycled content. 